\title{
SHRINKAGE AND TEMPERATURE REINFORCEMENT IN CONCRETE LIQUID-CONTAINING STRUCTURES
}

\author{
by \\ Nima Ziaolhagh \\ B.Sc., Azad University, Iran, 2002 \\ A thesis \\ presented to Ryerson University \\ in partial fulfillment of the \\ requirements for the degree of \\ Master of Applied Science \\ in the program of \\ Civil Engineering
}

Toronto, Ontario, Canada, 2008

CNima Ziaolhagh 2008 


\section{AUTHOR'S DECLARATION}

I hereby declare that I am the sole author of this thesis.

I authorize Ryerson University to lend this thesis to other institutions or individuals for th purpose of scholarly research.

I further authorize Ryerson University to reproduce this thesis by photocopying or by othe means, in total or in part, at the request of other institutions or individuals for the purpose o scholarly research. 


\section{BOROWER'S PAGE}

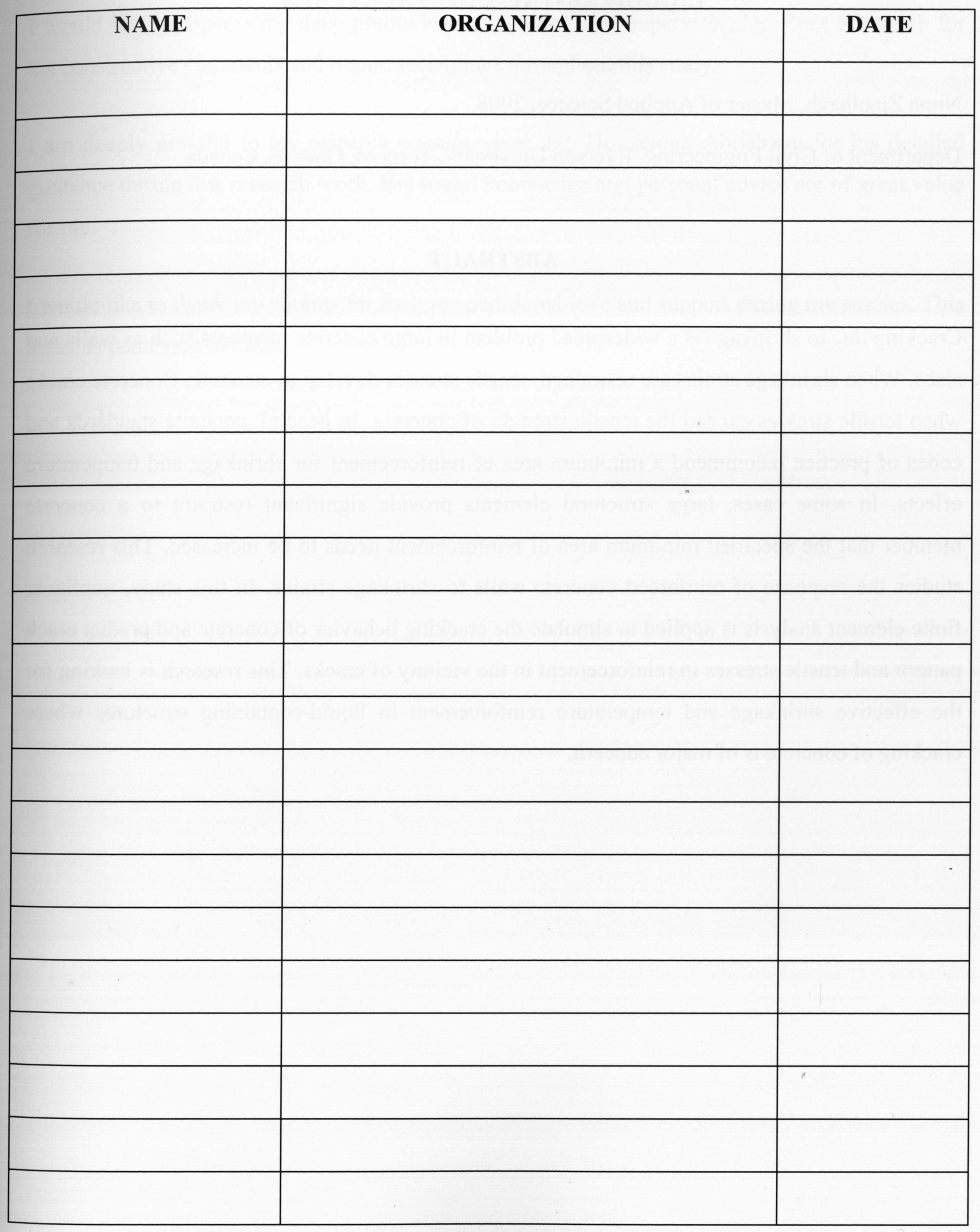




\title{
SHRINKAGE AND TEMPERATURE REINFORCEMENT IN CONCRETE LIQUID-CONTAINING STRUCTURES
}

\author{
nce, 2008 \\ in University, Toronto, Ontario, Canada
}

\section{ABSTRACT}

Cracking due to shrinkage is a widespread problem in large concrete members such as walls an slabs. When shrinkage strains are restrained, tensile stresses develop in concrete. Concrete crack when tensile stresses exceed the tensile strength of concrete. In general, concrete standards an codes of practice recommend a minimum area of reinforcement for shrinkage and temperatur effects. In some cases, large structural elements provide significant restraint to a concret member that the specified minimum area of reinforcement needs to be increased. This research studies the response of reinforced concrete walls to shrinkage strains. In this study, nonlineal finite element analysis is applied to simulate the cracking behavior of concrete and predict crack pattern and tensile stresses in reinforcement in the vicinity of cracks. This research is looking for the effective shrinkage and temperature reinforcement in liquid-containing structures where cracking of concrete is of major concern. 


\section{ACKNOWLEDGEMENTS}

I would like to express my deep gratitude to my research co-supervisor, Dr. Reza Kianoush for his constructive comments and important support throughout this study.

I am deeply grateful to my research co-supervisor, Dr. Homayoun Abrishami for his detailed guidance during this research work. His sound knowledge and personal advice are of great value for me.

I would like to thank my parents for their unconditional love and support during my studies. This thesis is dedicated to them. 
TABLE OF CONTENTS

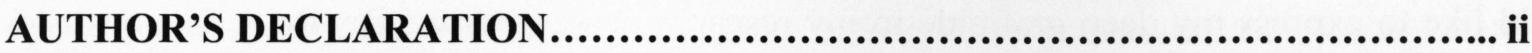

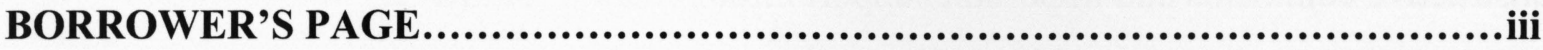

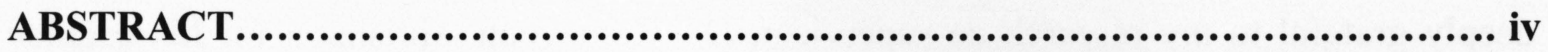

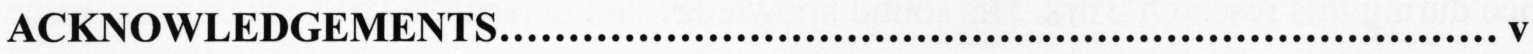

TABLE OF CONTENTS............................................................... vi

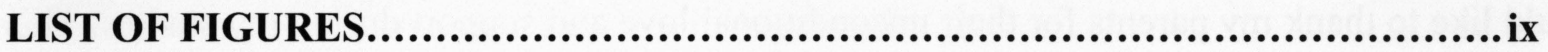

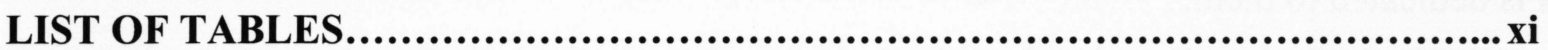

CHAPTER 1- INTRODUCTION........................................................

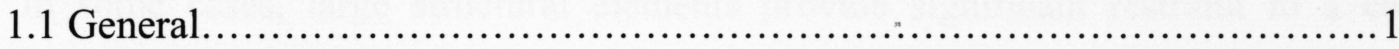

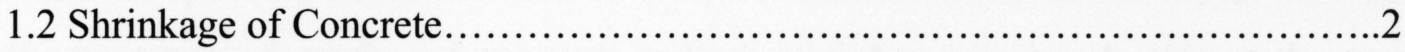

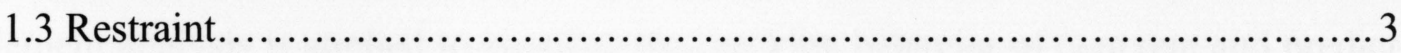

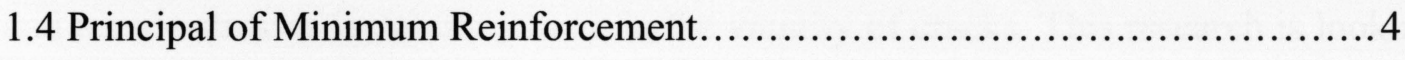

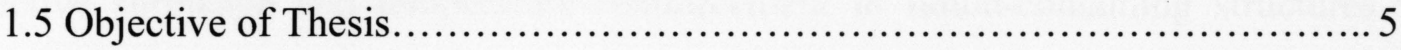

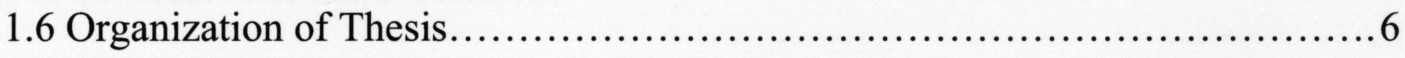

CHAPTER 2- THEORY OF SHRINKAGE CRACKING..............................

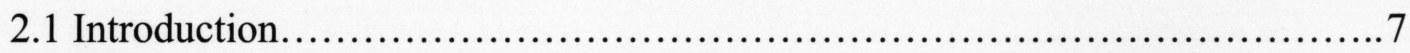

2.2 Theory of Restrained Shrinkage Cracking .................................

2.3 Effect of Restraint..................................................... 15

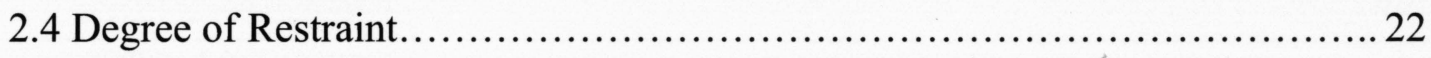

2.5 Degree of Restraint caused by Reinforcement..............................24 


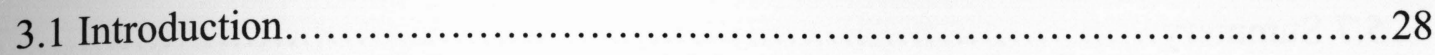

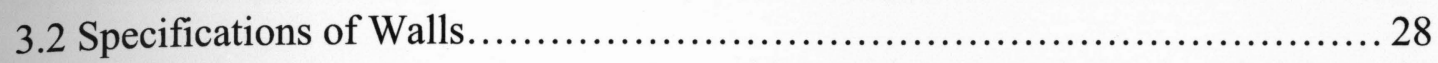

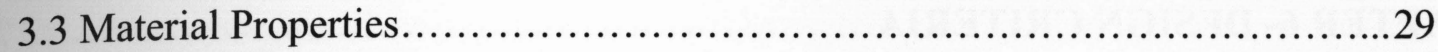

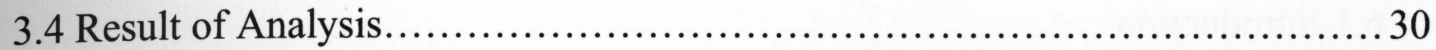

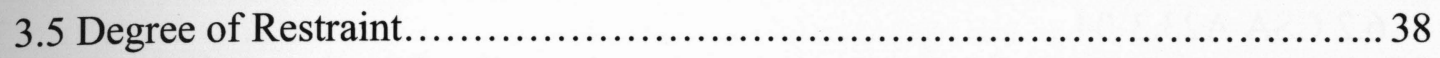

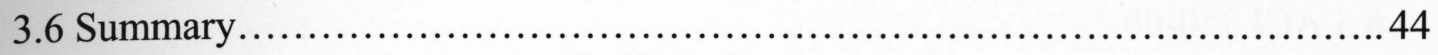

CHAPTER 4- NONLINEAR ANALYSIS OF WALLS...............................45

4.1 Introduction.............................................................. 45

4.2 Specifications of Walls.................................................. 45

4.3 Material Properties......................................................... 46

4.4 Inelastic Behavior Model for Concrete.................................. 47

4.4.1 Smeared Cracking Model...................................... 48

4.4.2 Brittle Cracking Model.......................................... 50

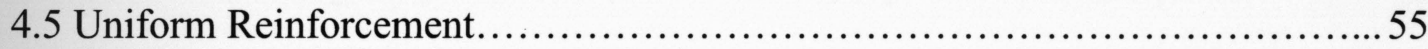

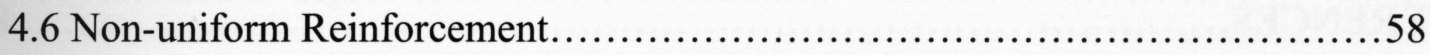

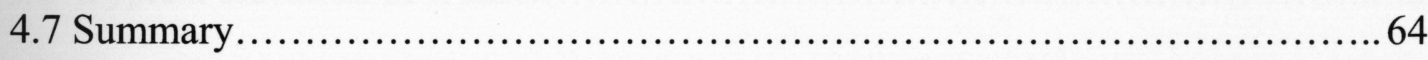

CHAPTER 5- NONLINEAR ANALYSIS OF RECTANGULAR TANKS............. 66

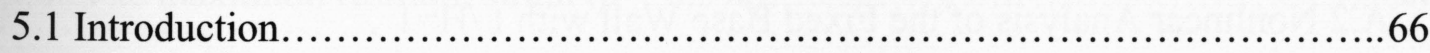

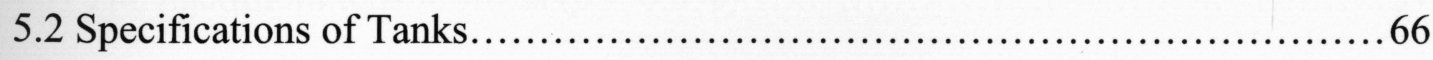

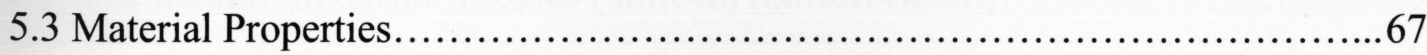

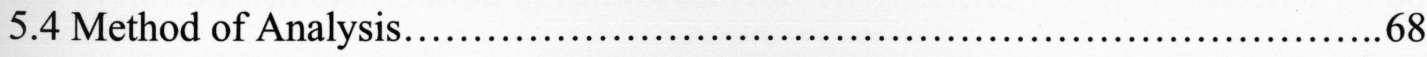

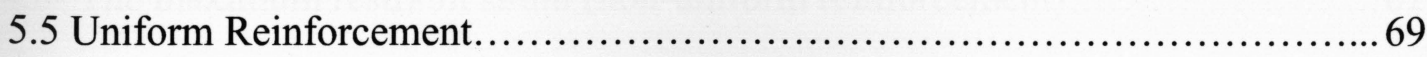


5.6 Non-uniform Reinforcement......................................... 71

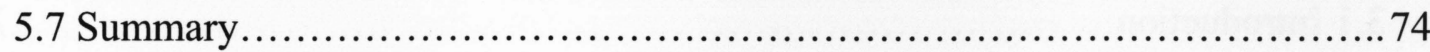

CHAPTER 6- DESIGN CRITERIA...................................................... 76

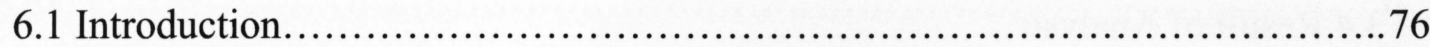

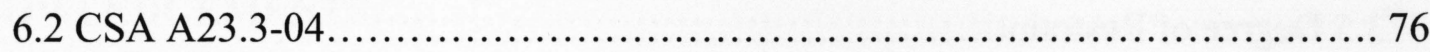

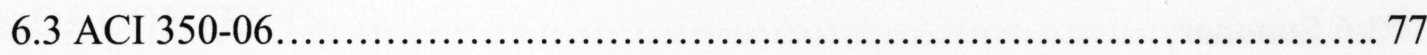

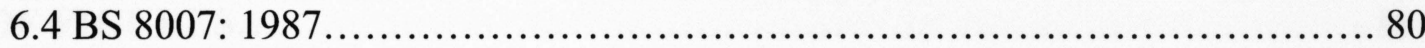

6.5 BS EN 1992-1-1: 2004_................................................. 82

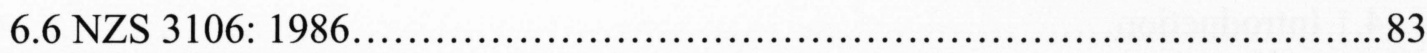

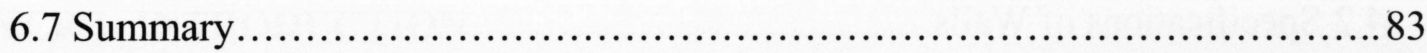

CHAPTER 7- CONCLUSION AND FUTURE WORK................................. 84

7.1 Concluding Remarks.................................................. 84

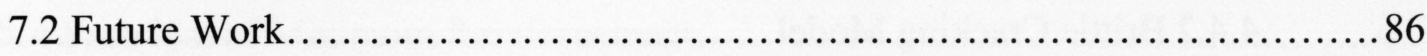

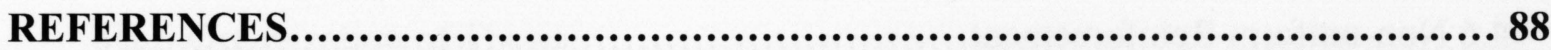

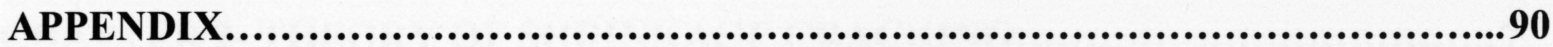

A.1 Linear Analysis of the Fixed Base Wall with $\mathrm{L} / \mathrm{H}=1 \ldots \ldots \ldots \ldots \ldots \ldots \ldots \ldots \ldots$

A.2 Nonlinear Analysis of the Fixed Base Wall with $\mathrm{L} / \mathrm{H}=1 \ldots \ldots \ldots \ldots \ldots \ldots \ldots \ldots$ 


\section{IST OF FIGURES}

igure 2.1- (a) Crack pattern, (b) concrete, and (c) steel stresses after first crack.......... 8 igure 2.2- (a) Final crack pattern, (b) concrete, and (c) steel stresses following shrinkage 11

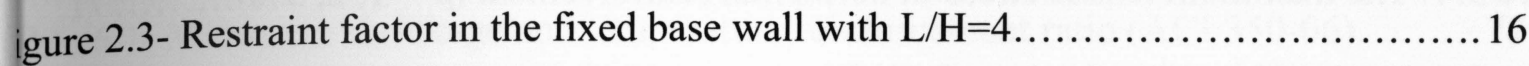

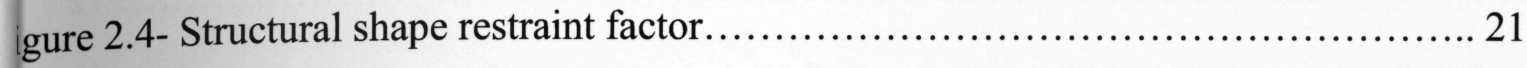

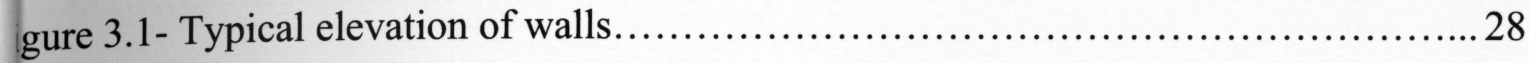

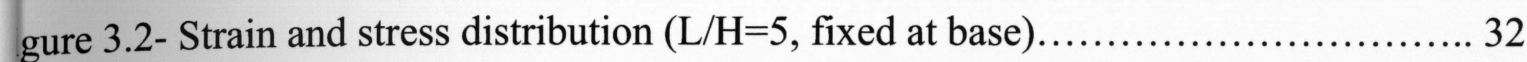

gure 3.3- Strain and stress distribution $(\mathrm{L} / \mathrm{H}=5$, fixed at base and top) ................ 33

gure 3.4- Strain and stress distribution ( $\mathrm{L} / \mathrm{H}=5$, fixed at base and both ends) $\ldots \ldots \ldots \ldots . \ldots 35$

gure 3.5- Strain and stress distribution ( $\mathrm{L} / \mathrm{H}=5$, fixed at base, top, and both ends)........ 36

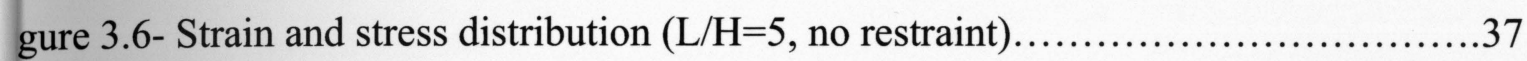

gure 3.7- Horizontal degree of restraint (fixed at base).................................. 39

gure 3.8- Horizontal degree of restraint (fixed at base and top) .......................40

gure 3.9- Horizontal degree of restraint (fixed at base and both ends)................. 41

gure 3.10- Horizontal degree of restraint (fixed at base, top, and both ends) ........... 42

gure 3.11- Horizontal degree of restraint (no restraint)...............................43

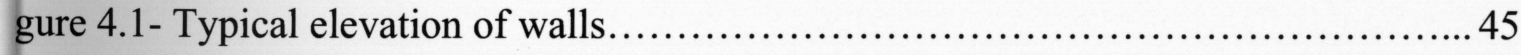

gure 4.2- Stress-strain diagram of (a) concrete in tension and (b) steel................. 46

gure 4.3- Horizontal stress in concrete at the center point $(\mathrm{L} / \mathrm{H}=1) \ldots \ldots \ldots \ldots \ldots \ldots \ldots . \ldots \ldots$

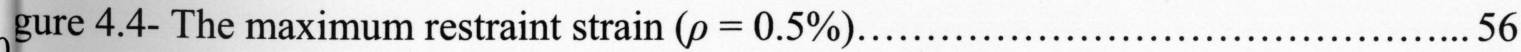

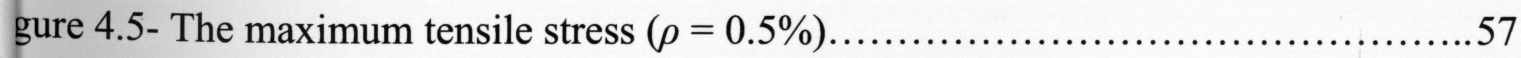

gure 4.6- The maximum tensile stresses (uniform reinforcement) ......................59

gure 4.7- Non-uniform distribution of reinforcement................................. 60

gure 4.8- The maximum restraint strain (non-uniform reinforcement)................. 62

gure 4.9- The maximum tensile stresses (non-uniform reinforcement).................6 63 
Figure 5.1- Typical perspective view of the tanks......................................66

Figure 5.2- Stress-strain diagram of (a) concrete in tension and (b) steel.................6 67

Figure 5.3- The maximum tensile stress in horizontal reinforcement $(\rho=0.5 \%) \ldots \ldots \ldots \ldots .70$

Figure 5.4- The maximum tensile stress in horizontal reinforcement $(\rho=1,2,3 \%) \ldots \ldots \ldots 71$

Figure 5.5- Non-uniform distribution of reinforcement............................. 72

Figure 5.6- The maximum tensile stress in reinforcement (non-uniform reinforcement)....73 


\section{LIST OF TABLES}

Table 2.1- Restraint factor on the centerline of fixed base concrete walls (Harrison)....... 17

Table 2.2- Restraint factor on the centerline of fixed base concrete walls (BS 8007)...... 19

Table 6.1- Minimum shrinkage and temperature reinforcement ratio (ACI 350-06)....... 77 


\section{CHAPTER 1}

\section{INTRODUCTION}

\subsection{General}

Concrete as the most commonly used construction material is relatively strong in compression but weak in tension. Concrete cracks when tensile stresses in a concrete member exceed the tensile strength of concrete. Cracks in concrete structures may lead to major structural problems. There are many causes of cracking in concrete. Among those, shrinkage cracking is a widespread problem in large concrete members such as walls and slabs.

In the construction of concrete structures such as reservoir tanks, it is a common practice that the foundation is cast first and then walls are added in intervals. Because of this construction procedure, the wall has different shrinkage movement than that of the foundation. In addition, any deformation at the contact surface between the wall and the foundation is prevented due to the rigid interconnection of the structural members. This restraint induces tensile stresses in concrete and may cause cracking in the wall.

Cracking due to the restraint volume change can be minimized by using proper curing procedures at the early age of concrete. Also, placing concrete in low temperature can minimize the temperature changes caused by hydration of cement. However, the strength of concrete placed at low temperature develops at later ages than that of the concrete placed at normal temperature which may delay the construction process. Shrinkagecompensating concrete can be very effective in limiting the cracks due to shrinkage (ACI 224.2R-92). However, significant cost is associated with such type of concrete.

Providing movement joints within the concrete member is another method to control shrinkage cracking. These joints increase the freedom of the member to move but may cause serviceability and maintenance problems. For example in liquid-containing structures movement joints could be source of leakage. 
In general, concrete standards and codes of practice recommend a minimum area of reinforcement for shrinkage and temperature effects. This reinforcement will not prevent shrinkage cracking but limits the size and the number of cracks.

\subsection{Shrinkage of Concrete}

Shrinkage of concrete is the reduction in volume. There are different types of shrinkage in a concrete member, such as drying shrinkage and carbonation shrinkage.

Drying shrinkage is caused by the loss of water in concrete mixture due to evaporation of water in capillary pores in the hardened concrete. Drying shrinkage along with changes in moisture content, are an inherent characteristic of hydraulic-cement paste in concrete (ACI 224R-01).

Carbonation shrinkage results from the chemical effects of carbon dioxide in atmosphere on the products of hydration. From reaction of carbon dioxide and hydration products, calcium carbonate will form and absorbs water available in capillary pores. However, in high-quality concrete with low porosity, carbonation shrinkage is of minor concern in the overall shrinkage of the structure because carbon dioxide does not penetrate much into the surface of the concrete member (ACI 224R-01).

Shrinkage of concrete develops slowly over time and makes it difficult to obtain an accurate prediction from short-term laboratory tests. In general, a coefficient variation of $20 \%$ is used in predicting long-term shrinkage of concrete. A typical value for the final shrinkage strain of concrete in most structures is $600 \times 10^{-6} \mathrm{~mm} / \mathrm{mm}$ (ACI 224R-01).

If shrinkage of concrete is restrained, cracking will result in a concrete member. If not controlled, cracking may lead to serviceability and durability problems such as excessive deflections and curvature, losses in prestress, freeze-thaw deterioration, and corrosion at cracks. 


\subsection{Restraint}

All concrete members are restrained to some degree either by supporting members or by different parts of the member itself. Restrained volume change can induce tensile or compressive stresses in a concrete member depending on the type of restraint and whether the member is contracting or expanding. Since concrete is relatively strong in compression, restraint conditions that induce compressive stresses in concrete is not of concern. Whereas, the primary concern is with those restraint conditions that induce tensile stresses in concrete that may lead to cracking in concrete.

The degree of restraint is the ratio of actual stress in concrete resulting from volume change to the stress that would result if concrete was completely restrained (ACI 207.2R07). Alternatively, the degree of restraint is the ratio of strain of concrete caused by restraint to the strain that would occur if concrete was not restrained (ACI 207.2R-07).

In general, two types of restraint exist in a concrete member; internal and external restraint.

Internal restraint arises from non-uniform volume change on a cross section within a concrete member. This restraint happens within large concrete members such as walls and slabs where interior temperature of concrete is greater than surface temperature or drying shrinkage is different from outside to inside of the member.

For example, in a concrete retaining wall with the base covered under the earth and the upper portions exposed to air some degree of internal restraint exist. Also, internal restraint will arise in a reservoir tank when filled with cold runoff. In this case, temperature near the surface of the tank drops substantially which result in tensile stresses and may cause cracking. When formwork is removed from a deep section while concrete is still hot, the surface zone contracts rapidly. However, the interior section of concrete which is still hot restrains any movement at the surface and concrete cracks. 
External restraint arises when fresh concrete is cast against hardened concrete or any other material. For instance, in a reservoir tank where the wall is cast against the base slab which was cast in advance, movements at the base are significantly restrained. However, the degree of restraint decreases considerably at locations above the base. Also, at the contact surface of new and old concrete in successive lifts of a wall or adjoining strips of a slab, external restraint to some degree exist. The external restraint depends on the relative dimensions, strength, and modulus of elasticity of concrete and restraining material.

\subsection{Principal of Minimum Reinforcement}

Tensile stresses develop in concrete when a restrained reinforced concrete member is subjected to shrinkage movement. When the tensile stress at any point in concrete reaches the tensile strength of concrete, cracking will happen. At crack location, all the cracking force is carried by reinforcement crossing the crack.

Reinforcement yields if the strength of reinforcement is less than the cracking force. As contraction continues to increase the deformation will be concentrated at the crack and crack becomes wider. However, if reinforcement is stronger than the cracking force, reinforcement remains elastic. As contraction continues to increase a new crack will form at the next weakest point. This process continues until the total contraction is absorbed and the final crack pattern is formed.

The force necessary to cause cracking in the member, $N_{c r}$, is given by

$N_{c r}=A_{c} f_{c r}$

leWhere,

$A_{c}$ is the area of concrete section

$f_{c r}$ is the cracking failure stress of concrete 
The strength of reinforcement is $A_{s} f_{y}$ where, $A_{s}$ is the area of reinforcement and $f_{y}$ is the yield stress of steel. In order to prevent yielding of reinforcement on first crack and therefore spread cracks in the member

$$
A_{s} f_{y}>A_{c} f_{c r}
$$

By substituting $\rho_{\min }=\frac{A_{s}}{A_{c}}$ in Eq. 1.2 and rearranging

$$
\rho_{\min }>\frac{f_{c r}}{f_{y}}
$$

Where,

$\rho_{\min }$ is the minimum required reinforcement ratio

This provides the principals of the minimum reinforcement ratio required to control cracking. However, the actual equation incorporates some factors taking account for different types of loading, non-uniform distribution of stresses within the concrete section, and exposure conditions.

\subsection{Objective of Thesis}

This research studies the behavior of reinforced concrete walls subjected to shrinkage strain using the finite element method. In addition to linear analysis, this study applies nonlinear finite element analysis to simulate the cracking behavior of concrete and predict crack pattern and tensile stresses in reinforcement in the vicinity of cracks.

The primary objective of this research is to find the effective shrinkage and temperature reinforcement in liquid-containing structures where cracking of concrete and leakage are of major concern. 


\subsection{Organization of Thesis}

This study is presented in 7 chapters. The mechanism of restrained shrinkage cracking in reinforced concrete members and a brief review of analytical and experimental work in this area are explained in Chapter 2. In addition, the concept of degree of restraint is discussed.

Chapter 3 studies the result of analysis assuming elastic material behaviour. The variation of the degree of restraint on the centerline of the walls with different aspect ratios and different boundary conditions is presented. The result of nonlinear analysis on fixed base reinforced concrete walls is discussed in Chapter 4. The effect of reinforcement ratio and uniform and non-uniform distribution of reinforcement on the cracking of the walls is presented. Chapter 5 investigates the cracking of walls in rectangular concrete tanks using nonlinear analysis.

Design requirements of shrinkage and temperature reinforcement recommended in major concrete standards and codes of practice are reviewed in Chapter 6. Chapter 7 concludes the research work and recommends areas of research for further studies. As an example, the input files of linear and nonlinear finite element analysis of the wall with length/height ratio of 1 are given in Appendices A.1 and A.2, respectively. 


\section{CHAPTER 2}

\section{THEORY OF SHRINKAGE CRACKING}

\subsection{Introduction}

This chapter explains the mechanism of direct tension cracking in reinforced concrete members developed by Gilbert (1992). A rational approach for the determination of the number and spacing of cracks and the average crack width in a fully restrained member and subjected to an axial restraining force caused by shrinkage is presented. This approach applies the principles of mechanics and the predictions agree well with observed cracking in a number of restrained members. The procedure is used to calculate the minimum shrinkage and temperature reinforcement in practical situations.

In addition, a review of analytical and experimental work in the area of restrained shrinkage cracking is presented. The definition of the degree of restraint is discussed and the degree of restraint caused by reinforcement is calculated.

\subsection{Theory of Restrained Shrinkage Cracking}

Consider a reinforced concrete member restrained at both ends and subjected to shrinkage strain as shown in Figure 2.1(a). As concrete shrinks, an axial restraining force, $N$, develops with time. In this case:

$$
N=A_{c} f_{t}
$$

Where,

$A_{c}$ is the area of concrete section

$f_{t}$ is the tensile stress in concrete 


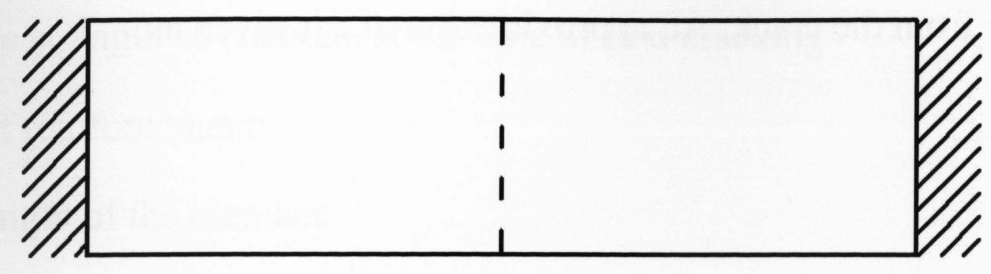

(a) Crack Pattern

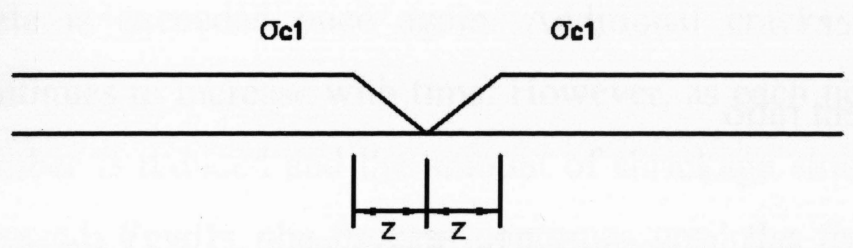

(b) Concrete Stress

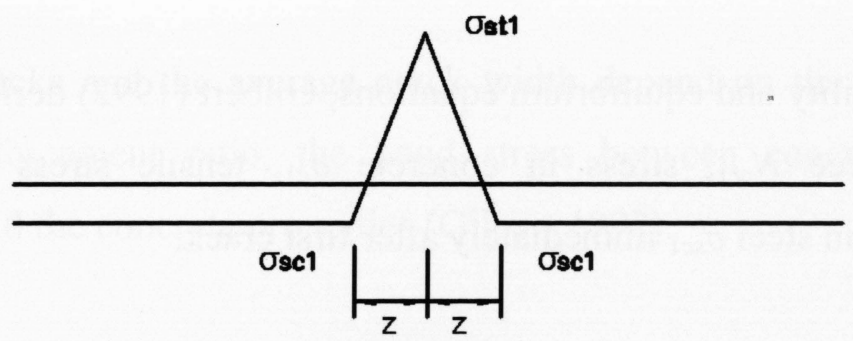

(c) Steel Stress

Figure 2.1- (a) Crack pattern, (b) concrete, and (c) steel stresses after first crack

When the stress in concrete at a particular cross section reaches the tensile strength of concrete, the first crack happens. After the first crack, the restraining force reduces. At this time, the stress in concrete away from the crack location is less than the tensile strength of concrete. At crack location, the entire restraining force is carried by reinforcement and the stress in concrete is zero.

In the region adjacent to the crack, the concrete and steel stresses vary considerably. As seen in Figure 2.1, reinforcement is in tension at crack location and is in compression in the region away from the crack. The tensile stress in steel at crack, $\sigma_{s t 1}$, drops gradually to the compressive stress, $\sigma_{s c 1}$, over the distance $z$ away from the crack. The stress in 
concrete is zero at crack location and increases gradually to the tensile stress, $\sigma_{c 1}$, over the distance $z$ away from the crack. An approximation of $z$ is given as

$$
z=\frac{d_{b}}{10 \rho}
$$

Where,

$d_{b}$ is the bar diameter

$\rho$ is the reinforcement ratio

This expression was earlier proposed by Favre et al (1983) for a member containing deformed bars or welded wire mesh.

Applying compatibility and equilibrium equations, Gilbert (1992) derived expressions for the restraining force $N_{c r 1}$, stress in concrete $\sigma_{c 1}$, tensile stress in steel $\sigma_{s t 1}$, and compressive stress in steel $\sigma_{s c 1}$ immediately after first crack.

$$
\begin{aligned}
& N_{c r 1}=\frac{n \rho f_{c r 1} A_{c}}{C_{1}+n \rho\left(1+C_{1}\right)} \\
& \sigma_{c 1}=\frac{N_{c r 1}\left(1+C_{1}\right)}{A_{c}} \\
& \sigma_{s t 1}=\frac{N_{c r 1}}{A_{s}} \\
& \sigma_{s c 1}=-C_{1} \sigma_{s t 1}
\end{aligned}
$$

In these equations,

$$
C_{1}=\frac{2 z}{3 L-2 z}
$$


$n$ is the ratio of the modulus of elasticity of steel to concrete

$f_{c r 1}$ is the tensile strength of concrete at the time of first cracking

$A_{s}$ is the area of reinforcement

$L$ is the total length of the member

As the member undergoes further shrinkage, the restraining force and the stress in concrete away from the crack location increase. The next crack happens when the tensile capacity of concrete is exceeded once again. Additional cracks may occur as the shrinkage strain continues to increase with time. However, as each new crack forms, the stiffness of the member is reduced and the amount of shrinkage strain required to form new cracks is increased. Finally, the process continues until the final crack pattern is established.

The number of cracks and the average crack width depend on the aspect ratio of the member, the reinforcement ratio, the bond stress between concrete and steel, the shrinkage strain, and the concrete properties (Gilbert 1992).

Figure 2.2 presents the final crack pattern, concrete and steel stresses in a member restrained at both ends after all shrinkage has taken place.

As seen in Figure 2.2, the final tensile stress in steel at crack, $\sigma_{s t}$, drops gradually to the final compressive stress, $\sigma_{s c}$, over the distance $z$ away from the crack. The stress in concrete is zero at crack location and increases gradually to the final stress, $\sigma_{c}$, over the distance $z$ away from the crack. It is assumed that the distance $z$ over which the stress in concrete and steel varies considerably on each side of the crack remains constant in the first cracking as well as the final cracking pattern. In addition, it is assumed that cracks are distributed equally in the member. Therefore, the minimum number of cracks $m$, distributed at a spacing of $s$ is

$$
m=\frac{L}{S}
$$




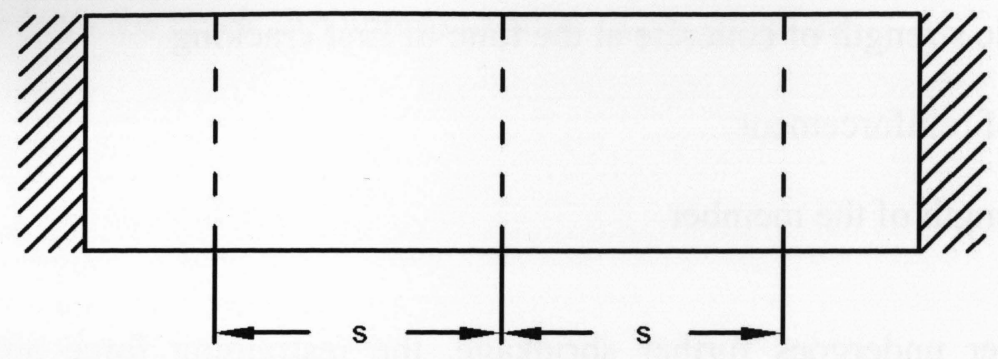

(a) Crack Pattern

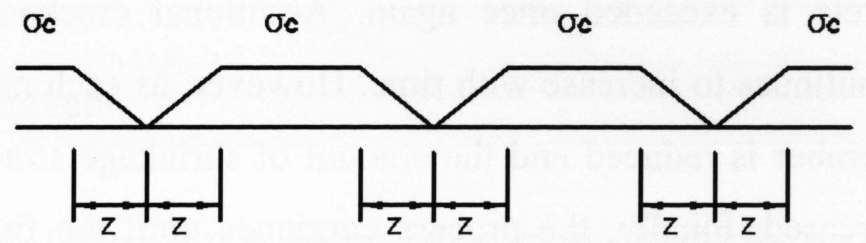

(b) Concrete Stress

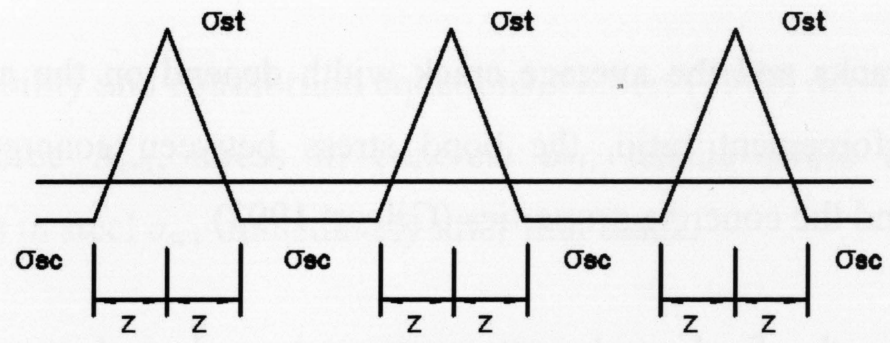

(c) Steel Stress

Figure 2.2- (a) Final crack pattern, (b) concrete, and (c) steel stresses following shrinkage

Applying compatibility and equilibrium equations, Gilbert (1992) derived expressions for the final restraining force $N_{c r}$, final stress in concrete $\sigma_{c}$, final tensile stress in steel $\sigma_{s t}$, final compressive stress in steel $\sigma_{s c}$, crack spacing $s$, and average crack width $w$, after all shrinkage has taken place. The equations are

$$
\begin{aligned}
& N_{c r}=-\frac{n_{e} A_{s}}{C_{2}}\left(\sigma_{a v}+\varepsilon_{s h} E_{c e}\right) \\
& \sigma_{s t}=\frac{N_{c r}}{A_{s}}
\end{aligned}
$$




$$
\begin{aligned}
& \sigma_{s c}=-C_{2} \sigma_{s t} \\
& \sigma_{c}=\frac{N_{c r}-\sigma_{s c} A_{s}}{A_{c}} \\
& s=\frac{2 z\left(1+C_{3}\right)}{3 C_{3}} \\
& w=-\left[\frac{\sigma_{c}}{E_{c e}}\left(s-\frac{2}{3} z\right)+\varepsilon_{s h} s\right]
\end{aligned}
$$

In these equations,

$$
\begin{aligned}
& C_{2}=\frac{2 z}{3 s-2 z} \\
& C_{3}=\frac{-n_{e} \rho\left(\sigma_{a v}+\varepsilon_{s h} E_{c e}\right)}{n_{e} \rho\left(\sigma_{a v}+\varepsilon_{s h} E_{c e}\right)+f_{c r}}
\end{aligned}
$$

$n_{e}$ is the ratio of the modulus of elasticity of steel to the effective modulus of elasticity of concrete

$E_{c e}$ is the effective modulus of elasticity of concrete given as

$$
E_{c e}=\frac{E_{c}}{1+\phi}
$$

$\phi$ is the final creep coefficient of concrete

$E_{c}$ is the modulus of elasticity of concrete

$\sigma_{a v}$ is the average stress in concrete given as

$$
\sigma_{a v}=\frac{\sigma_{c 1}+f_{c r}}{2}
$$

$f_{c r}$ is the final tensile strength of concrete 
$\varepsilon_{s h}$ is the final shrinkage strain

As an example the average crack width in a reinforced concrete slab restrained at both ends is estimated. The thickness of the slab is assumed $150 \mathrm{~mm}$. Reinforcement is provided by $12 \mathrm{~mm}$ diameter deformed bars at $300 \mathrm{~mm}$ spacing at both top and bottom of the slab. The material properties of concrete and steel are as follows:

$\phi($ Creep coefficient of concrete $)=2.5$

$\varepsilon_{s h}($ Shrinkage strain of concrete $)=-600 \times 10^{-6} \mathrm{~mm} / \mathrm{mm}$

$f_{c r}($ Tensile strength of concrete $)=2.0 \mathrm{MPa}$

$E_{c}($ Modulus of elasticity of concrete $)=25,000 \mathrm{MPa}$

$E_{s}($ Modulus of elasticity of steel $)=200,000 \mathrm{MPa}$

The concrete and steel areas are

$$
\begin{aligned}
& A_{c}=1,000 \times 150=150,000 \mathrm{~mm}^{2} / \mathrm{m} \\
& A_{s}=750 \mathrm{~mm}^{2} / \mathrm{m}
\end{aligned}
$$

The reinforcement ratio is

$$
\rho=\frac{750}{150,000}=0.005
$$

From Eq. 2.17

$$
E_{c e}=\frac{25,000}{1+2.5}=7143 \mathrm{MPa}
$$

And then $n_{e}$ is

$$
n_{e}=\frac{200,000}{7143}=28
$$


From Eq. 2.2

$$
z=\frac{12}{10 \times 0.005}=240 \mathrm{~mm}
$$

Eq. 2.7 gives

$$
C_{1}=\frac{2 \times 240}{3 \times 5,00-2 \times 240}=0.0331
$$

Using Eq. 2.3 and 2.4, the restraining force and the stress in concrete immediately after first crack are

$$
\begin{aligned}
& N_{c r 1}=161,300 \mathrm{~N} / \mathrm{m} \\
& \sigma_{c 1}=1.11 \mathrm{MPa}
\end{aligned}
$$

Eq. 2.18 gives

$$
\sigma_{a v}=\frac{1.11+2.0}{2}=1.56 \mathrm{MPa}
$$

From Eq. 2.16

$$
C_{3}=0.236
$$

From Eq. 2.13 the crack spacing is

$$
s=\frac{2 \times 240(1+0.236)}{3 \times 0.236}=839 \mathrm{~mm}
$$

From Eq. 2.15 


$$
C_{2}=\frac{2 \times 240}{3 \times 839-2 \times 240}=0.238
$$

Using Eq. 2.9, 10, 11, and 12 the final restraining force, final stress in concrete, final tensile stress in steel, and final compressive stress in steel after all shrinkage are

$$
\begin{aligned}
& N_{c r}=240,900 \mathrm{~N} / \mathrm{m} \\
& \sigma_{s t}=321 \mathrm{MPa} \\
& \sigma_{s c}=-7.643 \mathrm{MPa} \\
& \sigma_{c}=1.99 \mathrm{MPa}
\end{aligned}
$$

And finally the average crack width determined from Eq. 2.14 is

$$
w=0.31 \mathrm{~mm}
$$

In general, concrete standards and codes of practice limit the maximum crack width to $0.20 \mathrm{~mm}$ for members exposed to sever conditions (ACI 224.2R-92). In the slab of the example with 0.005 reinforcement ratio, the crack width was calculated just over $0.3 \mathrm{~mm}$. Therefore, this amount of reinforcement might be considered inadequate for some applications. Increasing the reinforcement ratio to 0.0063 , the crack width is calculated $0.21 \mathrm{~mm}$ which is acceptable for sever exposure conditions.

\subsection{Effect of Restraint}

Schleech (1962) derived horizontal and vertical restraint factor for an uncracked wall on the rigid base with length/height ratio of 4 . Figure 2.3 presents the value of the restraint factor at different locations on the wall.

As shown, except for the bottom strip, the horizontal restraint factor reduces towards the ends of the wall with the maximum value on the centerline of the wall. The vertical restraint factor is considerable only in small area near the ends of the wall. 
Stoffers (1978) developed a theory of cracking in concrete panels based on curvature analysis. It was shown that the degree of curvature affects considerably the resultant stresses and strains in a concrete member subjected to restrained deformation. A series of formulae was given to calculate the curvature and associated crack width. It was concluded that the degree of restraint can be taken as 0.9 at the wall-foundation junction and 0.1 at the top free edge.

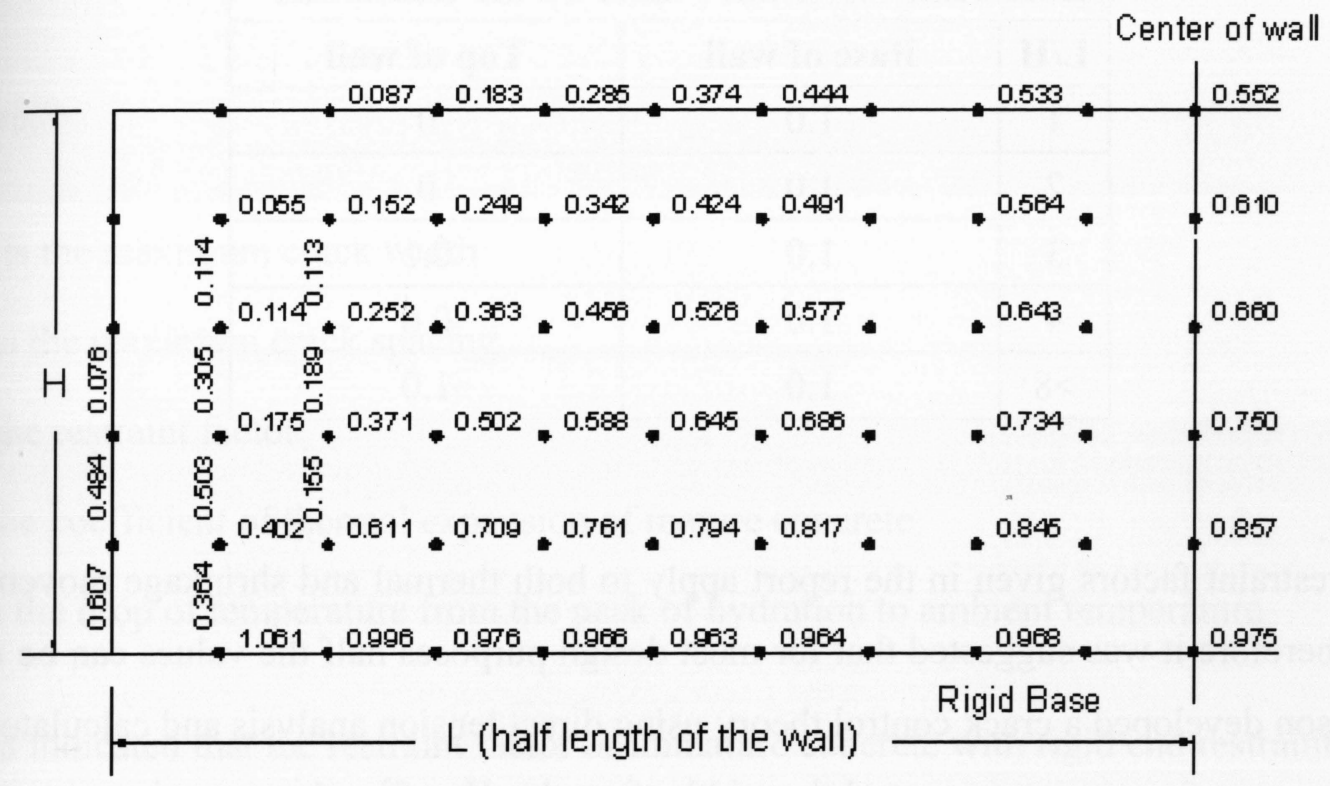

Figure 2.3- Restraint factor in the fixed base wall with $\mathrm{L} / \mathrm{H}=4$ (Schleech 1962)

Deacon (1978) reported that cracking was not observed within $2.4 \mathrm{~m}$ from the free edge in the walls with or greater than $4 \mathrm{~m}$ high built in UK. He showed that only one crack within the allowable width will form in the walls of 5 to $6 \mathrm{~m}$ long. However, this conclusion is relied only on the walls with or greater than $4 \mathrm{~m}$ high.

Anchor et al (1979) suggested that the horizontal restraint factor at the wall-foundation junction should be taken as 1.0. Also, the vertical restraint factor at the ends of the wall is 0.5. The restraint factor reduces to some negligible value above the base. However, the height at which the restraint factor is negligible is not mentioned. 
Harrison (1981) derived theoretical restraint factor in uncracked concrete for several wall and slab situation. It was indicated that these factors are very conservative and the initiation of cracks affect the value of the restraint factor. Table 2.1 presents horizontal restraint factor on the centerline of fixed base walls with different length/height ratios.

Table 2.1- Restraint factor on the centerline of fixed base concrete walls

\begin{tabular}{|c|c|c|}
\hline \multicolumn{3}{|c|}{ Horizontal Restraint Factor on the Centerline } \\
\hline L/H & Base of wall & Top of wall \\
\hline 1 & 1.0 & 0 \\
\hline 2 & 1.0 & 0 \\
\hline 3 & 1.0 & 0.1 \\
\hline 4 & 1.0 & 0.6 \\
\hline$>8$ & 1.0 & 1.0 \\
\hline
\end{tabular}

The restraint factors given in the report apply to both thermal and shrinkage movements and therefore it was suggested that for most design purposes half the values can be used. Harrison developed a crack control theory using direct tension analysis and calculated the reinforcement necessary to control the width of cracks. He offered an equation given as

$$
\rho=\frac{f_{c r}}{f_{b}} \frac{d_{b}}{2 w}\left[R \varepsilon_{s h}-\frac{\varepsilon_{c r}}{2}\right]
$$

Where,

$\rho$ is reinforcement ratio

$f_{c r}$ is tensile strength of concrete

$f_{b}$ is bond strength of concrete

$d_{b}$ is the bar diameter

$w$ is permitted crack width

$R$ is restraint factor 
$\varepsilon_{s h}$ is the shrinkage strain

$\varepsilon_{c r}$ is the tensile strain capacity of concrete

British Standards Institution (1987) introduced an expression relating the maximum crack width to the degree of restraint as

$w_{\max }=S_{\max } R \alpha \Delta T$

Where,

$w_{\max }$ is the maximum crack width

$S_{\max }$ is the maximum crack spacing

$R$ is the restraint factor

$\alpha$ is the coefficient of thermal expansion of mature concrete

$\Delta T$ is the drop of temperature from the peak of hydration to ambient temperature

It was indicated that the restraint factor of immature concrete with rigid end restraints can be taken as 0.5 . Also, within $2.4 \mathrm{~m}$ of the free edge of a concrete member cracking does not occur. The restraint factor varies from zero at the free edge to a maximum of 0.5 at $2.4 \mathrm{~m}$ from the free edge. However, if stress inducers such as pipes are installed within this area cracking is likely to happen. Table 2.2 presents recommended values for restraint factor on the centerline of fixed base concrete walls with different length/height ratios.

Murray (1991) proposed a simple relationship between reinforcement ratio, stiffness of the concrete panel, and flexibility of restraining system in order to keep the stresses in reinforcement to less than $200 \mathrm{MPa}$ when concrete is subjected to shrinkage. The expression is given as 
Table 2.2- Restraint factor on the centerline of fixed base concrete walls

\begin{tabular}{|c|c|c|}
\hline \multicolumn{3}{|c|}{ Horizontal Restraint Factor on the Centerline } \\
\hline L/H & Base of wall & Top of wall \\
\hline 1 & 0.5 & 0 \\
\hline 2 & 0.5 & 0 \\
\hline 3 & 0.5 & 0.05 \\
\hline 4 & 0.5 & 0.3 \\
\hline$>8$ & 0.5 & 0.5 \\
\hline
\end{tabular}

$\rho \times \frac{k_{\text {slab }}}{k_{\text {restraint }}}=2$

Where,

$\rho$ is the reinforcement ratio

$k_{s l a b}$ is the uniaxial elastic stiffness of the slab

$k_{\text {restraint }}$ is the spring stiffness of the restraining system

Kheder (1997) developed a finite element model for fixed base concrete walls and proposed a new method for the control of volume change cracking. This method is based on the change of degree of restraint in the wall.

He concluded that the crack width in the wall is proportional to the difference of the restraint factor before and after the cracking as follows

$w \propto\left(R_{b}-0.8 R_{a}\right) \varepsilon_{s h}$

Where,

$w$ is the crack width

$R_{b}$ is the restraint factor before cracking 
$R_{a}$ is the restraint factor after cracking

$\varepsilon_{s h}$ is the shrinkage strain

Diagrams of change of restraint factor in walls with length/height ratios of 1, 2, 3, 4, 6, and 8 were provided using two-dimensional finite element linear analysis.

Beeby and Forth (2004) developed a finite element model for edge restrained walls subjected to shrinkage and concluded that cracks are smaller in edge restrained walls than that in end restrained walls. In addition, it was stated that crack width is proportional to shrinkage strain in edge restraint walls whereas in end restraint walls crack width is proportional to the tensile strength of concrete.

ACI Committee 207 (2007) reported on the variation of degree of restraint in concrete walls restrained at the base and subjected to uniform contraction. The horizontal stress in concrete varies from point to point in accordance with the variation in degree of restraint throughout the member. The report considers two restraint factors to determine the degree of restraint: the structural shape restraint factor and the foundation restraint factor.

The variation of restraint in a wall depends on the length/height ratio of the member. Figure 2.4 presents the variation of the structural shape restraint factor, $K_{R}$, on the centerline of continuous base restrained walls with length/height ratios of 1 to 20 as reported by the Committee. This graph was developed from experimental data reported by Carlson (1937) and later published by the U.S. Bureau of Reclamation (1965).

The stresses in concrete due to base restraint are directly proportional to the stiffness of the foundation. As the stiffness of the restraining material decreases, the stress in concrete is reduced. An approximation of the foundation restraint factor, $K_{f}$, is given by (U.S. Bureau of Reclamation 1965) 


$$
K_{f}=\frac{1}{1+\frac{A_{g} E_{c}}{A_{F} E_{F}}}
$$

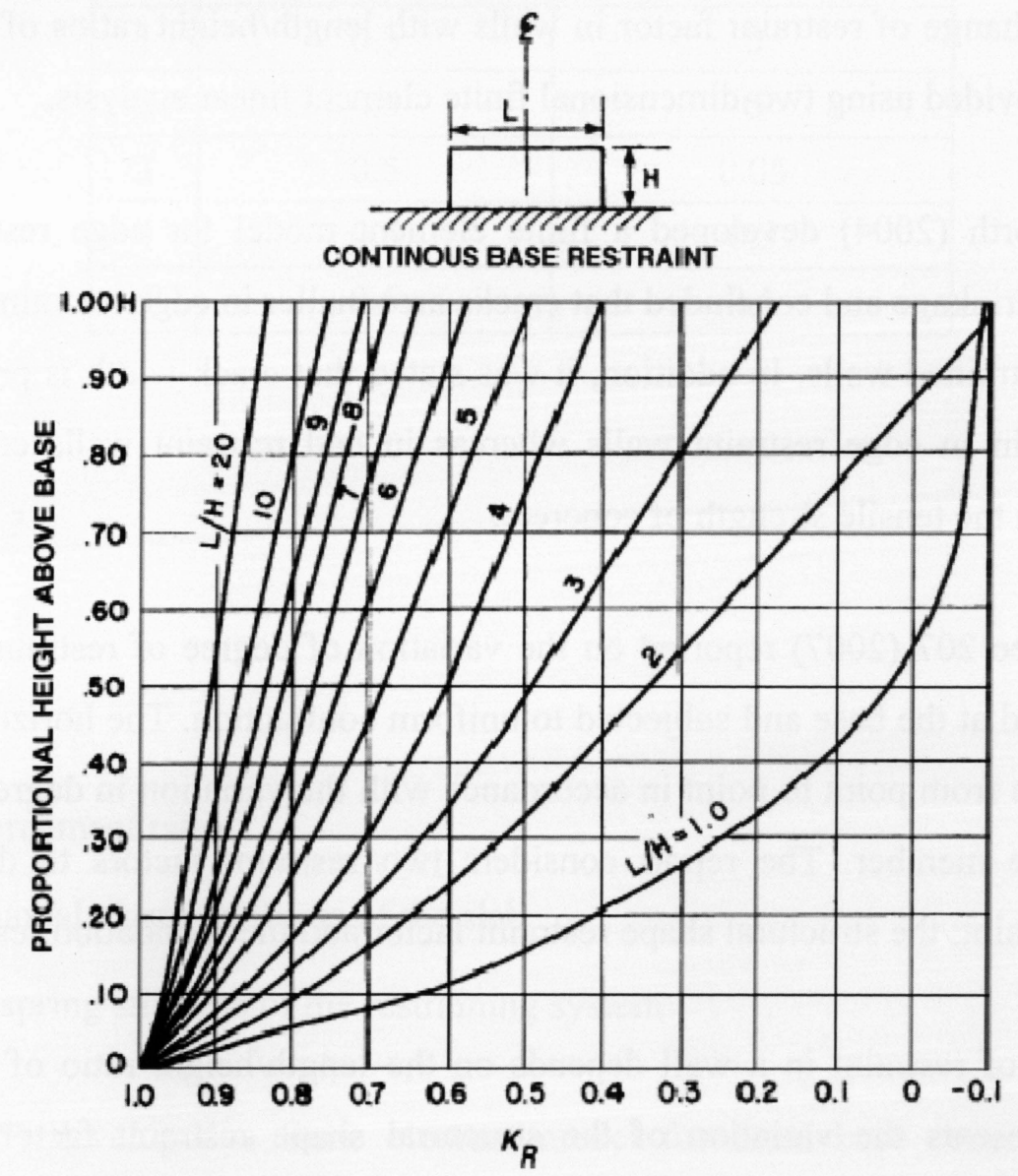

Figure 2.4- Structural shape restraint factor (ACI 207.2R-07)

Where,

$A_{F}$ is the area of foundation taken as a plane surface at contact

$A_{g}$ is the gross area of concrete cross section

$E_{c}$ is the modulus of elasticity of concrete

$E_{F}$ is the modulus of elasticity of foundation 
Using the structural shape restraint factor and the foundation restraint factor derived from Figure 2.4 and Eq. 2.23, respectively, the tensile stress in concrete at any point on the centerline of the wall due to shrinkage is calculated from

$$
f_{c}=K_{R} K_{F} \varepsilon_{s h} E_{c}
$$

Where,

$f_{c}$ is the tensile stress in concrete

$\varepsilon_{s h}$ is the shrinkage strain if there were no restraint

$E_{c}$ is sustained modulus of elasticity of the concrete at the time of shrinkage

The report states that in fixed base unreinforced concrete walls with length/height ratio greater than 2.5 and subjected to sufficient volume change, full block height cracks spaced at about 1.0 to 2.0 times the height of the block forms. The propagation of a crack depends on multiple factors, such as the shape of the crack tip whether it is pointed or rounded. If an initial crack reaches to 0.2 to 0.3 times the height of the wall, the crack will propagate to the full height of the wall without a further reduction in volume.

The minimum restraining force capable of producing full-block cracking happens in the wall with length/height ratio of 2.5 . In this case, the crack spacing is approximately 1.25 times the height of the wall.

\subsection{Degree of Restraint}

In concrete structures, the connection of a concrete member to other parts of the structure or to the foundation provides restraint to shrinkage which might lead to cracking. Thin slabs and walls are particularly prone to significant cracking caused by restrained shrinkage and temperature movements. 
The degree of restraint is the ratio of actual stress in concrete resulting from volume change to the stress that would result if concrete were completely restrained (ACI 207.2R-07). Based on this definition, the degree of restraint is expressed as

$$
K_{R}=\frac{f_{c, a}}{f_{c, r}}
$$

Where,

$K_{R}$ is the degree of restraint

$f_{c, a}$ is the actual stress in concrete

$f_{c, r}$ is the stress in concrete if the member is fully restrained

Consider a concrete member subjected to shrinkage. The total strain at each point in concrete is caused by shrinkage and restraint from surrounding parts of the member at that point. Therefore, the total strain in concrete is

$\varepsilon_{\text {total }}=\varepsilon_{\text {shrinkage }}+\varepsilon_{\text {restraint }}$

Where,

$\varepsilon_{\text {total }}$ is the total strain in concrete

$\varepsilon_{\text {shrinkage }}$ is the shrinkage strain

$\varepsilon_{\text {restraint }}$ is the restraint strain in concrete

The restraint strain in concrete is in the opposite direction of shrinkage strain. Therefore, tensile stresses develop in concrete. In uncracked concrete section, the actual stress in concrete, $f_{c, a}$, is

$f_{c, a}=E_{c} \varepsilon_{\text {restraint }}$ 
Where,

$E_{c}$ is the modulus of elasticity of concrete

By substituting Eq. 2.26 in Eq. 2.27 the actual stress in concrete, $f_{c, a}$, is

$$
f_{c, a}=E_{c}\left(\varepsilon_{\text {total }}-\varepsilon_{\text {shrinkage }}\right)
$$

When the concrete member is fully restrained to any movement, the total strain in concrete is zero. Therefore, Eq. 2.26 gives

$$
\varepsilon_{\text {restraint }}=-\varepsilon_{\text {shrinkage }}
$$

The stress in concrete when the member is fully restrained, $f_{c, r}$, is

$$
f_{c, r}=E_{c} \varepsilon_{\text {restraint }}
$$

By substituting Eq. 2.29 in Eq. 2.30 the stress in concrete when the member is fully restrained, $f_{c, r}$, is

$$
f_{c, r}=E_{c}\left(-\varepsilon_{\text {shrinkage }}\right)
$$

By substituting Eq. 2.28 and Eq. 2.31 in Eq. 2.25 the degree of restraint, $K_{R}$, can be expressed alternatively as

$$
K_{R}=-\frac{\varepsilon_{\text {total }}-\varepsilon_{\text {shrinkage }}}{\varepsilon_{\text {shrinkage }}}=-\frac{\varepsilon_{\text {restraint }}}{\varepsilon_{\text {shrinkage }}}
$$

\subsection{Degree of Restraint caused by Reinforcement}

Bonded reinforcement in reinforced concrete members provides restraint to shrinkage. As concrete shrinks, compressive stresses develop in the reinforcement and the 
reinforcement imposes an equal and opposite tensile force on the concrete. Applying compatibility and equilibrium equations, an expression is derived to determine the degree of restraint caused by reinforcement.

Consider a reinforced concrete member subjected to shrinkage. The total strain in concrete is caused by shrinkage and restraint from reinforcement. In addition, based on compatibility the total strain in concrete and reinforcement is the same. Therefore,

$\varepsilon_{s}=\varepsilon_{\text {total }}=\varepsilon_{\text {shrinkage }}+\varepsilon_{\text {restraint }}$

Where,

$\varepsilon_{s}$ is the strain in reinforcement

$\varepsilon_{\text {total }}$ is the total strain in concrete

$\varepsilon_{\text {shrinkage }}$ is the shrinkage strain

$\varepsilon_{\text {restraint }}$ is the restraint strain in concrete

In addition,

$\varepsilon_{s}=\frac{f_{s}}{E_{s}}$

$\varepsilon_{\text {restraint }}=\frac{f_{c}}{E_{c}}$

Where,

$f_{s}$ is the stress in reinforcement

$f_{c}$ is the stress in concrete

$E_{s}$ is the modulus of elasticity of steel

$E_{c}$ is the modulus of elasticity of concrete 
By substituting Eq. 2.34 and Eq. 2.35 in Eq. 2.33

$\varepsilon_{\text {shrinkage }}=\frac{f_{s}}{E_{s}}-\frac{f_{c}}{E_{c}}$

When a reinforced concrete member is subjected to shrinkage, concrete is in tension due to restraint caused by reinforcement and the reinforcement is in compression. Also, each section of the member is in equilibrium. Therefore,

$f_{c} A_{c}=-f_{s} A_{s}$

Where,

$A_{c}$ is the area of concrete section

$A_{s}$ is the area of reinforcement

Considering $\rho=\frac{A_{s}}{A_{c}}$ and rearranging Eq. 2.37 gives

$f_{s}=-\frac{f_{c}}{\rho}$

By substituting $E_{s}=n E_{c}$ and Eq. 2.38 in Eq. 2.36

$\varepsilon_{\text {shrinkage }}=-\frac{f_{c}}{E_{c}}\left(1+\frac{1}{n \rho}\right)$

By substituting Eq. 2.35 and Eq. 2.39 in Eq. 2.32 the degree of restraint caused by reinforcement is 


$$
K_{R}=\frac{1}{1+\frac{1}{n \rho}}
$$

For instance, in a reinforced concrete member with $n=8$ and $\rho=0.005$, the degree of restraint caused by reinforcement is equal to 0.038 . If the final shrinkage strain of concrete is $600 \times 10^{-6} \mathrm{~mm} / \mathrm{mm}$, reinforcement causes $20.4 \times 10^{-6} \mathrm{~mm} / \mathrm{mm}$ restraint strain in concrete. Considering the modulus of elasticity of concrete as $25,000 \mathrm{MPa}$, the tensile stress induced in concrete is $0.5 \mathrm{MPa}$ which is nearly $20 \%$ of the tensile strength of concrete. 


\section{CHAPTER 3}

\section{LINEAR ANALYSIS OF WALLS}

\subsection{Introduction}

This chapter studies the response of reinforced concrete walls subjected to shrinkage strain assuming linear elastic material behaviour. In this study, walls with different aspect ratios (length/height ratio) and different boundary conditions are investigated and the variation of the degree of restraint on the centerline of the walls is presented.

\subsection{Specifications of Walls}

Five reinforced concrete walls with length/height ratios of $1,2,5,10$, and 20 were analyzed. For all cases, the height and the thickness of the walls were $1 \mathrm{~m}$ and $200 \mathrm{~mm}$, respectively. Figure 3.1 presents a typical elevation of the walls.

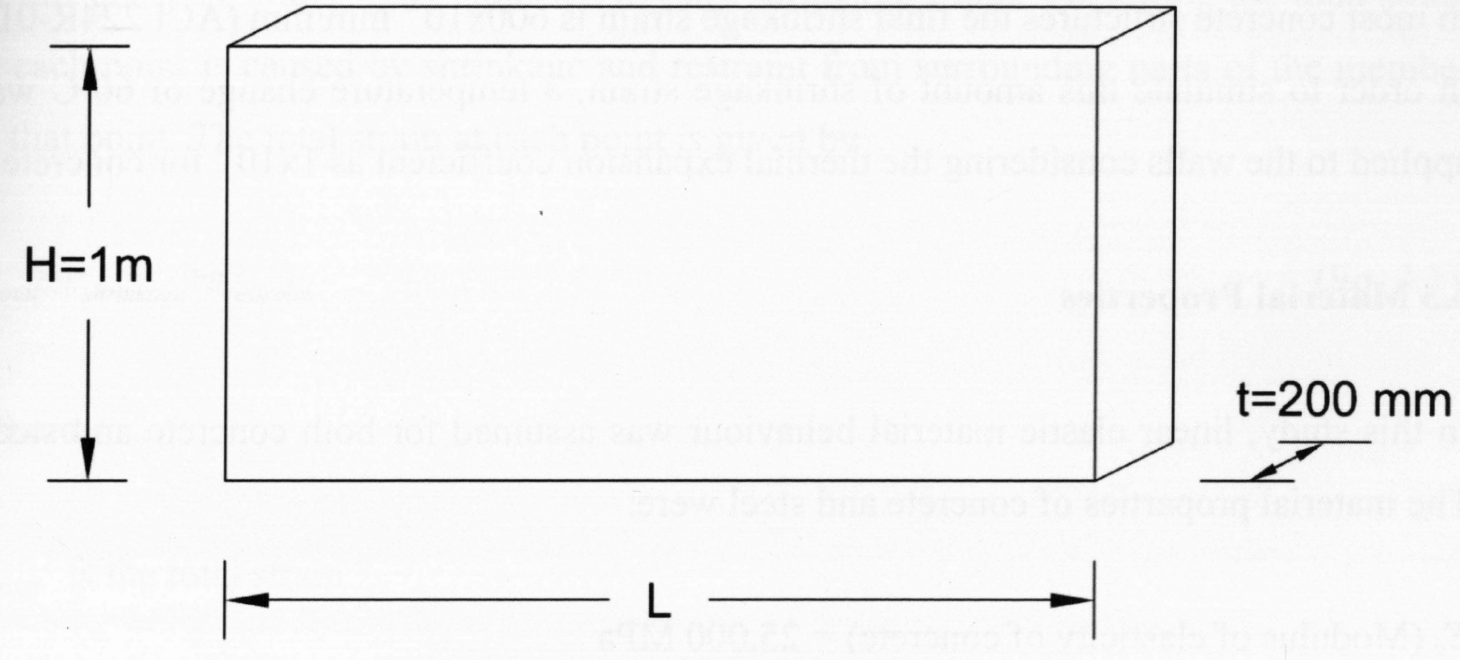

Figure 3.1- Typical elevation of walls

For each length/height ratio, five boundary conditions were applied: 


\section{1- Fixed at base}

\section{2- Fixed at base and top}

3- Fixed at base and both ends

4- Fixed at base, top, and both ends

5- No restraint (Rollers under the base)

The roller under the base boundary condition was implemented to investigate the restraining effect of reinforcement on the shrinkage of concrete.

In general, concrete standards and codes of practice recommend shrinkage and temperature reinforcement ratio of $0.3 \%$ for walls and slabs. The highest value of the shrinkage and temperature reinforcement ratio recommended by Standard Requirements for Environmental Engineering Concrete Structures (ACI 350R-06) is $0.5 \%$ for steel grade 60 where the length between movement joints is greater than $12 \mathrm{~m}$. In this study, the reinforcement ratio of the walls was $0.5 \%$ in both horizontal and vertical directions.

In most concrete structures the final shrinkage strain is $600 \times 10^{-6} \mathrm{~mm} / \mathrm{mm}$ (ACI 224R-01). In order to simulate this amount of shrinkage strain, a temperature change of $60^{\circ} \mathrm{C}$ was applied to the walls considering the thermal expansion coefficient as $1 \times 10^{-5}$ for concrete.

\subsection{Material Properties}

In this study, linear elastic material behaviour was assumed for both concrete and steel. The material properties of concrete and steel were:

$E_{c}($ Modulus of elasticity of concrete $)=25,000 \mathrm{MPa}$

$v_{c}$ (Poison's ratio of concrete $)=0.15$

$\alpha_{c}($ Thermal expansion coefficient of concrete $)=1 \times 10^{-5}$

$E_{s}($ Modulus of elasticity of steel $)=210,000 \mathrm{MPa}$

$v_{s}($ Poison's ratio of steel $)=0.0$ 
$\alpha_{s}($ Thermal expansion coefficient of steel $)=0.0$

Reinforcement in concrete structures is typically provided by means of reinforcing bars, which are one dimensional strain theory elements. In this analysis, reinforcement was modeled as a layer of steel embedded inside the walls. Therefore, the Poisson's ratio of steel was assumed zero to simulate the behaviour of reinforcing bars.

In reinforced concrete structures, concrete is expected to shrink and not the reinforcement. Therefore, the thermal expansion coefficient of steel was assumed zero.

\subsection{Result of Analysis}

In this study, the computer software ABAQUS version 6.7 was used for analysis. Concrete walls were modeled using quadratic $100 \mathrm{~mm}$ x $100 \mathrm{~mm}$ shell elements with 8 integration points. Reinforcement was modeled as one steel layer embedded in the mid thickness of the shell elements.

In this analysis, walls were subjected to only shrinkage strain. Therefore, the total strain at each point is caused by shrinkage and restraint from surrounding parts of the member at that point. The total strain at each point is given by

$\varepsilon_{\text {total }}=\varepsilon_{\text {shrinkage }}+\varepsilon_{\text {restraint }}$

Where,

$\varepsilon_{\text {total }}$ is the total strain

$\varepsilon_{\text {shrinkage }}$ is the shrinkage strain

$\varepsilon_{\text {restraint }}$ is the restraint strain 
The total strain at each point is derived from analysis output. Knowing that the shrinkage strain is $600 \times 10^{-6} \mathrm{~mm} / \mathrm{mm}$ for every point in the walls, the restraint strain can be determined from Eq. 3.1.

The result of analysis on the centerline of the wall with length/height ratio of 5 and having different boundary conditions is presented in the following sections.

\subsubsection{Fixed at Base}

Figure 3.2 presents total strain, restraint strain, stress in reinforcement, and stress in concrete in horizontal direction on the centerline of the wall with length/height ratio of 5 and fixed at the base. The negative and positive values represent compression and tension, respectively.

As seen in Figure 3.2(a), the wall is contracting. The total horizontal strain is zero at the base where the wall is fully fixed and the total horizontal strain is increasing from the base to the top of the wall.

Figure 3.2(b) shows that the centerline of the wall is under tension from restraint of the surrounding parts. The horizontal restraint strain at the base is equal to the value of shrinkage strain and the horizontal restraint strain is decreasing slightly from the base to the top of the wall.

As seen in Figure 3.2(c), horizontal reinforcing bars are under compression and the stress is increasing from the base to the top of the wall. In addition, the stress in horizontal reinforcing bars is proportional to the total horizontal strain.

Figure 3.2(d) shows that concrete is under tension and the horizontal stress in concrete is decreasing from the base to the top of the wall. Also, the horizontal stress in concrete is proportional to the horizontal restraint strain. 


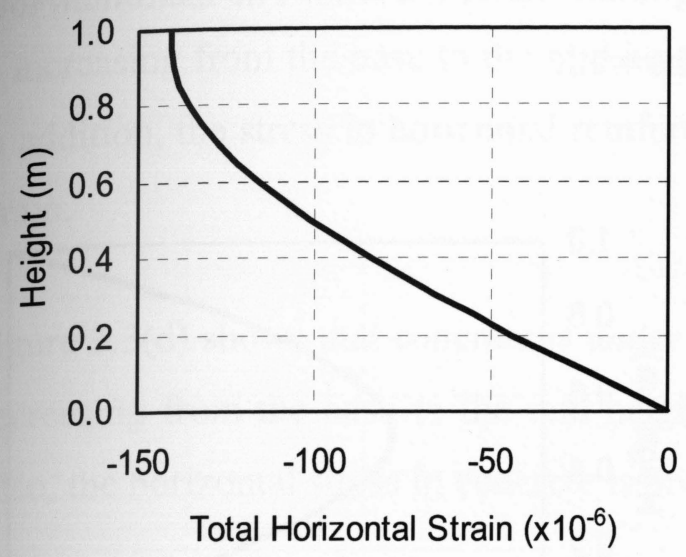

(a)

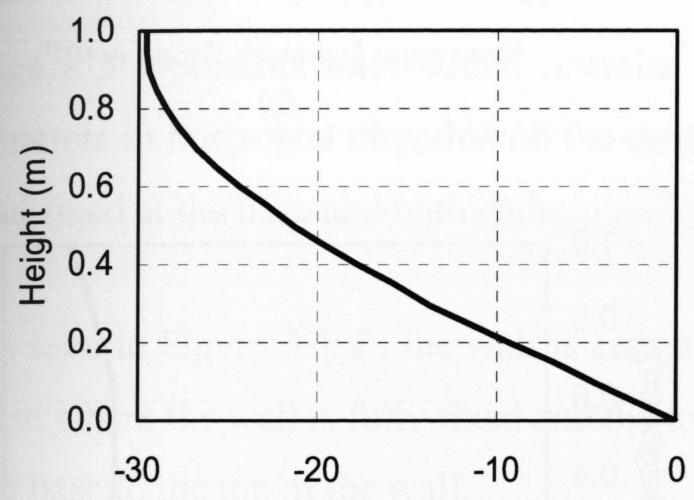

Stress in Horizontal Rebars (MPa)

(c)

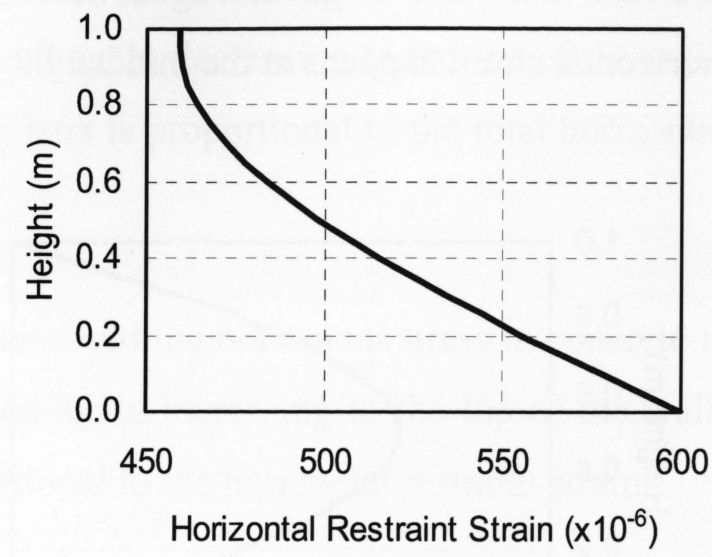

(b)

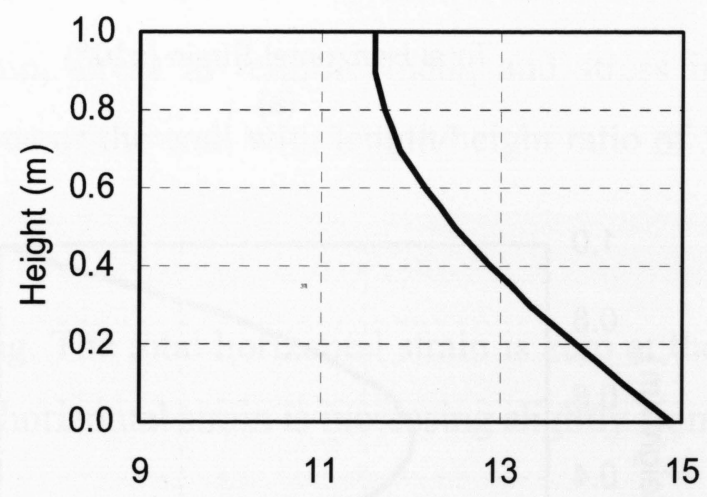

Horizontal Stress in Concrete (MPa)

(d)

Figure 3.2- Strain and stress distribution $(\mathrm{L} / \mathrm{H}=5$, fixed at base $)$

\subsubsection{Fixed at Base and Top}

Figure 3.3 presents total strain, restraint strain, stress in reinforcement, and stress in concrete in horizontal direction on the centerline of the wall with length/height ratio of 5 and fixed at the base and top.

As seen in Figure 3.3(a), the wall is contracting. The total horizontal strain is zero at the base and top where the wall is fully fixed and the total horizontal strain is increasing from 
the base to the mid height and again decreasing to the top of the wall. The maximum total horizontal strain happens at the mid height of the wall.

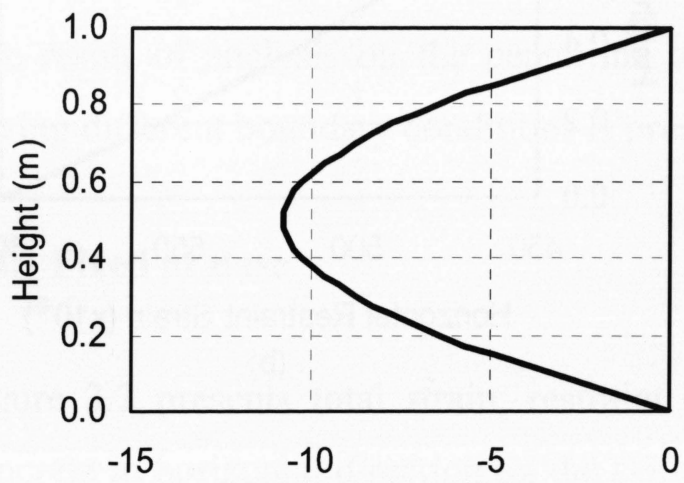

Total Horizontal Strain $\left(\times 10^{-6}\right)$

(a)

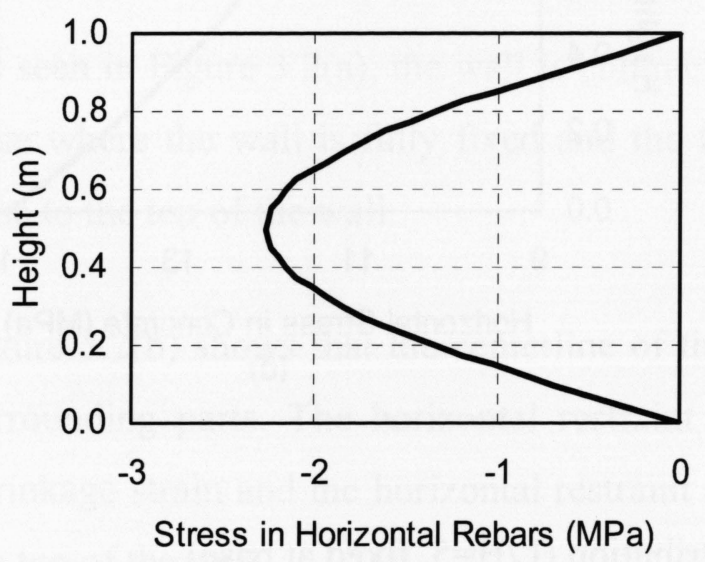

(c)

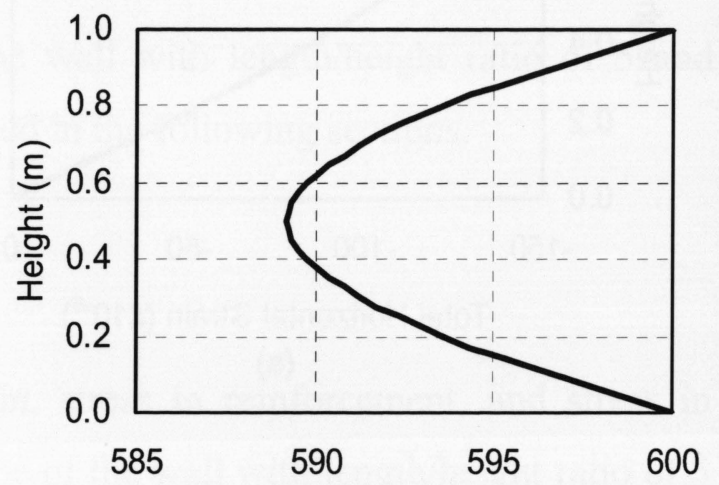

Horizontal Restraint Strain $\left(\times 10^{-6}\right)$

(b)

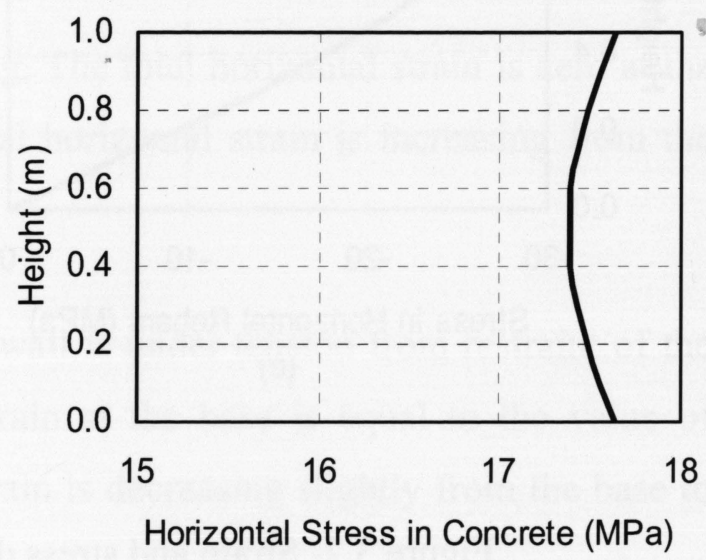

(d)

Figure 3.3- Strain and stress distribution $(\mathrm{L} / \mathrm{H}=5$, fixed at base and top)

Figure 3.3(b) shows that the centerline of the wall is under tension from restraint of the surrounding parts. The horizontal restraint strain at the base and top is equal to the value of shrinkage strain and the horizontal restraint strain is decreasing slightly from the base to the mid height and again increasing to the top of the wall. 
As seen in Figure 3.3(c), horizontal reinforcing bars are under compression and the stress is increasing from the base to the mid height and again decreasing to the top of the wall. In addition, the stress in horizontal reinforcing bars is proportional to the total horizontal strain.

Figure 3.3(d) shows that concrete is under tension and the horizontal stress in concrete is decreasing from the base to the mid height and again increasing to the top of the wall. Also, the horizontal stress in concrete is proportional to the horizontal restraint strain.

\subsubsection{Fixed at Base and Both Ends}

Figure 3.4 presents total strain, restraint strain, stress in reinforcement, and stress in concrete in horizontal direction on the centerline of the wall with length/height ratio of 5 and fixed at the base and both ends.

As seen in Figure 3.4(a), the wall is contracting. The total horizontal strain is zero at the base where the wall is fully fixed and the total horizontal strain is increasing slightly from the base to the top of the wall.

Figure 3.4(b) shows that the centerline of the wall is under tension from restraint of the surrounding parts. The horizontal restraint strain at the base is equal to the value of shrinkage strain and the horizontal restraint strain is decreasing slightly from the base to the top of the wall.

As seen in Figure 3.4(c), horizontal reinforcing bars are under compression and the stress is increasing slightly from the base to the top of the wall. In addition, the stress in horizontal reinforcing bars is proportional to the total horizontal strain.

Figure 3.4(d) shows that concrete is under tension and the horizontal stress in concrete is decreasing slightly from the base to the top of the wall. Also, the horizontal stress in concrete is proportional to the horizontal restraint strain. 


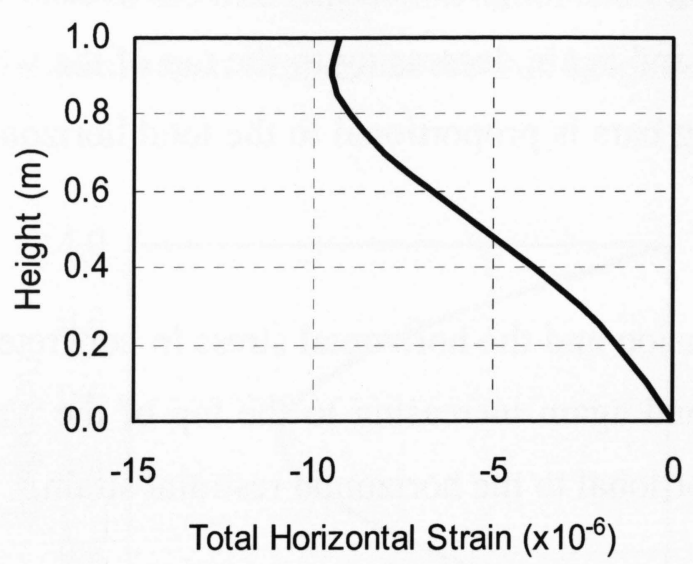

(a)

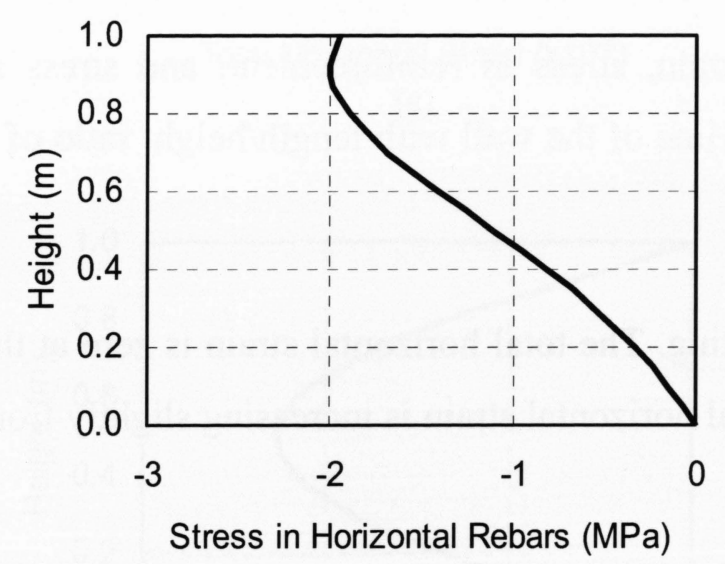

(c)

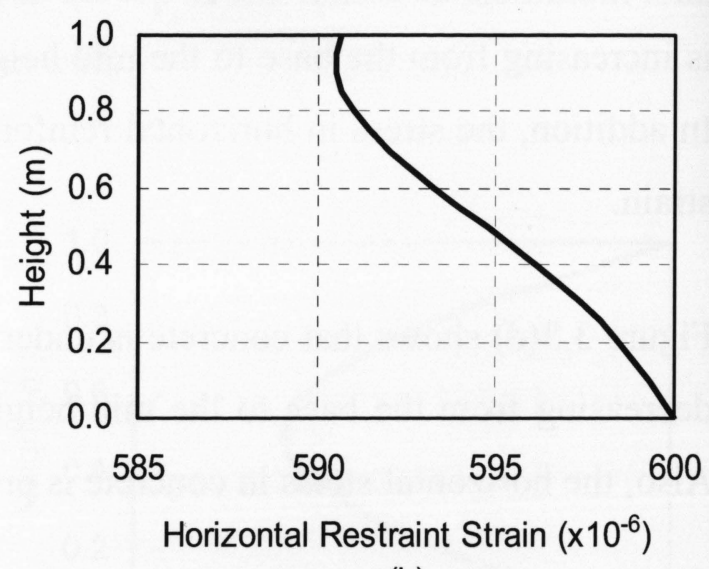

(b)

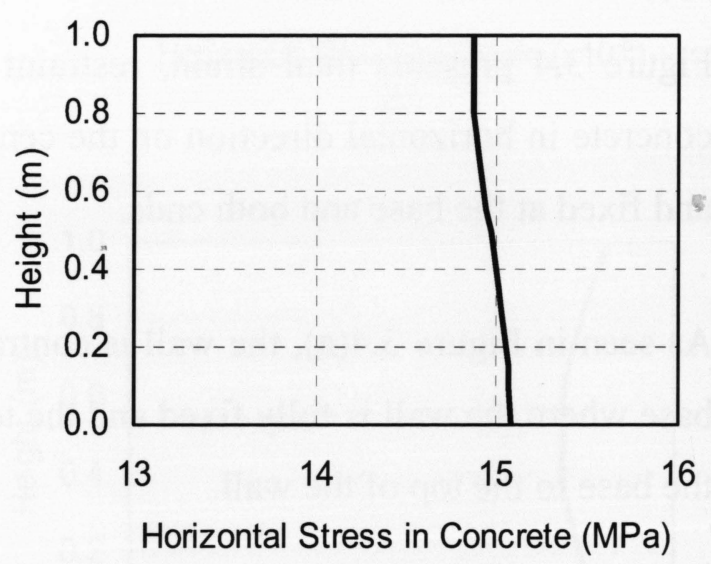

(d)

Figure 3.4- Strain and stress distribution $(\mathrm{L} / \mathrm{H}=5$, fixed at base and both ends)

\subsubsection{Fixed at Base, Top, and Both Ends}

Figure 3.5 presents total strain, restraint strain, stress in reinforcement, and stress in concrete in horizontal direction on the centerline of the wall with length/height ratio of 5 and fixed at the base, top, and both ends.

As seen in Figure 3.5(a), the wall remains unchanged and the total horizontal strain is constant and equal to zero from the base to the top of the wall. 


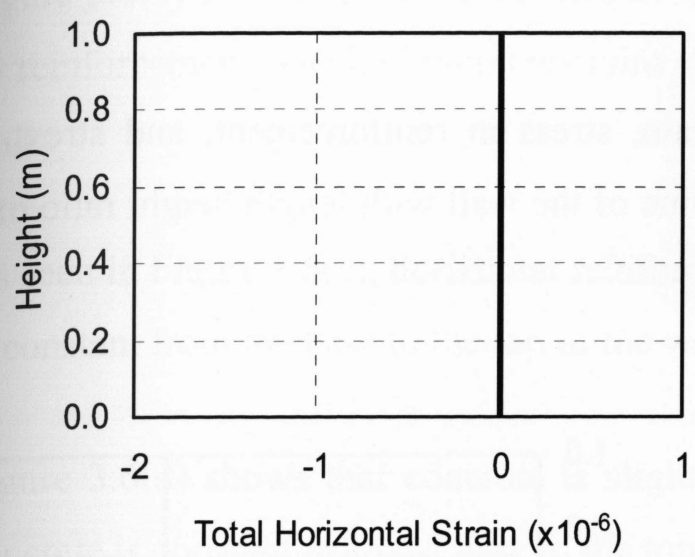

(a)

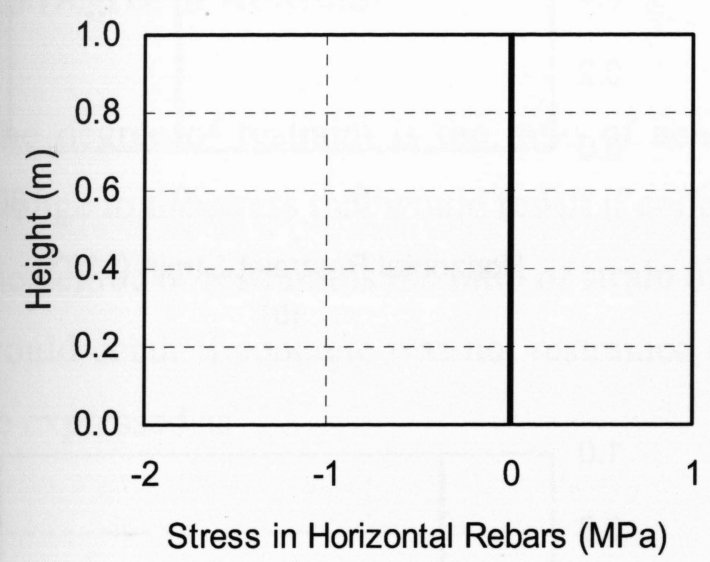

(c)

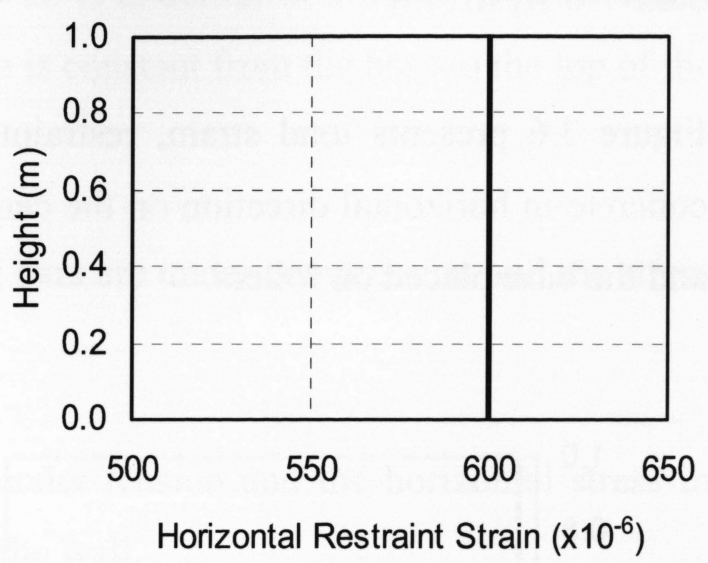

(b)

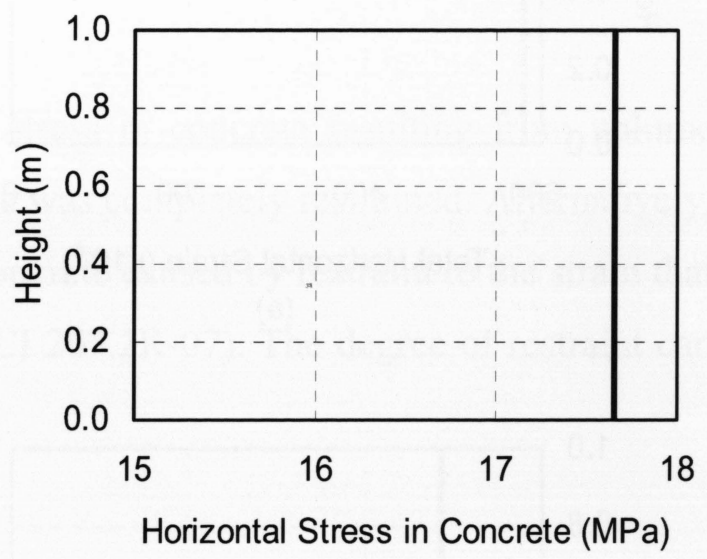

(d)

Figure 3.5- Strain and stress distribution ( $\mathrm{L} / \mathrm{H}=5$, fixed at base, top, and both ends)

Figure 3.5(b) shows that the centerline of the wall is under tension from restraint of the surrounding parts. The horizontal restraint strain is constant and equal to the value of shrinkage strain from the base to the top of the wall.

As seen in Figure 3.5(c), horizontal reinforcing bars do not carry any stress from the base to the top of the wall.

Figure 3.5(d) shows that concrete is under tension and the horizontal stress in concrete is constant from the base to the top of the wall. 


\subsubsection{No Restraint}

Figure 3.6 presents total strain, restraint strain, stress in reinforcement, and stress in concrete in horizontal direction on the centerline of the wall with length/height ratio of 5 and the base placed on rollers.

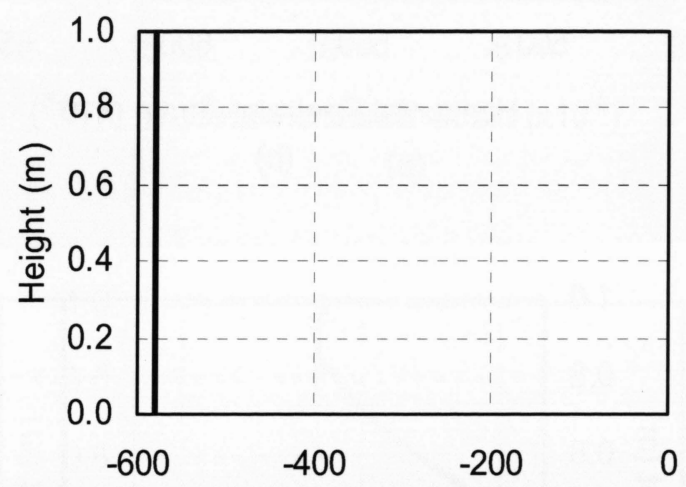

Total Horizontal Strain $\left(\times 10^{-6}\right)$

(a)

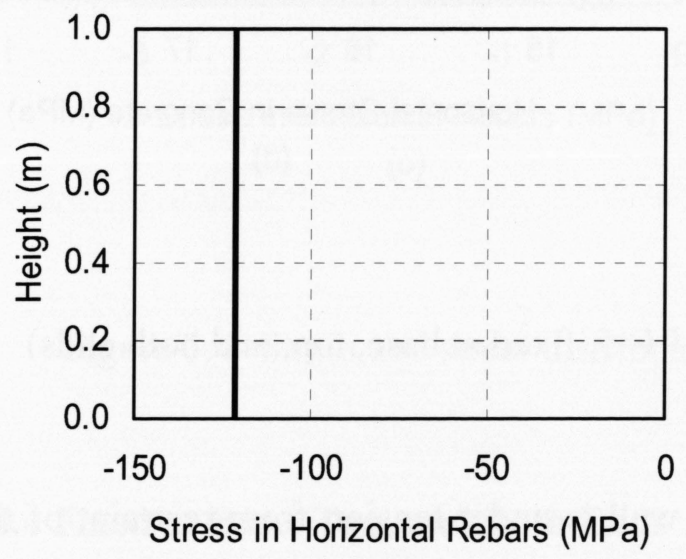

(c)

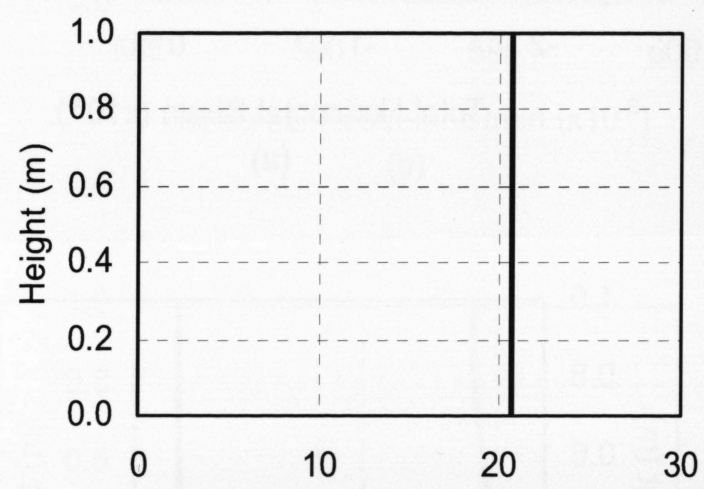

Horizontal Restraint Strain $\left(\times 10^{-6}\right)$

(b)

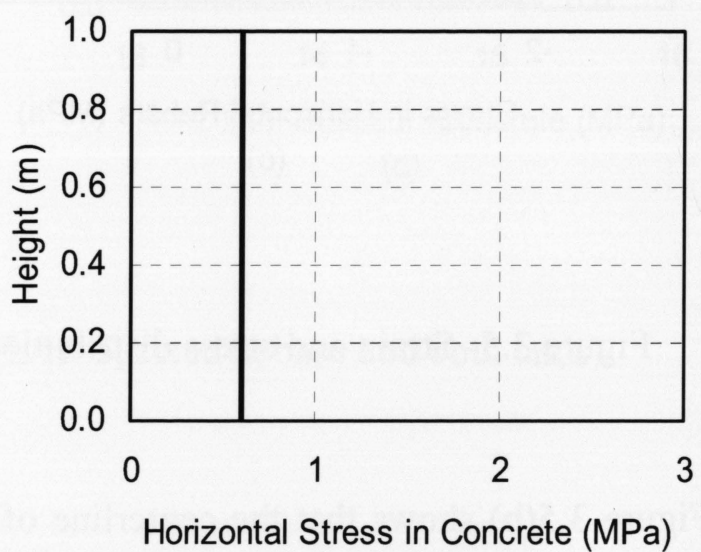

(d)

Figure 3.6- Strain and stress distribution ( $\mathrm{L} / \mathrm{H}=5$, no restraint)

As seen in Figure 3.6(a), the wall is contracting. The total horizontal strain is constant and slightly less than the shrinkage strain $\left(600 \times 10^{-6} \mathrm{~mm} / \mathrm{mm}\right)$ from the base to the top of the wall. 
Figure 3.6(b) shows that the centerline of the wall is under tension from restraint caused by reinforcement. The horizontal restraint strain is constant from the base to the top of the wall.

As seen in Figure 3.6(c), horizontal reinforcing bars are under compression and the stress is constant from the base to the top of the wall.

Figure 3.6(d) shows that concrete is slightly under tension and the horizontal stress in concrete is constant from the base to the top of the wall.

\subsection{Degree of Restraint}

The degree of restraint is the ratio of actual stress in concrete resulting from volume change to the stress that would result if concrete was completely restrained. Alternatively, the degree of restraint is the ratio of strain of concrete caused by restraint to the strain that would occur if concrete was not restrained (ACI 207.2R-07). The degree of restraint can be expressed as

$$
K_{R}=-\frac{\varepsilon_{\text {restraint }}}{\varepsilon_{\text {shrinkage }}}
$$

Where,

$K_{R}$ is the degree of restraint

$\varepsilon_{\text {restraint }}$ is the restraint strain of concrete

$\varepsilon_{\text {shrinkage }}$ is the shrinkage stain of concrete

In this analysis, the restraint strain at each point is determined from Eq. 3.1 knowing the shrinkage strain is $600 \times 10^{-6} \mathrm{~mm} / \mathrm{mm}$ at every point in the walls. Then, the degree of restraint at each point in the wall is determined from Eq. 3.2. 
In the following sections, the horizontal degree of restraint on the centerline of the walls with length/height ratios of $1,2,5,10$, and 20 and having different boundary conditions is presented.

\subsubsection{Fixed at Base}

Figure 3.7 presents the horizontal degree of restraint on the centerline of the walls with length/height ratios of 1, 2, 5, 10 and 20 and fixed at the base.

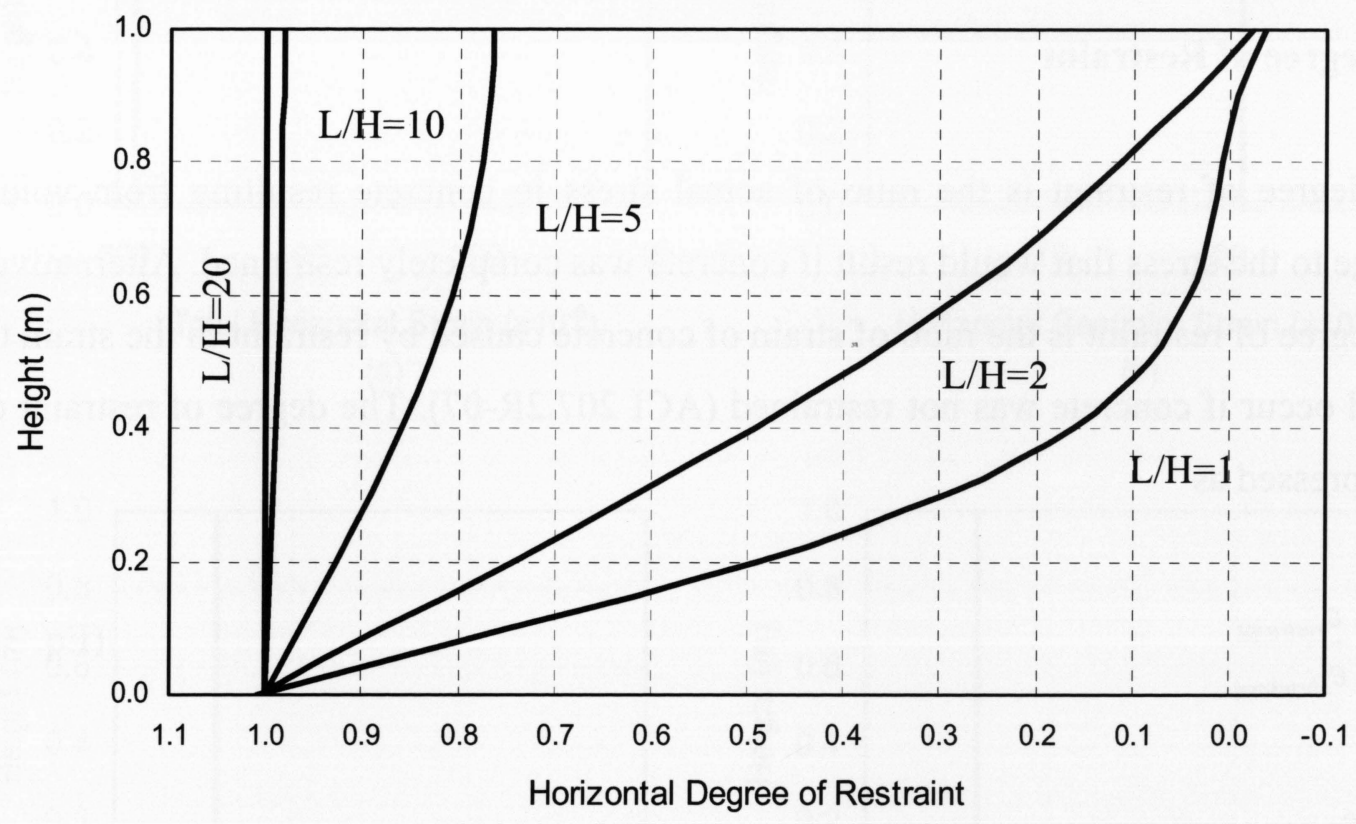

Figure 3.7- Horizontal degree of restraint (fixed at base)

As shown, the degree of restraint at the base of the walls where any movement is fully restrained is equal to 1.0. In the walls with length/height ratios of 1 and 2 the degree of restraint is dramatically decreasing over the height to approximately zero at the top. In the wall with length/height ratio of 5 the degree of restraint is decreasing slightly from 1.0 at the base to approximately 0.8 at the top. In the walls with length/height ratios of 10 and 20 the degree of restraint remains constant from the base to the top. 


\subsubsection{Fixed at Base and Top}

Figure 3.8 presents the horizontal degree of restraint on the centerline of the walls with length/height ratios of 1, 2, 5, 10 and 20 and fixed at the base and top.

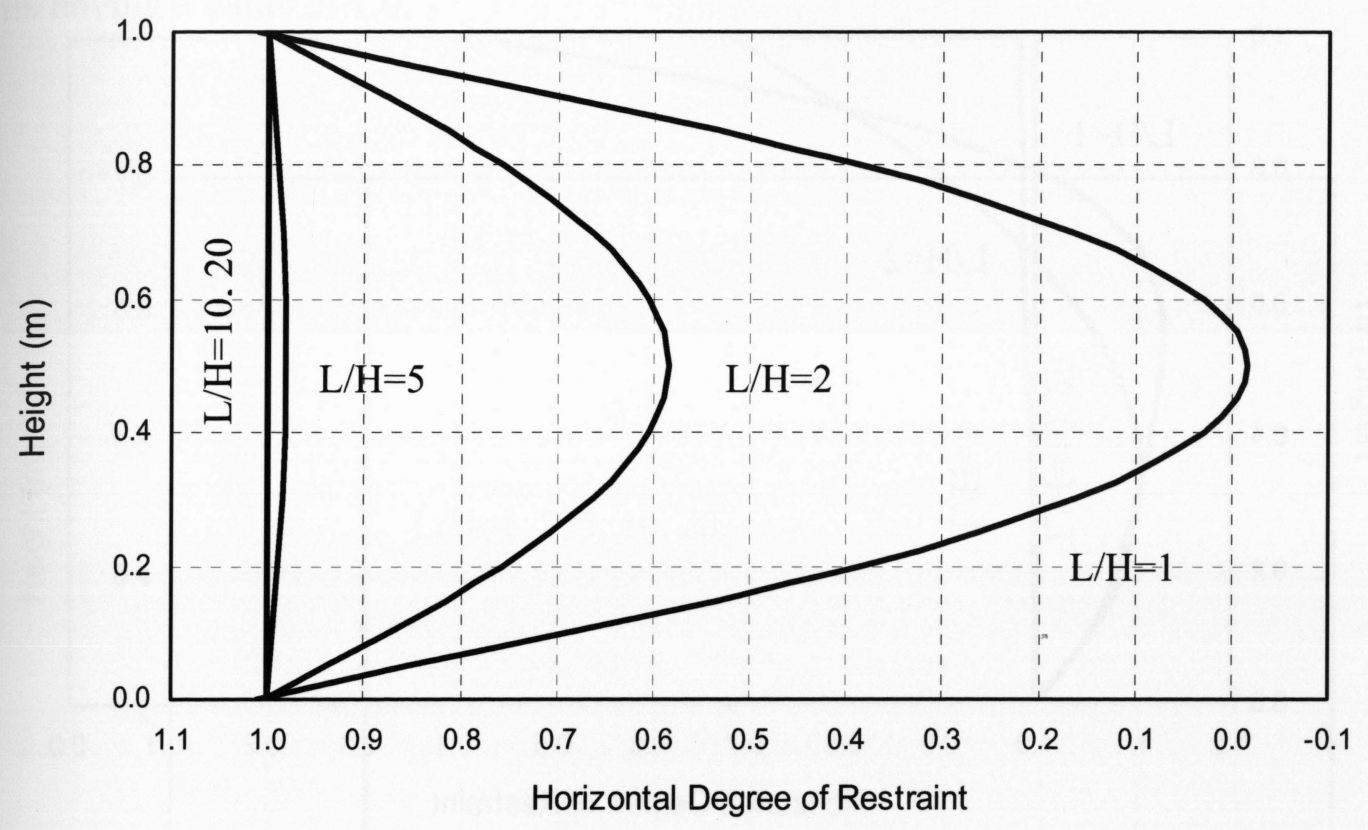

Figure 3.8- Horizontal degree of restraint (fixed at base and top)

The degree of restraint at the base and top of the walls where movements are fully restrained is equal to 1.0. In the wall with length/height ratio of 1 , the degree of restraint is dramatically decreasing from 1.0 at the base to approximately zero at the mid height and again increasing to 1.0 at the top. In the wall with length/height ratio of 2 , the degree of restraint is decreasing from 1.0 at the base to roughly 0.6 at the mid height and again increasing to 1.0 at the top. In the walls with length/height ratios of 5, 10, and 20 the degree of restraint remains constant from the base to the top. 


\subsubsection{Fixed at Base and Both Ends}

Figure 3.9 presents the horizontal degree of restraint on the centerline of the walls with length/height ratios of 1, 2, 5, 10 and 20 and fixed at the base and both ends.

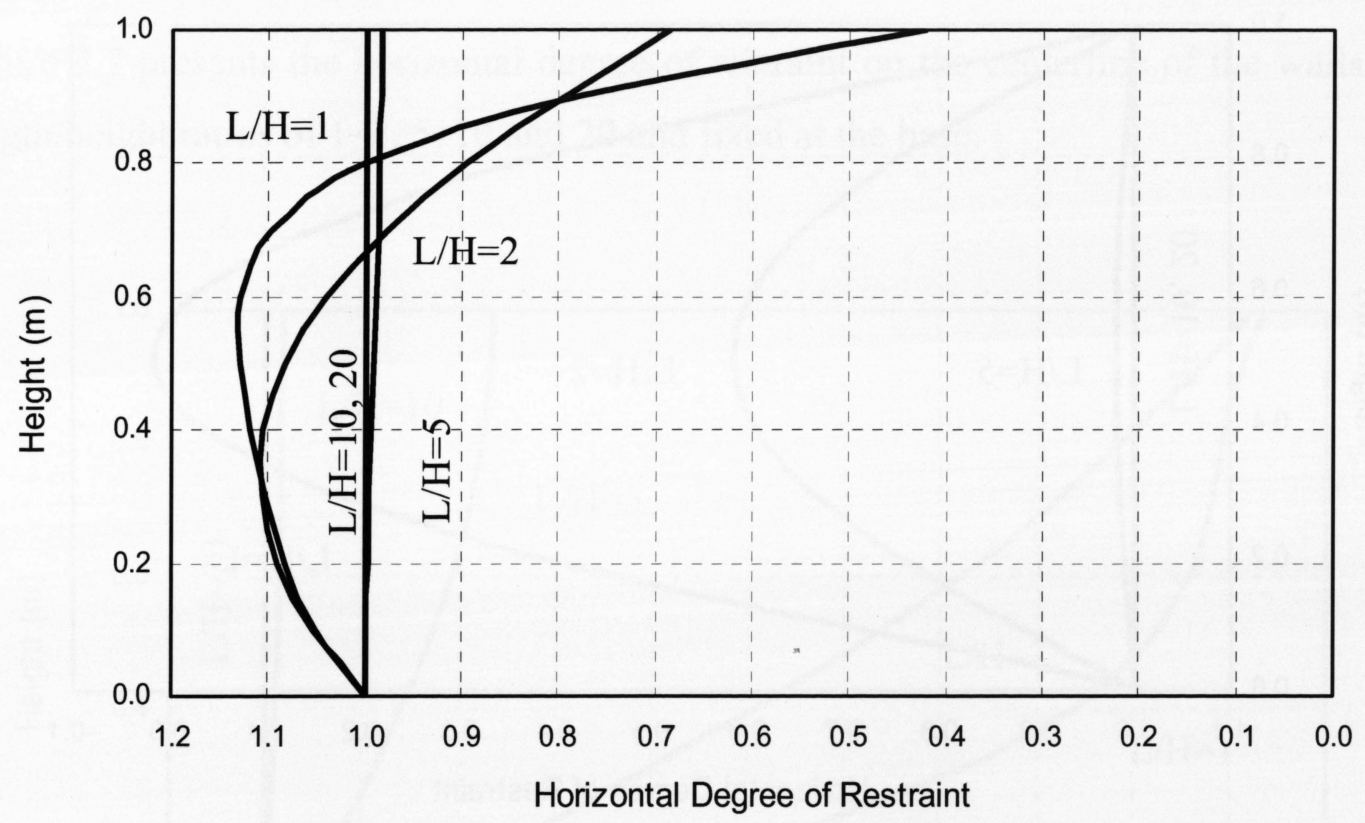

Figure 3.9- Horizontal degree of restraint (fixed at base and both ends)

The degree of restraint at the base of the walls where any movement is fully restrained is equal to 1.0. In the wall with length/height ratio of 1 , the degree of restraint is increasing from 1.0 at the base to approximately 1.15 at mid height and then decreasing to roughly 0.4 at the top. In the wall with length/height ratio of 2 , the degree of restraint is increasing from 1.0 at the base to approximately 1.1 at mid height and then decreasing to 0.7 at the top. In the walls with length/height ratios of 5, 10, and 20 the degree of restraint remains constant from the base to the top. 


\subsubsection{Fixed at Base, Top, and Both Ends}

Figure 3.10 presents the horizontal degree of restraint on the centerline of the walls with length/height ratios of 1, 2, 5, 10 and 20 and fixed at the base, top, and both ends. As seen, the degree of restraint in all cases remains constant from the base to the top of the walls having a value of 1.0 .

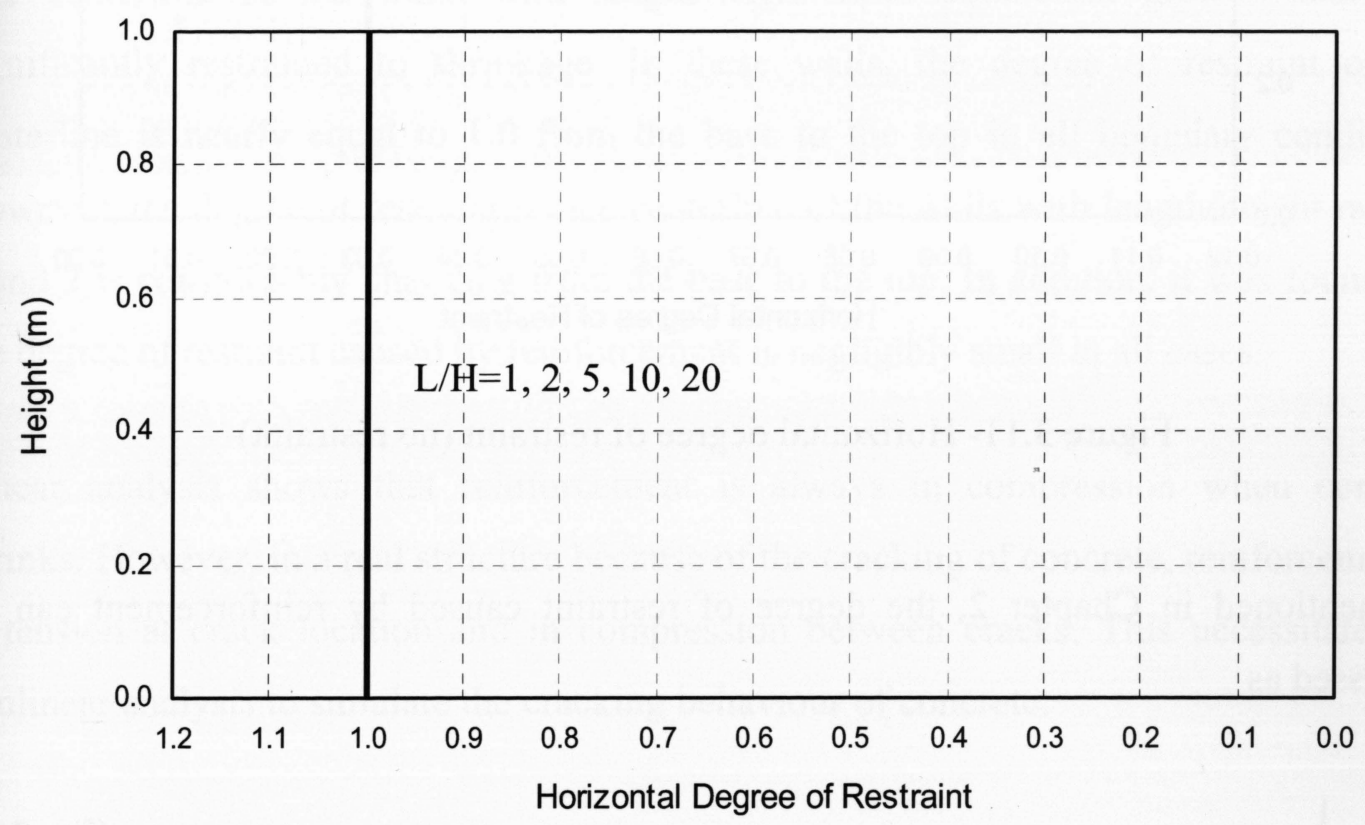

Figure 3.10- Horizontal degree of restraint (fixed at base, top, and both ends)

\subsubsection{No Restraint}

Figure 3.11 presents the horizontal degree of restraint on the centerline of the walls with length/height ratios of $1,2,5,10$ and 20 and the base placed on rollers.

As seen in Figure 3.11, the provided reinforcement ratio of $0.5 \%$ has minor restraining effect on the shrinkage of concrete in all cases and the degree of restraint is close to zero on the centerline of the walls. 


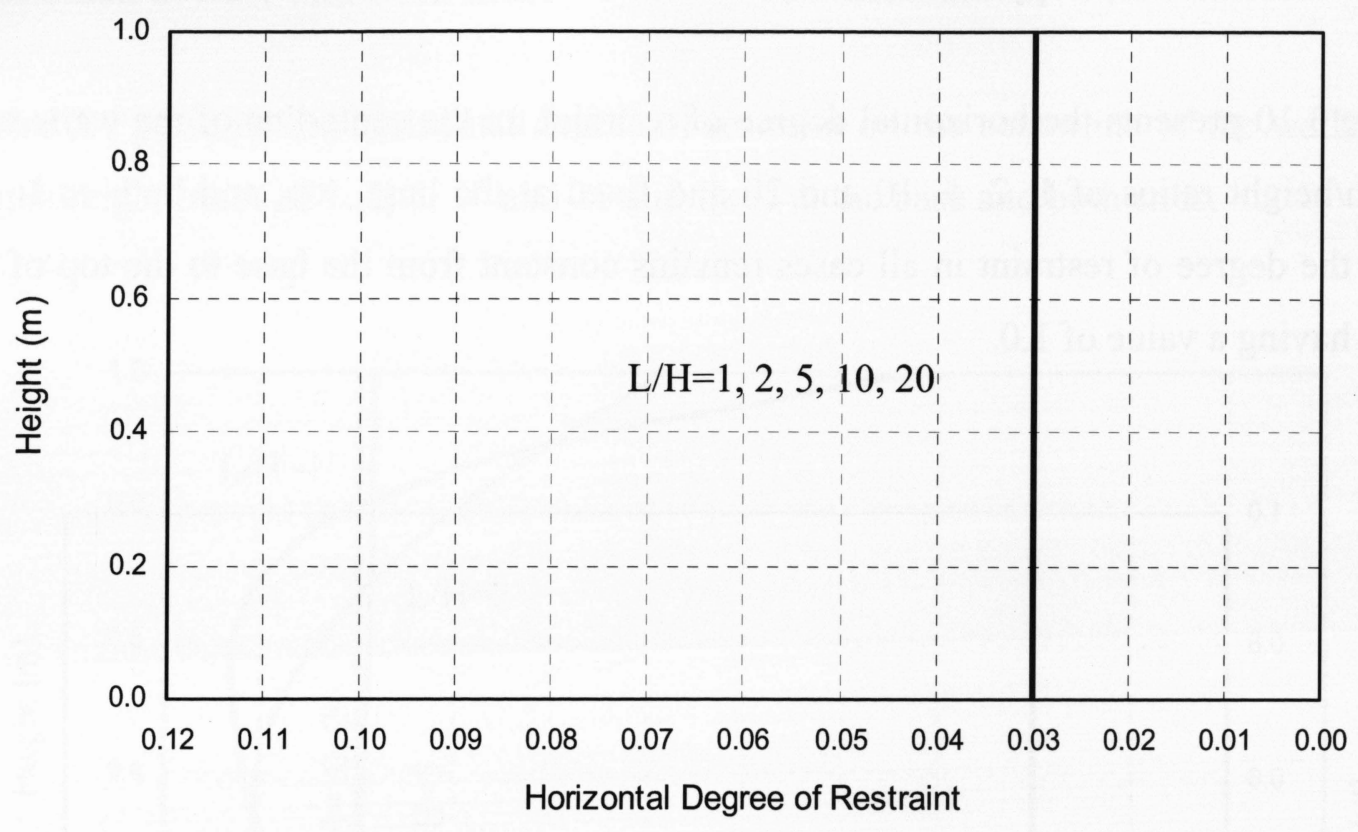

Figure 3.11- Horizontal degree of restraint (no restraint)

As mentioned in Chapter 2, the degree of restraint caused by reinforcement can be expressed as

$$
K_{R}=\frac{1}{1+\frac{1}{n \rho}}
$$

Where,

$K_{R}$ is the degree of restraint caused by reinforcement

$n$ is the ratio of the modulus of elasticity of steel to concrete

$\rho$ is the reinforcement ratio

In this case, $n$ and $\rho$ are equal to 8.4 and 0.005 , respectively. The degree of restraint is calculated as 0.04 which is very close to the value derived from the analysis. 


\subsection{Summary}

This chapter studied the behaviour of reinforced concrete walls with multiple length/height ratios and different boundary conditions subjected to shrinkage assuming linear elastic material behaviour. The variation of the degree of restraint on the centerline of the walls was investigated.

The centerline of the walls with length/height ratio equal and greater than 5 is significantly restrained to shrinkage. In these walls, the degree of restraint on the centerline is nearly equal to 1.0 from the base to the top in all boundary conditions. However, the degree of restraint on the centerline of the walls with length/height ratio of 1 and 2 is considerably changing from the base to the top. In addition, it was found that the degree of restraint caused by reinforcement is negligibly small in all cases.

Linear analysis shows that reinforcement is always in compression when concrete shrinks. However, in a real structure because of the cracking of concrete, reinforcement is in tension at crack location and in compression between cracks. This necessitates the nonlinear analysis to simulate the cracking behaviour of concrete. 


\section{CHAPTER 4}

\section{NONLINEAR ANALYSIS OF WALLS}

\subsection{Introduction}

This chapter studies the response of fixed base reinforced concrete walls subjected to shrinkage strain assuming nonlinear material behaviour. In this study, walls with different aspect ratios (length/height ratio) and different reinforcement ratios are investigated and the effect of uniform and non-uniform distribution of the reinforcement is presented. In addition, the use of smeared cracking model and brittle cracking model for concrete available in the computer software ABAQUS in the analysis of restrained shrinkage problems is examined.

\subsection{Specifications of Walls}

Five fixed base reinforced concrete walls with length/height ratios of 1, 2, 5, 10, and 20 were analyzed. For all cases, the height and the thickness of the walls were $1 \mathrm{~m}$ and 200 $\mathrm{mm}$, respectively. Figure 4.1 presents a typical elevation of the walls.
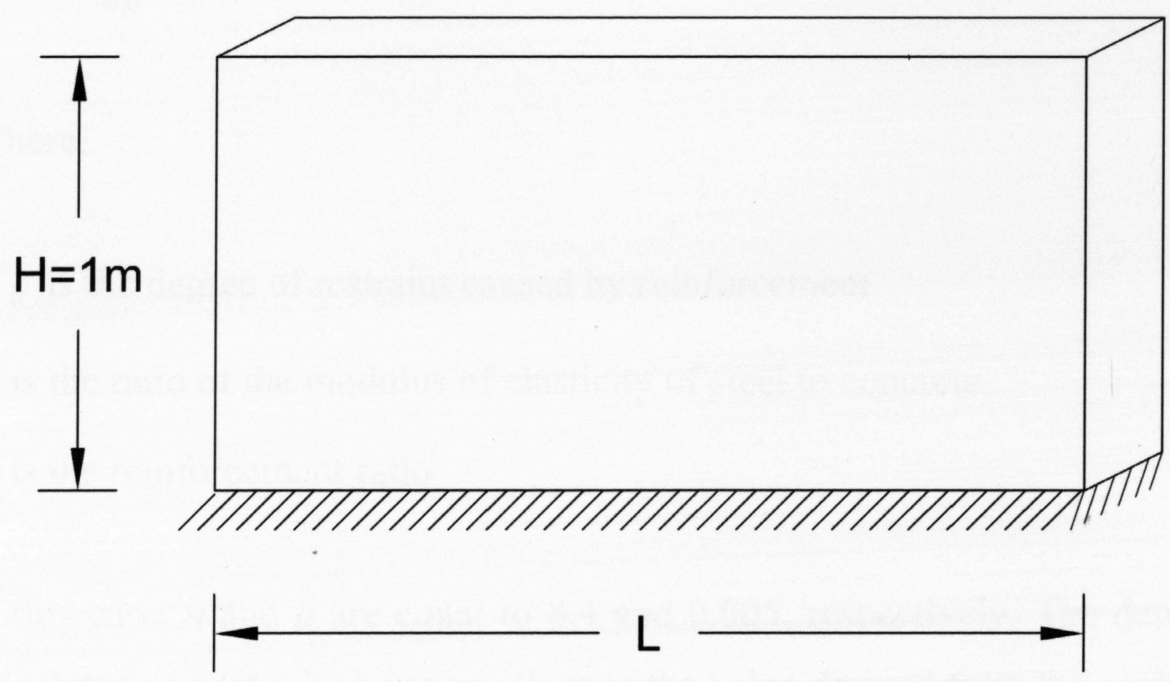

$\mathrm{t}=200 \mathrm{~mm}$

Figure 4.1- Typical elevation of walls 
In most concrete structures the final shrinkage strain is $600 \times 10^{-6} \mathrm{~mm} / \mathrm{mm}$ (ACI 224R-01). In order to simulate this amount of shrinkage strain, a temperature change of $60^{\circ} \mathrm{C}$ was applied to the walls considering the thermal expansion coefficient as $1 \times 10^{-5}$ for concrete.

\subsection{Material Properties}

In this analysis, nonlinear material behaviour was assumed for both concrete and steel. In the shrinkage of reinforced concrete walls, concrete is assumed to be in tension. Under this effect, the behaviour of concrete in tension is of importance. Figure 4.2 presents the stress-strain diagram of concrete in tension and the idealized stress-strain diagram of steel.

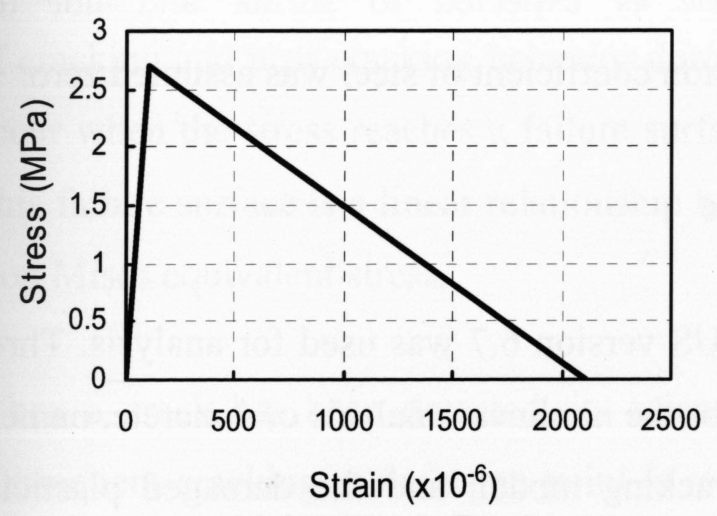

(a) Concrete in Tension

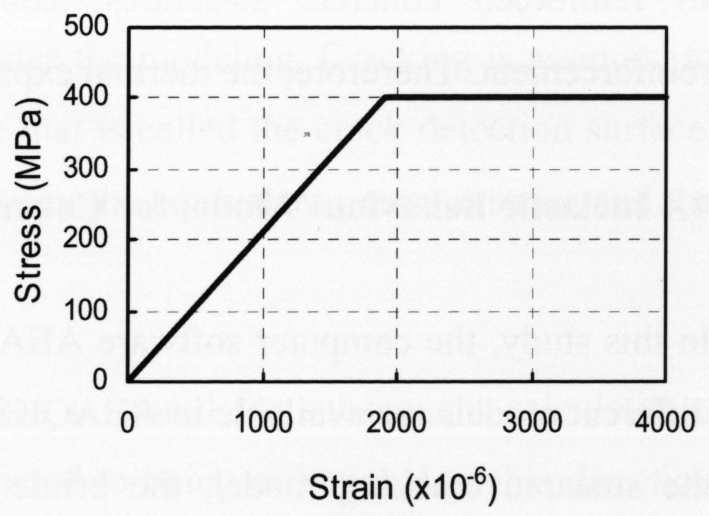

(b) Steel

Figure 4.2- Stress-strain diagram of (a) concrete in tension and (b) steel

As seen in Figure 4.2(a), tension stiffening of concrete was assumed as a linear decrease of the stress at failure to zero stress at a strain of $2 \times 10^{-3} \mathrm{~mm} / \mathrm{mm}$.

The material properties of concrete and steel were:

$f_{t}($ Cracking failure stress of concrete $)=2.7 \mathrm{MPa}$

$E_{c}$ (Modulus of elasticity of concrete) $=25,000 \mathrm{MPa}$

$v_{c}($ Poison's ratio of concrete $)=0.15$ 
$\alpha_{c}$ (Thermal expansion coefficient of concrete $)=1 \times 10^{-5}$

$f_{y}($ Yield stress of steel $)=400 \mathrm{MPa}$

$E_{s}($ Modulus of elasticity of steel $)=210,000 \mathrm{MPa}$

$v_{s}($ Poison's ratio of steel $)=0.0$

$\alpha_{s}($ Thermal expansion coefficient of steel $)=0.0$

Reinforcement in concrete structures is typically provided by means of reinforcing bars, which are one dimensional strain theory elements. In this analysis, the reinforcement was modeled as a layer of steel embedded inside the walls. Therefore, the Poisson's ratio of steel was assumed zero to simulate the behaviour of reinforcing bars.

In reinforced concrete structures, concrete is expected to shrink and not the reinforcement. Therefore, the thermal expansion coefficient of steel was assumed zero.

\subsection{Inelastic Behaviour Model for Concrete}

In this study, the computer software ABAQUS version 6.7 was used for analysis. Three different models are available in ABAQUS for the nonlinear analysis of concrete, namely the smeared cracking model, the brittle cracking model, and the damaged plasticity model. Each model is designed to provide a general capability for modeling plain and reinforced concrete in all types of structures (ABAQUS Documentation v. 6.7).

The smeared cracking model is intended for applications in which the concrete is subjected to monotonic loading. The concrete failure is dominated by either tensile cracking or compressive crushing. The brittle cracking model is intended for applications in which the concrete failure is dominated by tensile cracking and compressive failure is not important. The damaged plasticity model is designed for applications in which the concrete is subjected to cyclic loading. The model considers the degradation of the elastic stiffness induced by plastic straining both in tension and compression. 
In the following sections, the smeared cracking model and the brittle cracking model for concrete in ABAQUS which are suitable for static and quasi-static analysis are discussed in detail.

\subsubsection{Smeared Cracking Model}

The smeared cracking model in ABAQUS provides a general capability for modeling concrete in all types of structures, including beams, trusses, shells, and solids. It can be used for plain concrete, even though it is intended primarily for the analysis of reinforced concrete structures. The model is designed for applications in which the concrete is subjected to essentially monotonic straining at low confining pressures.

Cracking is assumed to be the most important aspect of the behavior and representation of cracking and post cracking behavior dominates the modeling. Cracking is assumed to occur when the stress reaches a failure surface that is called the crack detection surface. This failure surface is a linear relationship between the equivalent pressure stress and the Von Mises equivalent stress.

When a crack has been detected, its orientation is stored for subsequent calculations. Subsequent cracking at the same point is restricted to being orthogonal to this direction since stress components associated with an open crack are not included in the definition of the failure surface used for detecting the additional cracks. Cracks are irrecoverable and they remain for the rest of the calculation but may open and close. Following crack detection, the crack affects the calculations because a damaged elasticity model is used.

Reinforcement is typically modeled using metal plasticity models to describe the behavior of the reinforcement material and is superposed on the elements used to model the concrete. With this modeling approach, the concrete behavior is considered independently of the reinforcement. Effects associated with the reinforcement-concrete interface, such as bond slip and dowel action, are modeled approximately by introducing some tension stiffening into the concrete modeling to simulate load transfer across cracks through the reinforcement. 
The post failure behavior for direct straining across cracks is modeled with tension stiffening, which allows defining the strain-softening behavior for cracked concrete. This behavior allows that the reinforcement-concrete interaction be simulated in a simple manner. Tension stiffening can be specified by means of a post failure stress-strain relationship.

The tension stiffening depends on factors such as the density of reinforcement, the quality of the bond between the rebar and the concrete, the relative size of the concrete aggregate compared to the rebar diameter, and the mesh. A reasonable starting point for relatively heavily reinforced concrete modeled with a fairly detailed mesh is to assume that the strain softening after failure reduces the stress linearly to zero at a total strain of about 10 times the strain at failure. The strain at failure in standard concretes is typically $10^{-4}$ $\mathrm{mm} / \mathrm{mm}$ which suggests that tension stiffening that reduces the stress to zero at a total strain of about $10^{-3} \mathrm{~mm} / \mathrm{mm}$ is reasonable.

The choice of tension stiffening parameters is very important in ABAQUS. In general, more tension stiffening makes it easier to obtain numerical solutions. However, too little tension stiffening may cause the local cracking failure in the concrete which introduces temporarily unstable behavior in the overall response of the model.

As the concrete cracks, its shear stiffness is diminished. This effect is defined by introducing shear retention model which specifies the reduction in the shear modulus as a function of the opening strain across the crack. In addition, a reduced shear modulus can be specified for closed cracks too. This reduced shear modulus will have an effect when the normal stress across a crack becomes compressive.

The modulus of shear of cracked concrete is defined as $\alpha G$, where $G$ is the elastic shear modulus of the uncracked concrete and $\alpha$ is a multiplying factor. The shear retention model assumes that the shear stiffness of open cracks reduces linearly to zero as the crack opening increases. The multiplying factor, $\alpha$, is determined from 


$$
\alpha=\left(1-\frac{\varepsilon}{\varepsilon_{\max }}\right) \text { for } \quad \varepsilon<\varepsilon_{\max } \text { and } \alpha=0 \text { for } \varepsilon \geq \varepsilon_{\max }
$$

Where,

$\varepsilon$ is the direct strain across the crack

$\varepsilon_{\max }$ is the specified maximum direct strain across the crack

The model also assumes that cracks that subsequently close have a reduced shear modulus. The multiplying factor, $\alpha$, for the closed crack is determined from

$\alpha=\alpha_{\text {close }} \quad$ for $\quad \varepsilon<0$

Where,

$\alpha_{\text {close }}$ is the specified multiplying factor

\subsubsection{Brittle Cracking Model}

The brittle cracking model in ABAQUS is designed for applications in which the behavior of concrete is dominated by tensile cracking and assumes that the compressive behavior of concrete is always linear elastic. It can be used to model both plain and reinforced concrete structures. In addition, it allows removal of elements based on a brittle failure criterion.

ABAQUS uses a smeared crack model to represent the discontinuous brittle behavior in concrete. It does not track individual macro cracks. Instead, constitutive calculations are performed independently at each material point of the finite element model. The presence of cracks enters into these calculations by the way in which the cracks affect the stress and material stiffness associated with the material point. 
The brittle cracking model assumes fixed, orthogonal cracks, with the maximum number of cracks at a material point limited by the number of direct stress components present at that material point of the finite element model. In three dimensional, plane-strain, and axisymmetric problems a maximum of three cracks, in plane-stress and shell problems a maximum of two cracks, and in beam or truss problems a maximum of one crack is considered.

A simple Rankine criterion is used to detect crack initiation. This criterion states that a crack forms when the maximum principal tensile stress exceeds the tensile strength of the concrete.

As soon as the Rankine criterion for crack formation has been met, the model assumes that a first crack has formed. The crack surface is taken to be normal to the direction of the maximum tensile principal stress. Subsequent cracks may form with crack surface normal in the direction of the maximum principal tensile stress.

When one, two, or all three local direct cracking strain components at a material point reach the value defined as the failure strain, the material point fails and all the stress components are set to zero. If all of the material points in an element fail, the element is removed from the mesh.

Cracks are irrecoverable in the sense that, once a crack has occurred at a point, it remains throughout the rest of the calculation. However, crack closing and reopening may take place along the direction of the crack surface normal. The model neglects any permanent strain associated with cracking. It is assumed that the cracks can close completely when the stress across them becomes compressive.

Reinforcement is typically modeled using elastic-plastic material behavior models and is superimposed on elements used to model the plain concrete. With this modeling approach, the concrete cracking behavior is considered independently of the reinforcement. Effects associated with the reinforcement-concrete interface, such as bond slip and dowel action, are modeled approximately by introducing some tension stiffening 
into the concrete cracking model to simulate load transfer across cracks through the reinforcement.

The tension stiffening is specified by means of a post failure stress-strain relationship which defines the post failure stress as a function of strain across the crack.

The tension stiffening effect depends on factors such as the density of reinforcement, the quality of the bond between the reinforcement and the concrete, the relative size of the concrete aggregate compared to the rebar diameter, and the mesh. A reasonable starting point for relatively heavily reinforced concrete modeled with a fairly detailed mesh is to assume that the strain softening after failure reduces the stress linearly to zero at a total strain about ten times the strain at failure. Since the strain at failure in standard concretes is typically $10^{-4} \mathrm{~mm} / \mathrm{mm}$ this suggests that tension stiffening that reduces the stress to zero at a total strain of about $10^{-3} \mathrm{~mm} / \mathrm{mm}$ is reasonable.

In static applications, too little tension stiffening will cause the local cracking failure in the concrete to introduce temporarily unstable behavior in the overall response of the model.

As cracks open the shear modulus is reduced. ABAQUS offers a shear retention model in which the post cracked shear stiffness is defined as a function of the opening strain across the crack.

In order to choose the appropriate model for concrete in this study, the wall with length/height ratio of 1 was analysed using smeared cracking and brittle cracking model and the behaviour of concrete was investigated. The reinforcement ratio of the wall was $0.5 \%$ in both horizontal and vertical directions.

In the analysis, concrete walls were modeled using quadratic $50 \mathrm{~mm}$ x $50 \mathrm{~mm}$ shell elements with 4 integration points and reinforcement was modeled as a steel layer embedded in the mid thickness of the shell elements. 
Figure 4.3 presents horizontal stress in concrete at the center point of the wall with length/height ratio of 1 and modeled with smeared cracking and brittle cracking model.

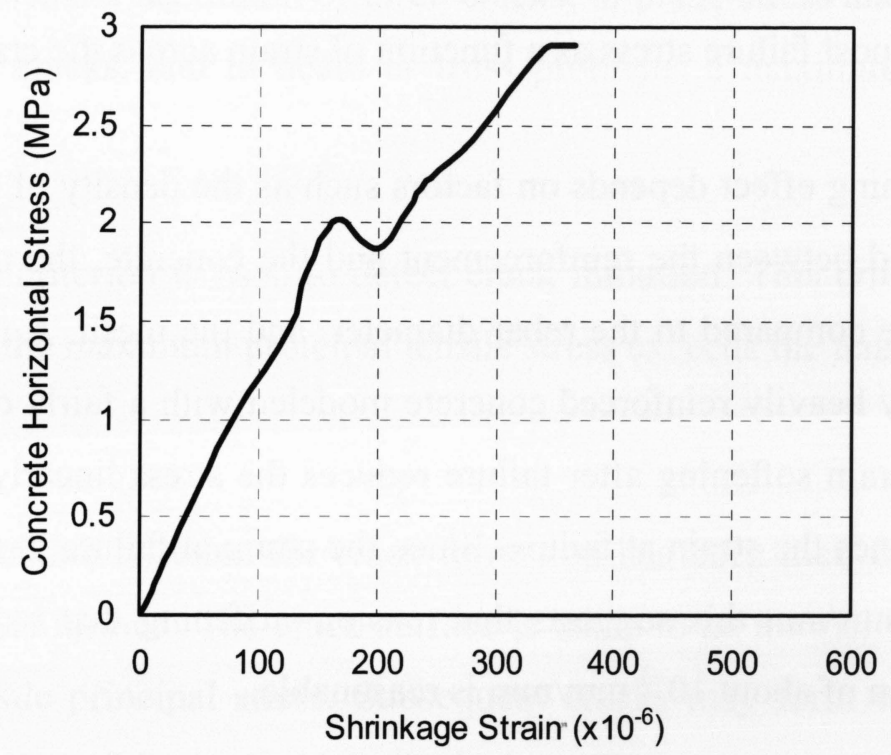

(a) Smeared Cracking

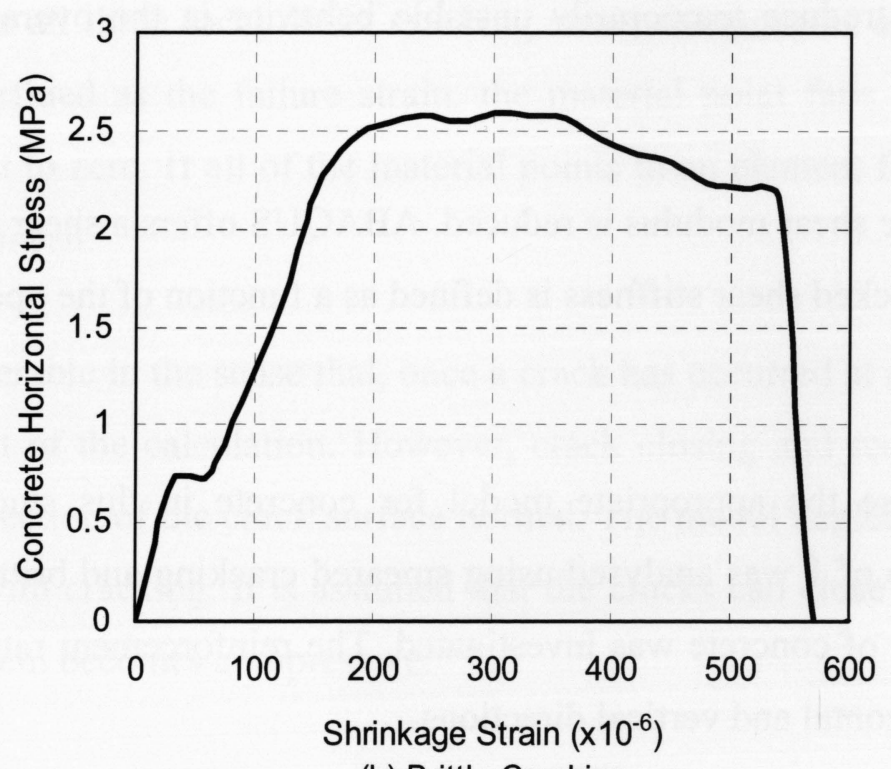

(b) Brittle Cracking

Figure 4.3- Horizontal stress in concrete at the center point $(\mathrm{L} / \mathrm{H}=1)$ 
The analysis of the wall modeled with smeared cracking model aborted at nearly $60 \%$ of shrinkage strain and the program was unable to complete the analysis because of diverging from the solution. However, the program completed the analysis of the wall modeled with brittle cracking model and the total amount of shrinkage strain was applied to the wall.

According to the material properties defined in section 4.3, the cracking failure stress of concrete $\left(f_{t}\right)$ was $2.7 \mathrm{MPa}$. As seen in Figure 4.3(a), the tensile stress of concrete modeled with smeared cracking model exceeds the failure stress. However, Figure 4.3(b) shows that the maximum tensile stress of concrete modeled with brittle cracking model is slightly less than the failure stress. In addition, after concrete cracks, the tensile stress of concrete declines to zero at approximately $95 \%$ of shrinkage strain and remains zero to the end of analysis which is in compliance with the tension stiffening defined for concrete.

The smeared cracking model for concrete in ABAQUS applies Von Mises failure criterion to detect cracking in concrete. However, Von Mises failure criterion is most applicable to ductile materials. In this criterion, plastic yield initiates when the Von Mises stress reaches the initial yield stress in uniaxial tension. Then, the Von Mises stress is used to predict failure by ductile tearing. The failure of concrete in tension is dominated by crack propagation which depends on the maximum principal stress and Von Mises failure criterion is not appropriate in such type of failure.

The brittle cracking model for concrete in ABAQUS applies the maximum principal stress to detect crack initiation. This model is considered functional in the restrained shrinkage problems as the concrete compressive stresses are expected to remain low and within the elastic range of material behaviour. From the comparison of the behaviour of concrete modeled with smeared cracking and brittle cracking, it is concluded that brittle cracking model simulates more accurately the behaviour of reinforced concrete walls subjected to restrained shrinkage. In this study, the brittle cracking model for concrete is used in nonlinear analysis of the walls. 


\subsection{Uniform Reinforcement}

In general, concrete standards and codes of practice recommend the shrinkage and temperature reinforcement ratio of $0.3 \%$ for walls and slabs. The highest value of the shrinkage and temperature reinforcement ratio recommended by Standard Requirements for Environmental Engineering Concrete Structures (ACI 350R-06) is $0.5 \%$ for steel grade 60 where the length between movement joints is greater than $12 \mathrm{~m}$. As the first step, the reinforcement ratio of the walls was considered $0.5 \%$ in both horizontal and vertical directions.

In this study, the computer software ABAQUS version 6.7 was used for the analysis. Concrete walls were modeled using quadratic $50 \mathrm{~mm} \times 50 \mathrm{~mm}$ shell elements with 4 integration points and reinforcement was modeled as a steel layer embedded in the mid thickness of the shell elements.

In this analysis, walls were subjected to only shrinkage. Therefore, the total strain at each point is caused by shrinkage and restraint from surrounding parts of the member at that point. The total strain at each point can be expressed as

$\varepsilon_{\text {total }}=\varepsilon_{\text {shrinkage }}+\varepsilon_{\text {restraint }}$

Where,

$\varepsilon_{\text {total }}$ is the total strain

$\varepsilon_{\text {shrinkage }}$ is the shrinkage strain

$\varepsilon_{\text {restraint }}$ is the restraint strain

The total strain at each point is derived from analysis output. Knowing that the shrinkage strain is $600 \times 10^{-6} \mathrm{~mm} / \mathrm{mm}$ at every point in the walls, the restraint strain which causes cracking in concrete is determined from Eq. 4.3. 
Figure 4.4 presents the maximum restraint strain in the vicinity of cracks along the height of the walls with length/height ratios of $1,2,5,10$, and 20 and having $0.5 \%$ uniform reinforcement.

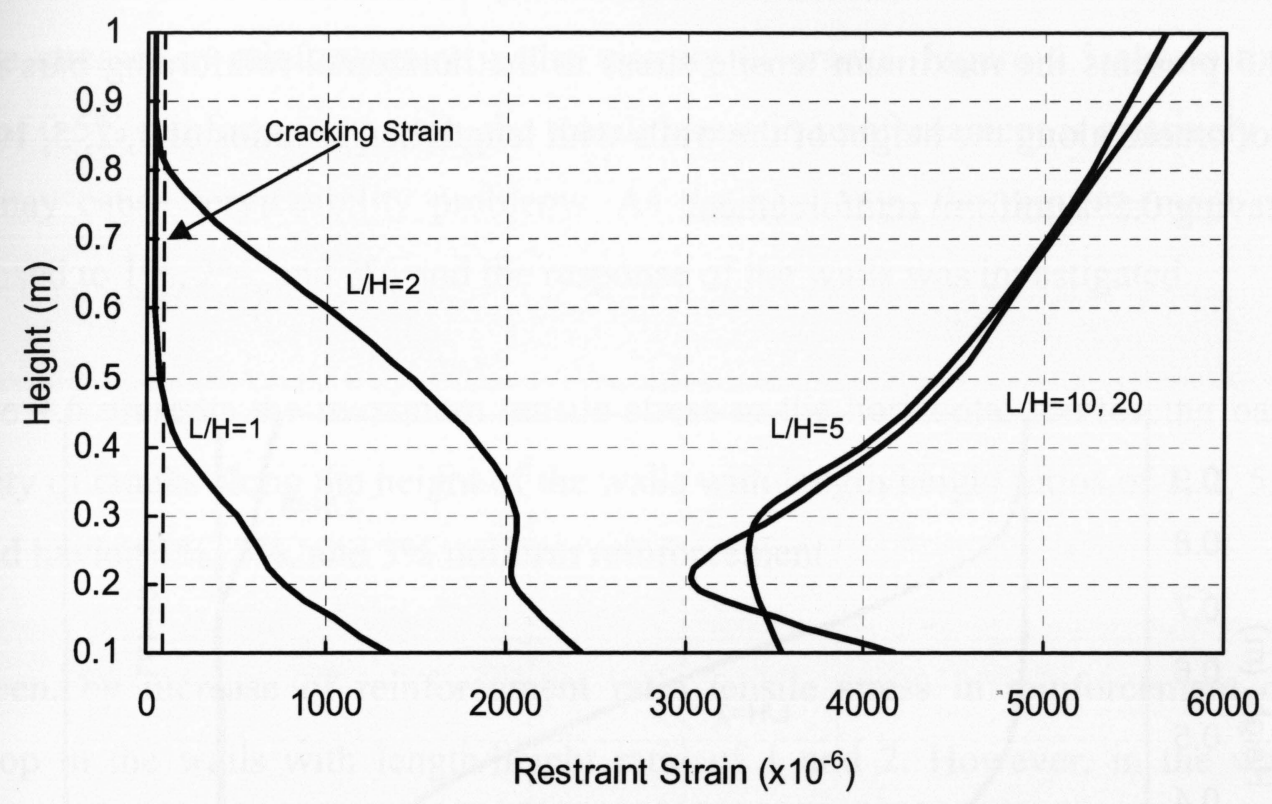

Figure 4.4- The maximum restraint strain $(\rho=0.5 \%)$

According to the material properties defined in section 4.3, the cracking failure stress of concrete $\left(f_{t}\right)$ and the modulus of elasticity of concrete $\left(E_{c}\right)$ was $2.7 \mathrm{MPa}$ and $25,000 \mathrm{MPa}$, respectively. The cracking strain of concrete $\left(\varepsilon_{c r a c k}\right)$ is determined from

$$
\varepsilon_{\text {crack }}=\frac{f_{t}}{E_{c}}=\frac{2.7}{25000}=108 \times 10^{-6}
$$

The cracking strain of concrete is shown with a broken line on Figure 4.4.

As seen in Figure 4.4, cracks develop to nearly $500 \mathrm{~mm}$ height from the base in the wall with length/height ratio of 1 and to $800 \mathrm{~mm}$ height in the wall with length/height ratio of 2. However, in the walls with length/height ratio of 5, 10, and 20 full height cracks are observed. In addition, the restraint strain decreases from the base to the top in the walls 
with length/height ratios of 1 and 2 whereas, in the walls with length/height ratio of 5,10 , and 20 the restraint strain increases from the base to the top. Consequently, cracks are wider at the top of the walls with length/height ratios of 5, 10, and 20 than those near the base of the walls.

Figure 4.5 presents the maximum tensile stress in the horizontal reinforcing bars in the vicinity of cracks along the height of the walls with length/height ratios of $1,2,5,10$, and 20 and having $0.5 \%$ uniform reinforcement.

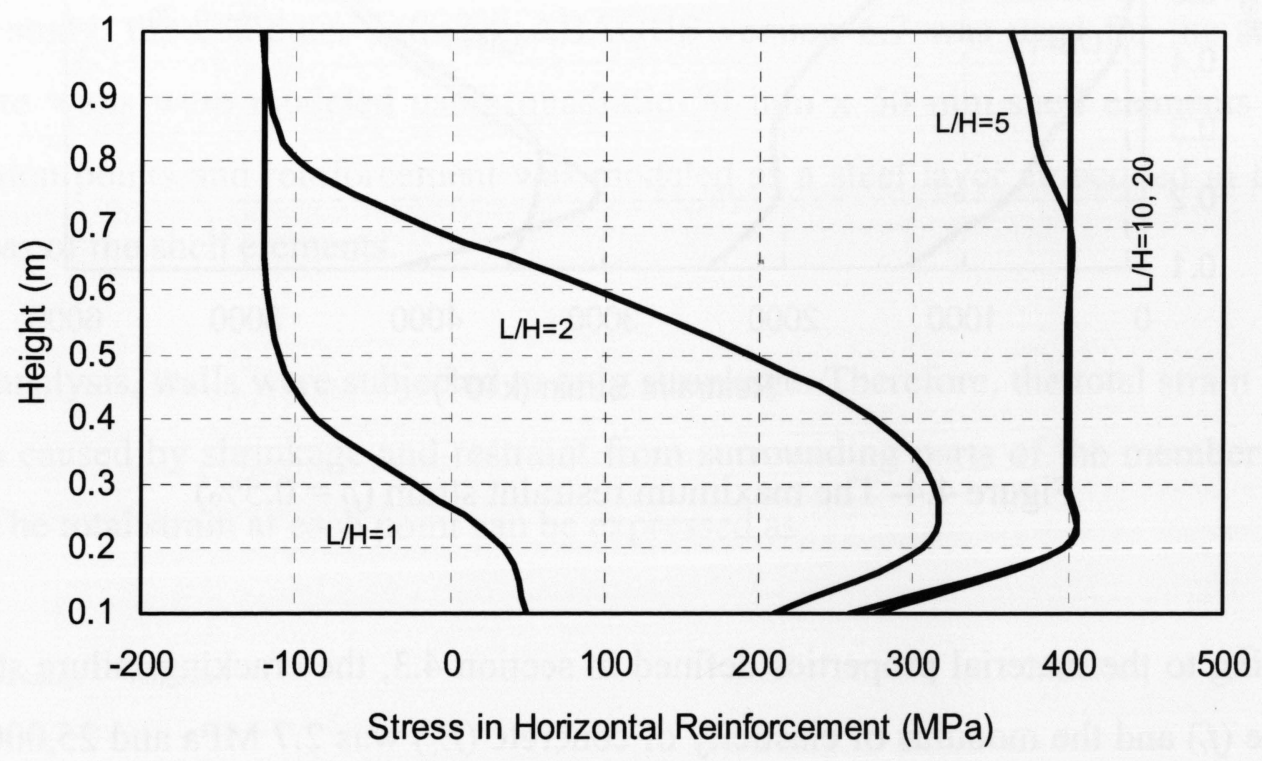

Figure 4.5- The maximum tensile stress $(\rho=0.5 \%)$

As seen in Figure 4.5, in the wall with length/height ratio of 1 , the tensile stress in reinforcement develops up to nearly $300 \mathrm{~mm}$ height from the base and in the rest of the height, reinforcing bars are in compression. In this case, the maximum tensile stress in reinforcement is quite small. In the wall with length/height ratio of 2 , the tensile stress in reinforcement develops up to nearly $700 \mathrm{~mm}$ height from the base and in the rest of the height, reinforcing bars are in compression. In such case, the maximum tensile stress in reinforcement reaches to nearly $300 \mathrm{MPa}$. In the walls with length/height ratios of 5, 10, 
and 20 the tensile stress in reinforcement develops over the wall height and almost all the reinforcement yields.

Since concrete is weak in tension, cracking is inevitable in concrete structures. However, crack width can be controlled by providing sufficient amount of reinforcement to limit tensile stresses in reinforcement in the vicinity of cracks. Figure 4.5 shows that in the case of $0.5 \%$ reinforcement ratio, the tensile stress in reinforcement is relatively high and this may cause serviceability problems. As the next step, the reinforcement ratio was increased to $1 \%, 2 \%$, and $3 \%$ and the response of the walls was investigated.

Figure 4.6 presents the maximum tensile stress in the horizontal reinforcing bars in the vicinity of cracks along the height of the walls with length/height ratios of $1,2,5,10$, and 20 and having $1 \%, 2 \%$, and $3 \%$ uniform reinforcement.

As seen, by increase of reinforcement ratio tensile stress in reinforcement does not develop in the walls with length/height ratio of 1 and 2 . However, in the walls with length/height ratio of 5,10 , and 20 by increase of reinforcement ratio from $0.5 \%$ to $1 \%$, cracks develop up to mid height and the maximum tensile stress in reinforcement is less than $100 \mathrm{MPa}$. In addition, by increase of reinforcement ratio from $1 \%$ to $2 \%$ and $3 \%$ tensile stress in reinforcement does not develop in such walls.

\subsection{Non-uniform Reinforcement}

Cracking in concrete structures is inevitable and in the areas where concrete cracks, reinforcement is provided to control crack width and crack spacing. In section 4.4, it was concluded that by increase of reinforcement ratio, the development of full height cracks in the walls is prevented and keeping the same amount of reinforcement ratio in the areas where concrete does not crack may not be economical. As the next step in this study, the reinforcement ratio was reduced from the base to the top and the response of the walls to the non-uniform distribution of the reinforcement was investigated. 


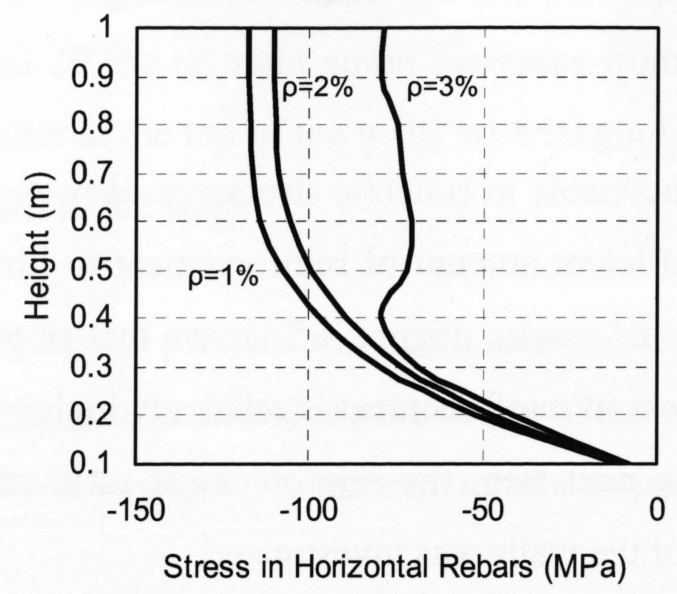

(a) $\mathrm{L} / \mathrm{H}=1$

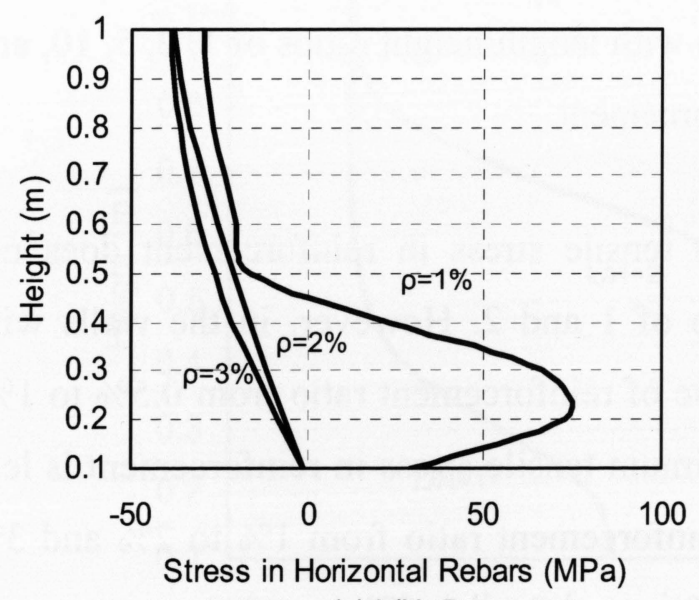

(c) $\mathrm{L} / \mathrm{H}=5$

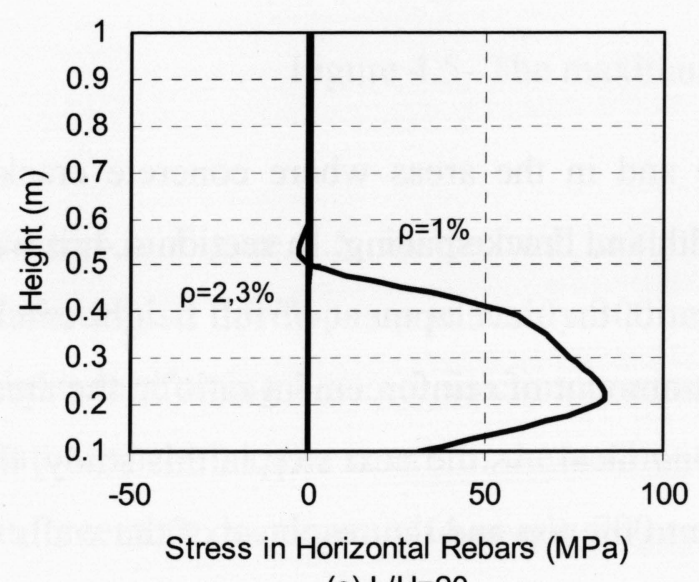

(e) $\mathrm{L} / \mathrm{H}=20$

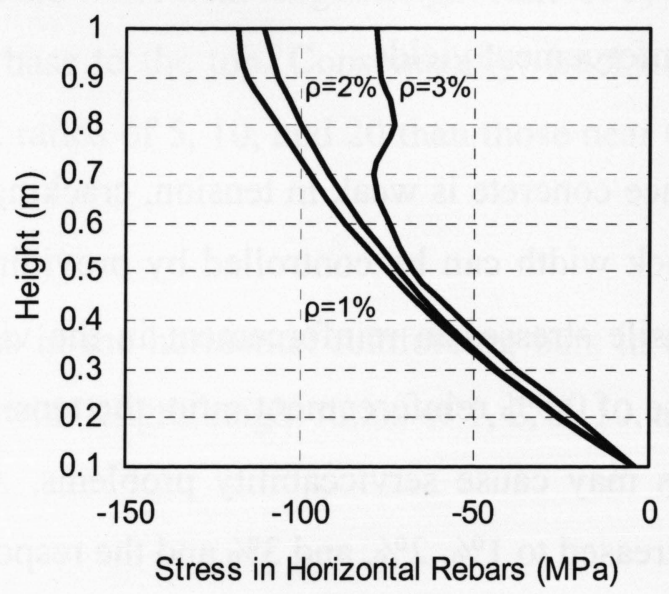

(b) $\mathrm{L} / \mathrm{H}=2$

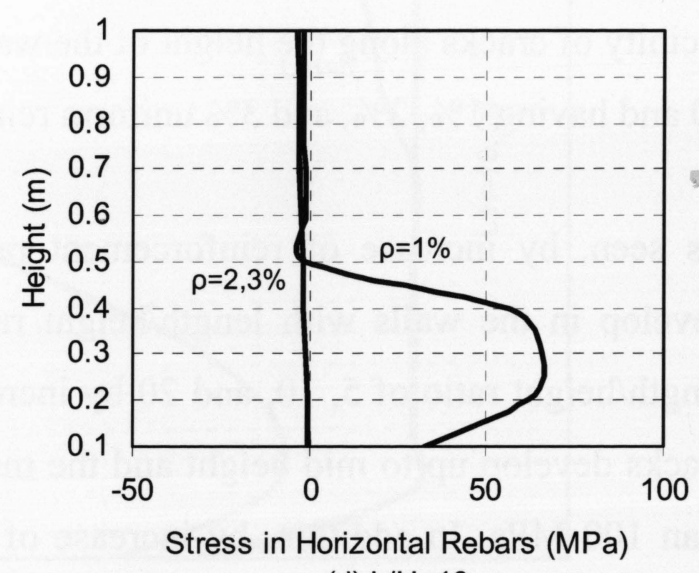

(d) $\mathrm{L} / \mathrm{H}=10$

Figure 4.6- The maximum tensile stresses (uniform reinforcement) 
Figure 4.7 presents the profile of the non-uniform distribution of reinforcement.

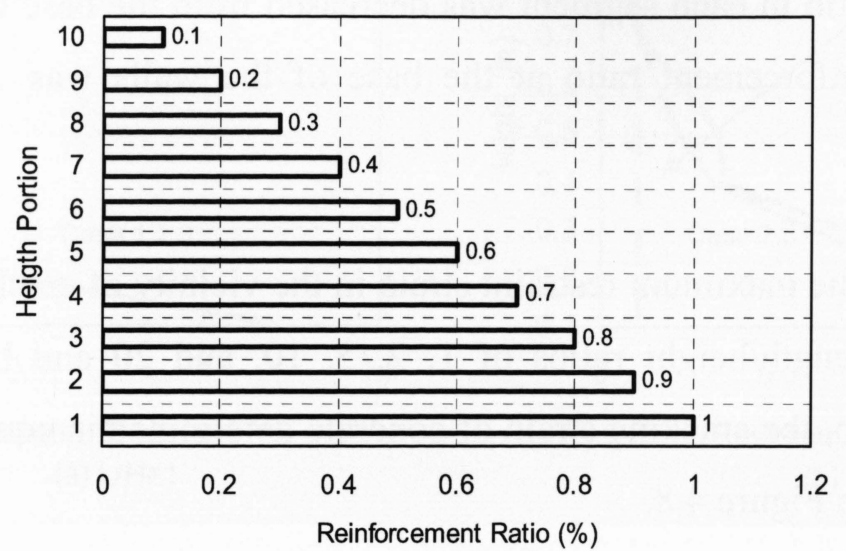

(a) Case 1

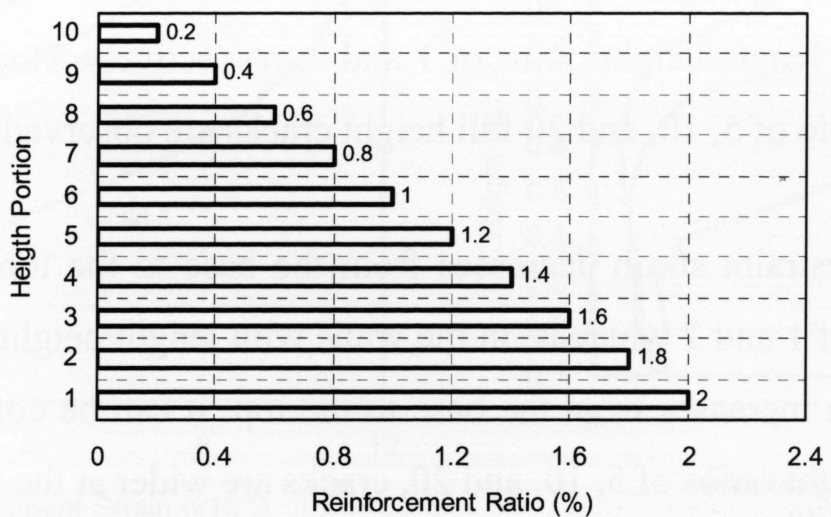

(b) Case 2

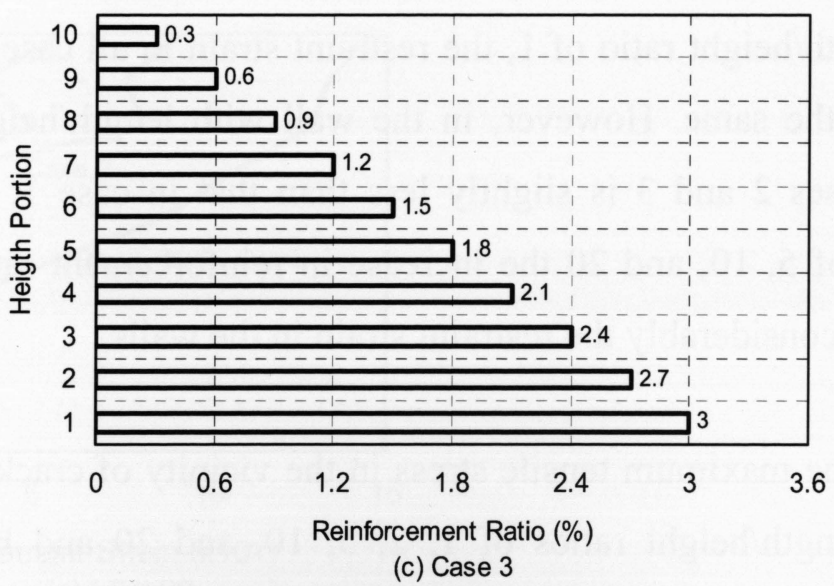

Figure 4.7- Non-uniform distribution of reinforcement 
In this analysis, three cases of non-uniform distribution of reinforcement were considered. In all cases, the height of the walls was divided into 10 equal segments and the reinforcement ratio in each segment was decreased from the base to the top. In cases 1,2 , and 3 the reinforcement ratio at the base of the walls was $1 \%, 2 \%$, and $3 \%$, respectively.

Figure 4.8 presents the maximum restraint strain in the vicinity of cracks along the height of the walls with length/height ratios of 1, 2, 5, 10, and 20 and having no-uniform reinforcement. Again, the cracking strain of concrete determined in equation 4.4 is shown with a broken line on Figure 4.8.

As seen in Figure 4.8, cracks develop to nearly $400 \mathrm{~mm}$ and $700 \mathrm{~mm}$ height from the base in the wall with length/height ratios of 1 and 2, respectively. However, in the walls with length/height ratio of 5,10 , and 20 full height cracks are observed.

On the whole, the restraint strain decreases from the base to the top in the walls with length/height ratios of 1 and 2 whereas, in the walls with length/height ratio of 5,10 , and 20 the restraint strain increases from the base to the top. It can be concluded that in the walls with length/height ratios of 5,10 , and 20 , cracks are wider at the top than those near the base of the walls.

In the wall with length/height ratio of 1 , the restraint strain in all cases of reinforcement distribution is quite the same. However, in the wall with length/height ratio of 2 , the restraint strain in cases 2 and 3 is slightly less than that in case 1 . In the walls with length/height ratios of 5,10, and 20 the increase in reinforcement ratio from case 1 to case 2 and 3 reduces considerably the restraint strain in the walls.

Figure 4.9 presents the maximum tensile stress in the vicinity of cracks along the height of the walls with length/height ratios of $1,2,5,10$, and 20 and having no-uniform reinforcement. 


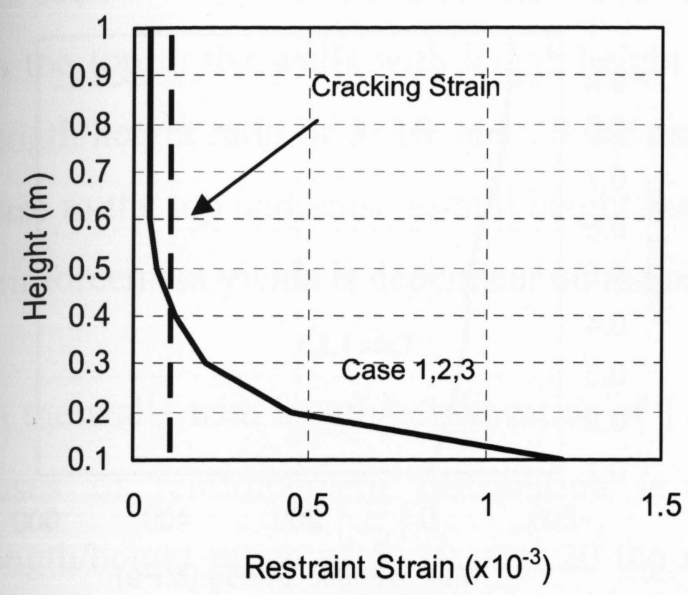

(a) $\mathrm{L} / \mathrm{H}=1$

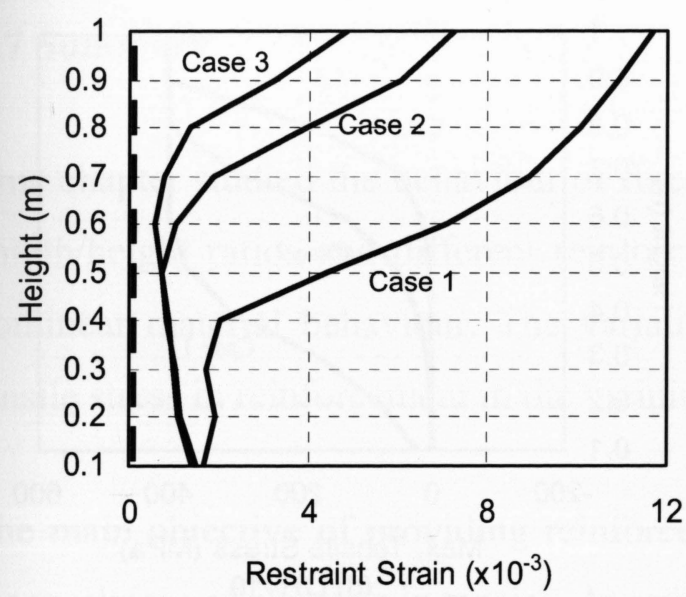

(c) $\mathrm{L} / \mathrm{H}=5$

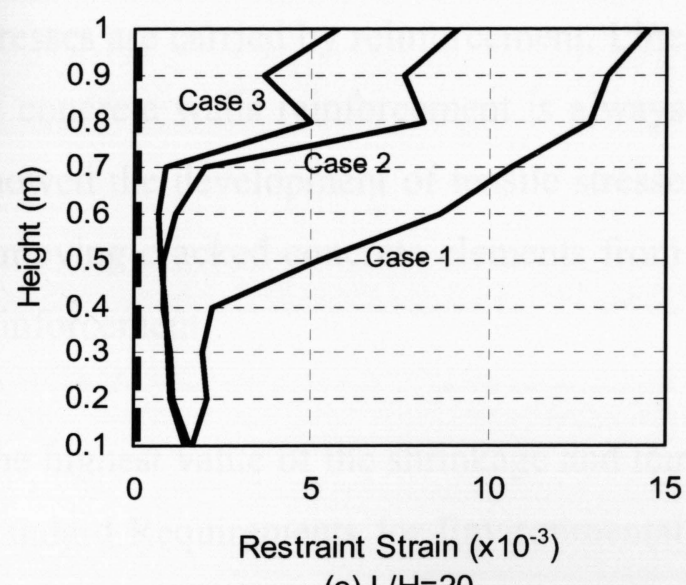

(e) $\mathrm{L} / \mathrm{H}=20$

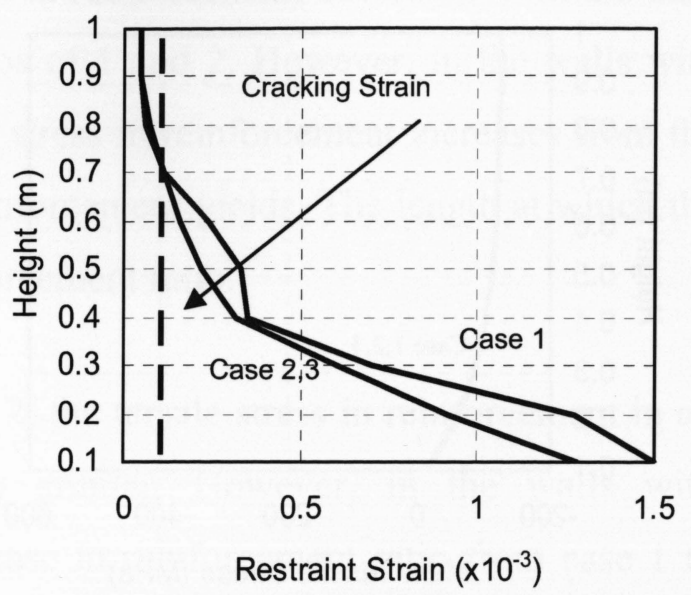

(b) $\mathrm{L} / \mathrm{H}=2$

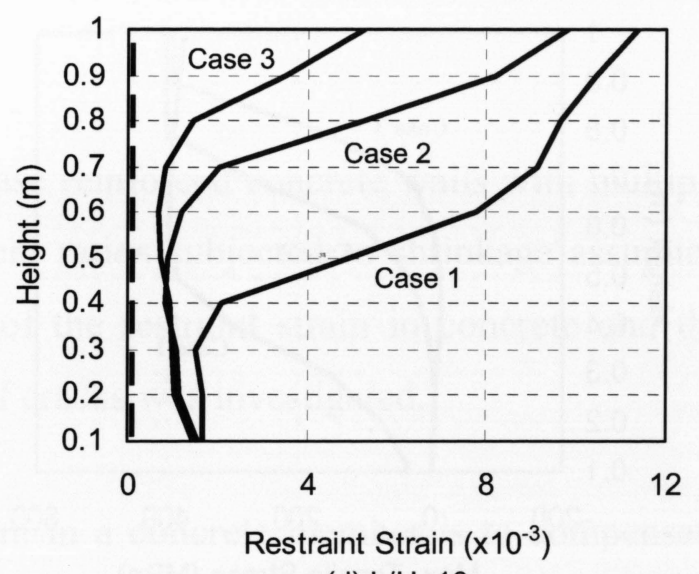

(d) $\mathrm{L} / \mathrm{H}=10$

Figure 4.8- The maximum restraint strain (non-uniform reinforcement) 


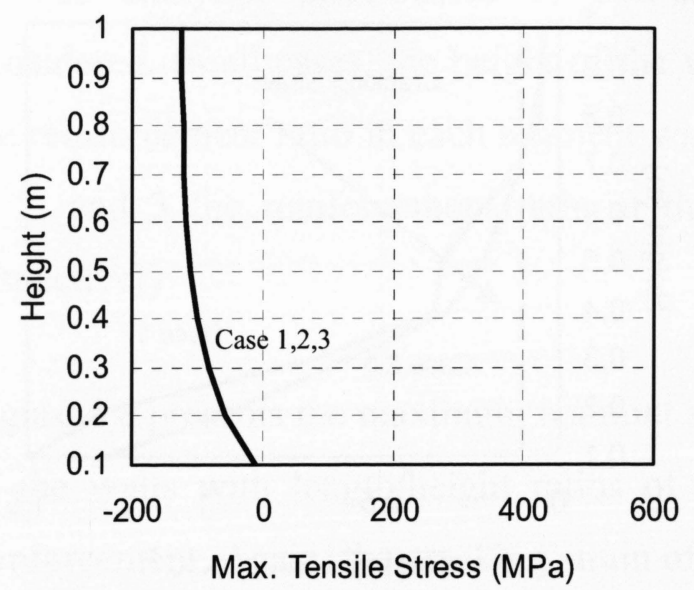

(a) $\mathrm{L} / \mathrm{H}=1$

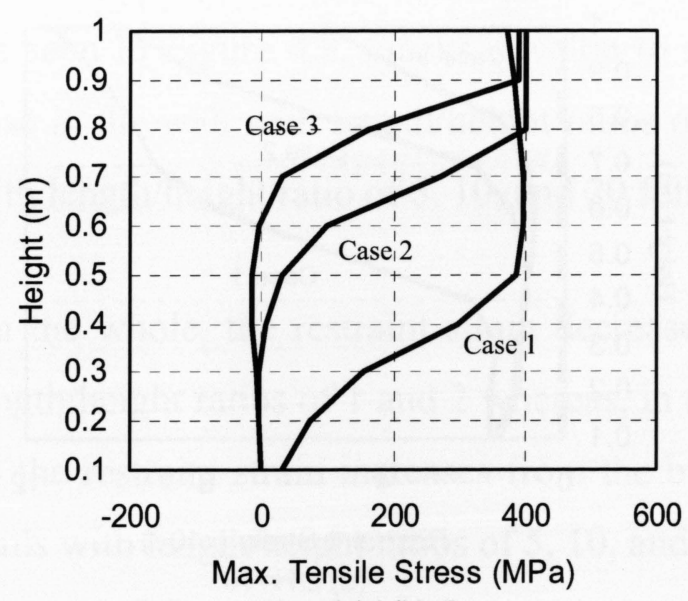

(c) $\mathrm{L} H=5$

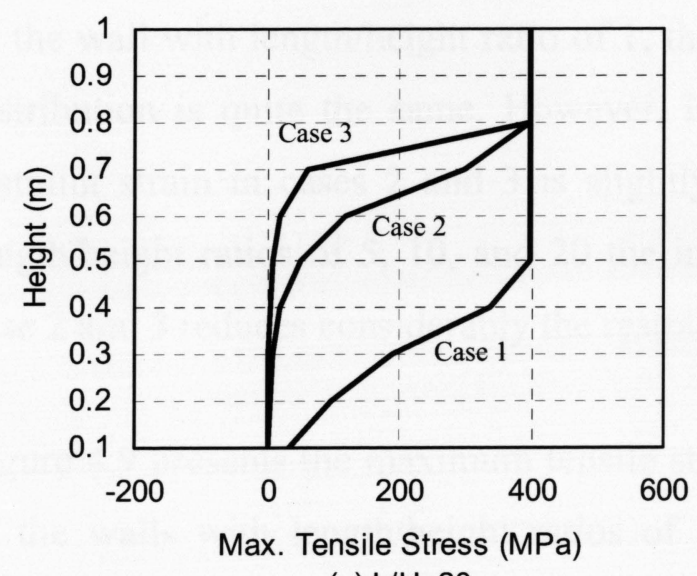

(e) $\mathrm{L} / \mathrm{H}=20$

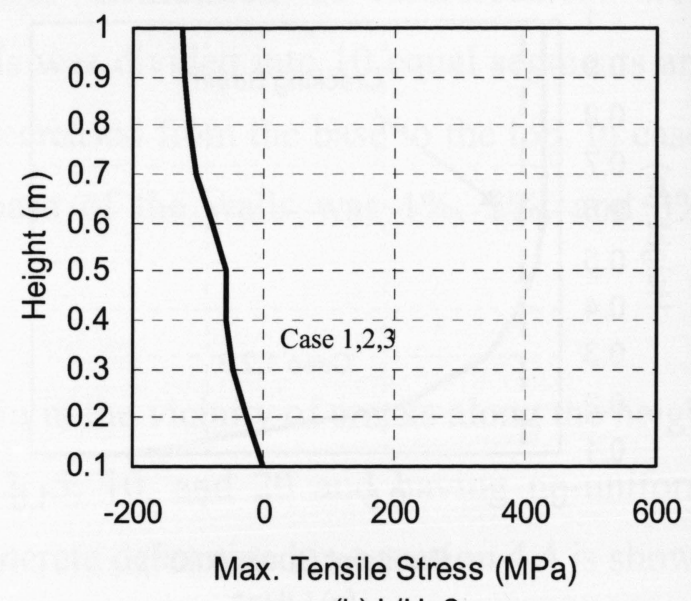

(b) $\mathrm{L} / \mathrm{H}=2$

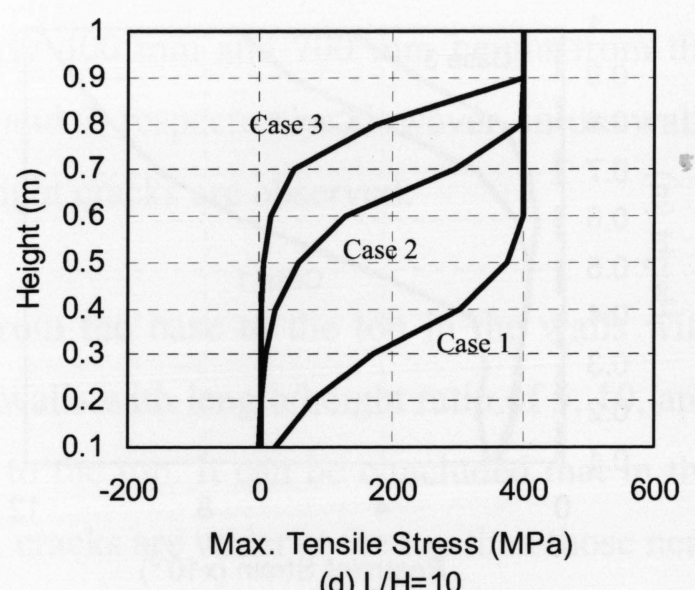

(d) $\mathrm{L} / \mathrm{H}=10$

Figure 4.9- The maximum tensile stresses (non-uniform reinforcement) 
As seen in Figure 4.9, overall the tensile stress in reinforcement decreases from the base to the top in the walls with length/height ratios of 1 and 2 . However, in the walls with length/height ratio of 5,10 , and 20 the tensile stress in reinforcement increases from the base to the top and close to mid height the reinforcement yields. The length at which the reinforcement yields is dependent on the reinforcement ratio.

In the walls with length/height ratios of 1 and 2, the tensile stress in reinforcement in all cases of reinforcement distribution is very similar. However, in the walls with length/height ratios of 5,10, and 20 the increase in reinforcement ratio from case 1 to case 2 and 3 reduces considerably the tensile stress in reinforcement.

\subsection{Summary}

This chapter studied the behaviour of fixed base reinforced concrete walls with multiple length/height ratios and different reinforcement ratios subjected to shrinkage assuming nonlinear material behaviour. The variation of the restraint strain in concrete and the tensile stress in reinforcement in the vicinity of cracks was investigated.

The main objective of providing reinforcement in a concrete member is to compensate the weakness of concrete in tension. In restrained shrinkage of a concrete member, tensile stresses develop in concrete and concrete may crack. At crack locations the entire tensile stresses are carried by reinforcement. Linear analysis showed that in restrained shrinkage of concrete walls reinforcement is always in compression. However, nonlinear analysis showed the development of tensile stresses in reinforcement in the vicinity of cracks by removing cracked concrete elements from calculation and transferring tensile stresses to reinforcement.

The highest value of the shrinkage and temperature reinforcement ratio recommended by Standard Requirements for Environmental Engineering Concrete Structures (ACI 350R06 ) is $0.5 \%$. It was found that in the walls with length/height ratios of 1 and 2 and having $0.5 \%$ reinforcement ratio, cracks develop to a certain height and in the walls with length/height ratios of 5, 10, and 20 and having $0.5 \%$ reinforcement ratio, cracks develop 
to the full height and cracks are wider at the top of such walls. Except for the wall with length/height ratio of 1 , in the other cases the tensile stress in reinforcement in the vicinity of cracks is high and even reinforcement yields which may cause serviceability problems. In addition, it was found that increase of reinforcement ratio to $1 \%$, reduces considerably the stress in reinforcement.

The effect of non-uniform distribution of reinforcement was investigated. It was found that except for the walls with length/height ratio of 1 and 2, in the other cases cracks develop to the full height of the walls. The tensile stresses in reinforcement in the vicinity of cracks are high and above certain height reinforcement yields. The variation of the stress in reinforcement in the walls with length/height ratio of 1 and 2 and with uniform and non-uniform distribution of reinforcement is quite similar which suggests that nonuniform distribution of reinforcement in such walls is desired.

In this chapter, the application of smeared cracking model versus brittle cracking model for concrete available in ABAQUS was examined. It was found that brittle cracking model simulates more accurately the behaviour of reinforced concrete walls subjected to restrained shrinkage. 


\section{CHAPTER 5}

\section{NONLINEAR ANALYSIS OF RECTANGULAR TANKS}

\subsection{Introduction}

This chapter studies the response of reinforced concrete tanks subjected to shrinkage strain assuming nonlinear material behaviour. In this study, tanks with different aspect ratios (length/height ratio of walls) and different reinforcement ratios are investigated and the effect of uniform and non-uniform distribution of the reinforcement is presented.

\subsection{Specifications of Tanks}

In this study, three rectangular reinforced concrete tanks were analyzed. In all cases, the height and the thickness of the walls were $1 \mathrm{~m}$ and $200 \mathrm{~mm}$, respectively. Figure 5.1 presents a typical perspective view of the tanks.

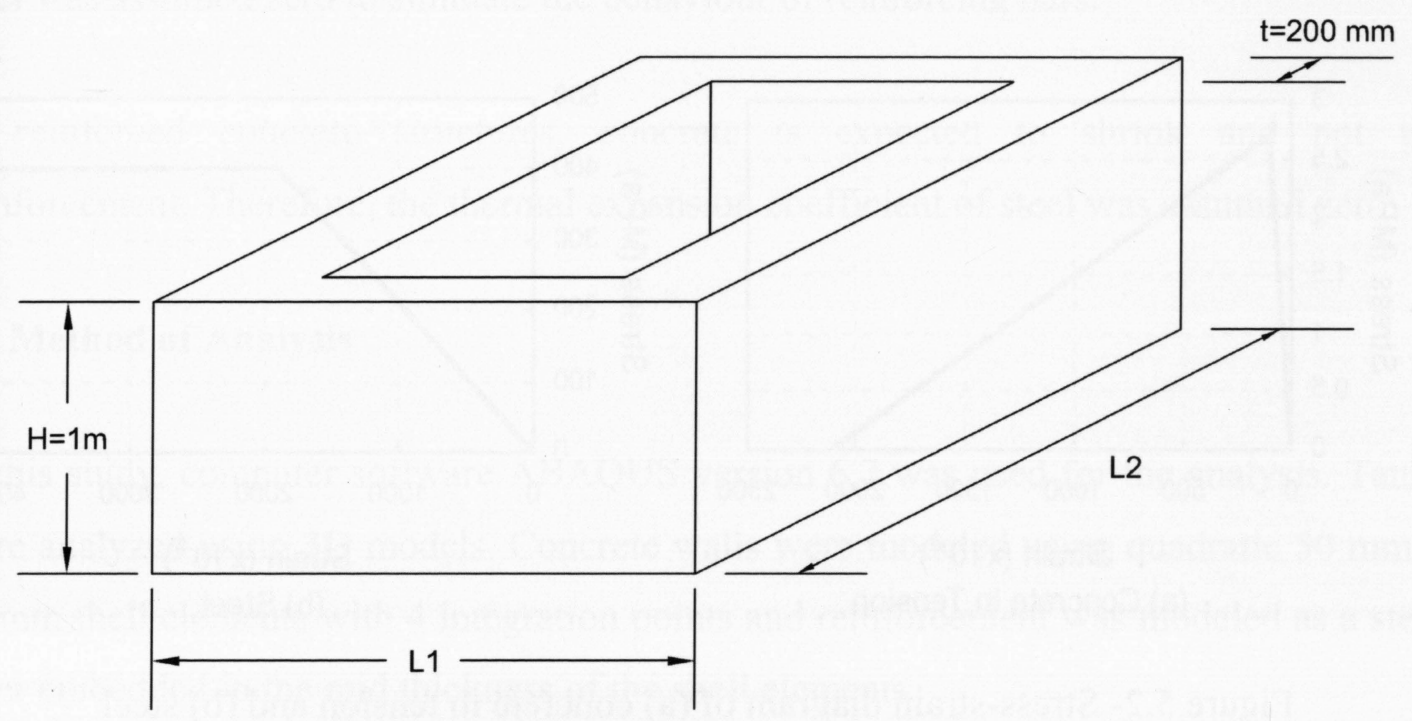

Figure 5.1- Typical perspective view of the tanks 
In two cases, all the walls had equal length/height ratio of 1 and $2(\mathrm{~L} 1=\mathrm{L} 2=1 \mathrm{~m}$ and $2 \mathrm{~m})$ and in the third case, two walls had length/height ratio of 1 and the rest had length/height ratio of $2(\mathrm{~L} 1=1 \mathrm{~m}$ and $\mathrm{L} 2=2 \mathrm{~m})$. In the analysis, the base of the walls was assumed fully fixed.

In most concrete structures the final shrinkage strain is $600 \times 10^{-6} \mathrm{~mm} / \mathrm{mm}$ (ACI 224R-01). In order to simulate this amount of shrinkage strain, a temperature change of $60^{\circ} \mathrm{C}$ was applied to the tanks considering the thermal expansion coefficient as $1 \times 10^{-5}$ for concrete.

\subsection{Material Properties}

In this analysis, nonlinear material behaviour was assumed for both concrete and steel. In the shrinkage of reinforced concrete members, concrete is assumed to be in tension. Therefore, the behaviour of concrete in tension is of importance. Figure 5.2 presents the stress-strain diagram of concrete in tension and the idealized stress-strain diagram of steel.

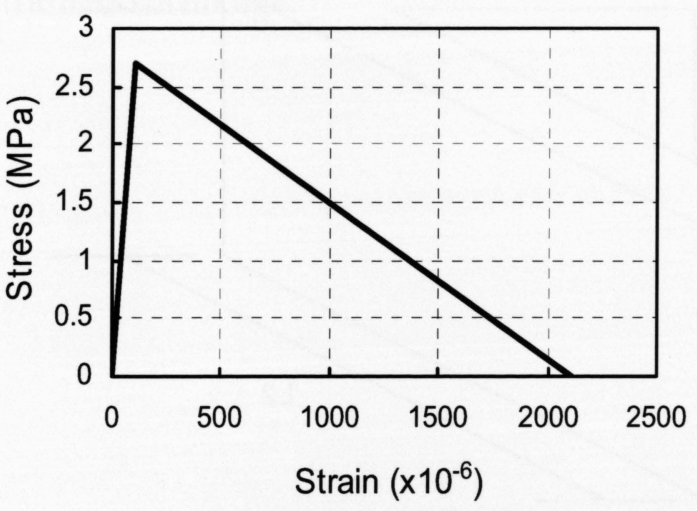

(a) Concrete in Tension

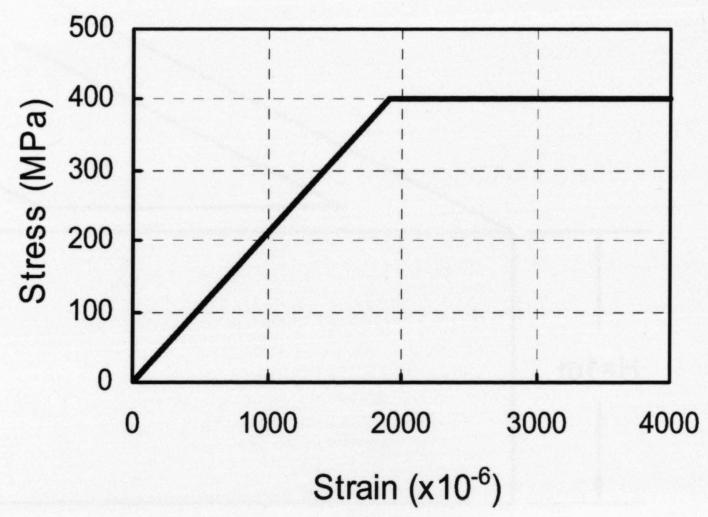

(b) Steel

Figure 5.2- Stress-strain diagram of (a) concrete in tension and (b) steel

As seen in Figure 5.2(a), tension stiffening of concrete was assumed as a linear decrease of the stress at failure to zero stress at a strain of $2 \times 10^{-3} \mathrm{~mm} / \mathrm{mm}$. 
The material properties of concrete and steel were:

$f_{t}($ Cracking failure stress of concrete $)=2.7 \mathrm{MPa}$

$E_{c}$ (Modulus of elasticity of concrete $)=25,000 \mathrm{MPa}$

$v_{c}($ Poison's ratio of concrete $)=0.15$

$\alpha_{c}$ (Thermal expansion coefficient of concrete $)=1 \times 10^{-5}$

$f_{y}($ Yield stress of steel $)=400 \mathrm{MPa}$

$E_{s}($ Modulus of elasticity of steel $)=210,000 \mathrm{MPa}$

$v_{s}($ Poison's ratio of steel $)=0.0$

$\alpha_{s}($ Thermal expansion coefficient of steel $)=0.0$

Reinforcement in concrete structures is typically provided by means of reinforcing bars, which are one dimensional strain theory elements. In this analysis, reinforcement was modeled as a layer of steel embedded inside the walls. Therefore, the Poisson's ratio of steel was assumed zero to simulate the behaviour of reinforcing bars.

In reinforced concrete structures, concrete is expected to shrink and not the reinforcement. Therefore, the thermal expansion coefficient of steel was assumed zero.

\subsection{Method of Analysis}

In this study, computer software ABAQUS version 6.7 was used for the analysis. Tanks were analyzed using 3D models. Concrete walls were modeled using quadratic $50 \mathrm{~mm} \mathrm{x}$ $50 \mathrm{~mm}$ shell elements with 4 integration points and reinforcement was modeled as a steel layer embedded in the mid thickness of the shell elements.

In chapter 4 , it was concluded that brittle cracking model for concrete available in ABAQUS simulates more accurately the behaviour of reinforced concrete walls subjected to restrained shrinkage than smeared cracking model. In this study, the brittle cracking model for concrete was used in nonlinear analysis of the tanks. 


\subsection{Uniform Reinforcement}

In general, concrete standards and codes of practice recommend the shrinkage and temperature reinforcement ratio of $0.3 \%$ for walls and slabs. The highest value of the shrinkage and temperature reinforcement ratio recommended by Standard Requirements for Environmental Engineering Concrete Structures (ACI 350R-06) is 0.5\% for steel grade 60 where the length between movement joints is greater than $12 \mathrm{~m}$. As the first step, the reinforcement ratio of the walls was considered $0.5 \%$ in both horizontal and vertical directions.

Figure 5.3 presents the maximum tensile stress in the horizontal reinforcing bars in the vicinity of cracks along the height of the tanks with $0.5 \%$ uniform reinforcement ratio.

As seen in Figure 5.3, in the tank with length/height ratio of 1, the tensile stress in reinforcement develops up to nearly 0.4 heights from the base and in the rest of the height, reinforcing bars are in compression. In this case, the maximum tensile stress in reinforcement is quite small. In the tank with length/height ratio of 2 , the tensile stress in reinforcement develops up to nearly 0.75 heights from the base and in the rest of the height, reinforcing bars are in compression. In such case, the maximum tensile stress in reinforcement reaches to nearly $300 \mathrm{MPa}$. In the tank with length/height ratio of 1 and 2 , the tensile stress in reinforcement develops up to nearly 0.16 heights and 0.8 heights in the smaller and bigger wall, respectively. In this case, the maximum tensile stress in reinforcement reaches to nearly $200 \mathrm{MPa}$. In all cases, in the area where reinforcement is in tension, the stress in reinforcement decreases from the base to the top.

Concrete is weak in tension and cracking is inevitable in concrete structures. However, crack width can be controlled by providing sufficient amount of reinforcement to limit tensile stresses in reinforcement in the vicinity of cracks. Figure 5.3 shows that in the tank with length/height ratio of 2 and having $0.5 \%$ reinforcement ratio, the tensile stress in reinforcement near the base is relatively high and this may cause serviceability problems. As the next step, the reinforcement ratio was increased to $1 \%, 2 \%$, and $3 \%$ and the response of the tanks was investigated. 


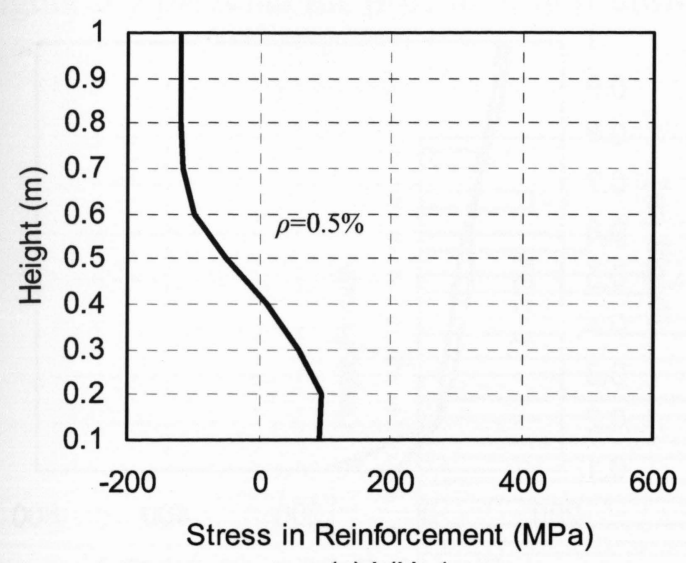

(a) $\mathrm{L} / \mathrm{H}=1$

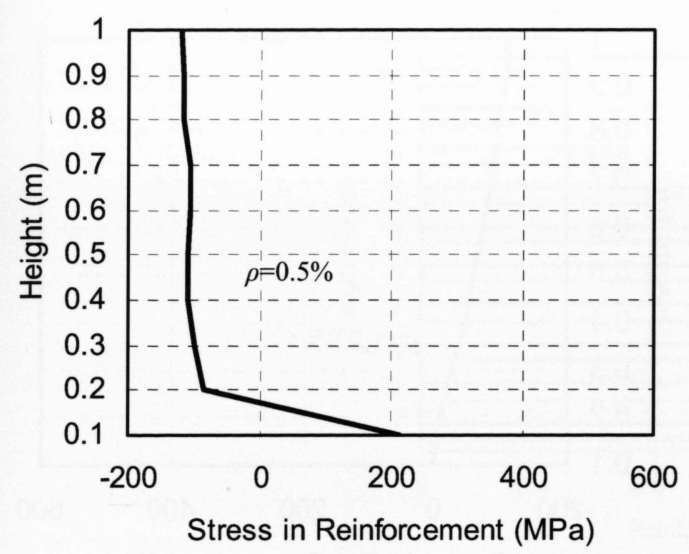

(c) $\mathrm{L} / \mathrm{H}=1,2$ (L1)

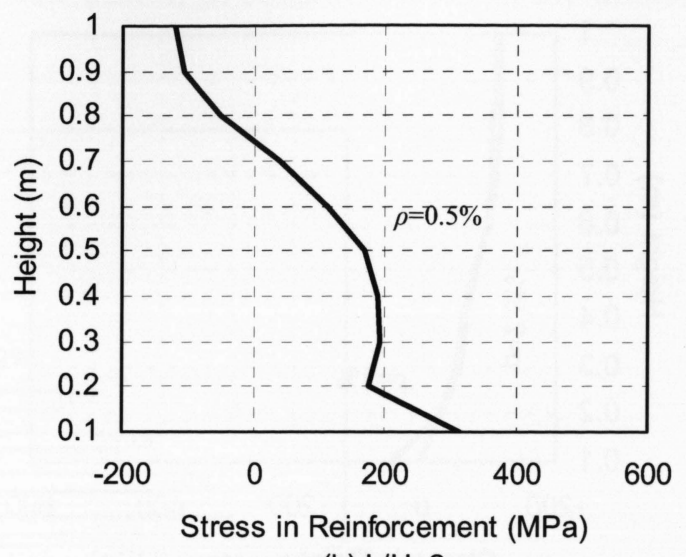

(b) $\mathrm{L} / \mathrm{H}=2$

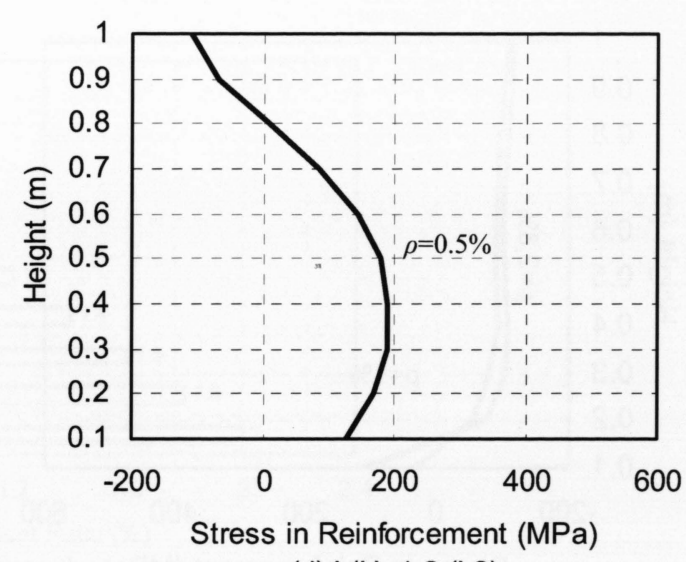

(d) $\mathrm{L} / \mathrm{H}=1,2$ (L2)

Figure 5.3- The maximum tensile stress in horizontal reinforcement $(\rho=0.5 \%)$

Figure 5.4 presents the maximum tensile stress in the horizontal reinforcing bars in the vicinity of cracks along the height of the tanks with $1 \%, 2 \%$, and $3 \%$ uniform reinforcement ratio.

As seen in Figure 5.4, by increase of reinforcement ratio from $0.5 \%$ to $1 \%$, tensile stresses in reinforcement are reduced dramatically to the extent that the maximum tensile stress in reinforcement does not exceed $150 \mathrm{MPa}$ and in all cases tensile stresses in reinforcement develop to less than 0.2 heights from the base. In addition, by increase of reinforcement ratio from $1 \%$ to $2 \%$ and $3 \%$ the stresses in reinforcement are not reduced considerably which suggests that $1 \%$ reinforcement ratio might be sufficient. 


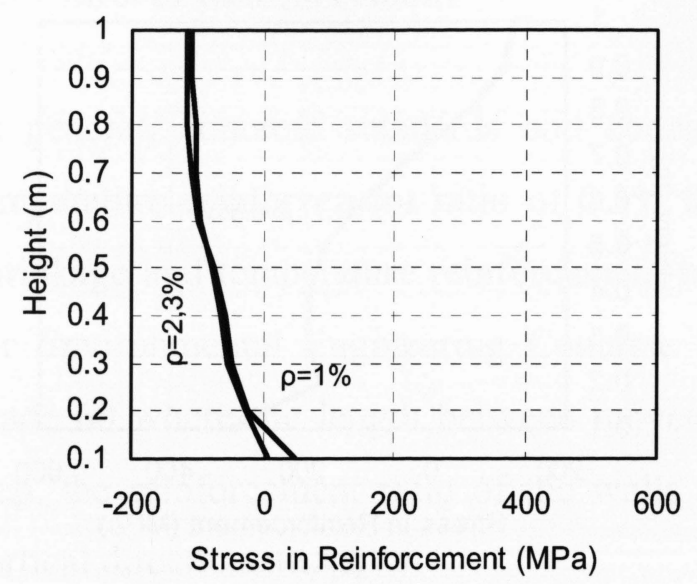

(a) $\mathrm{L} / \mathrm{H}=1$

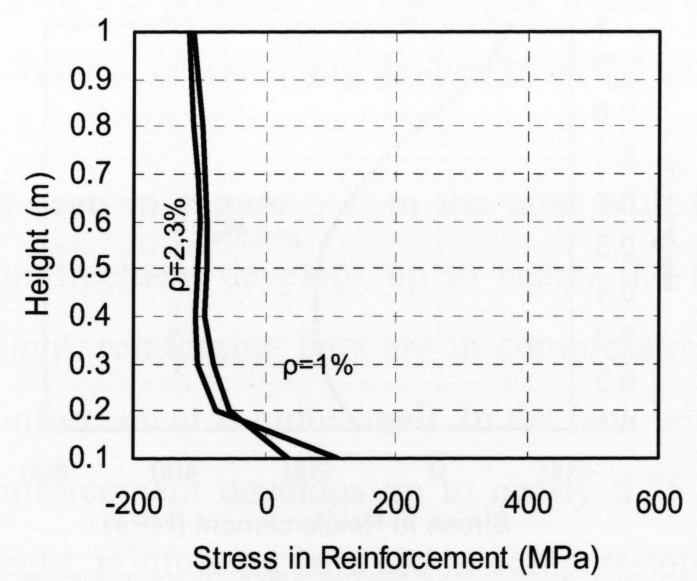

(c) $\mathrm{L} / \mathrm{H}=1,2$ (L1)

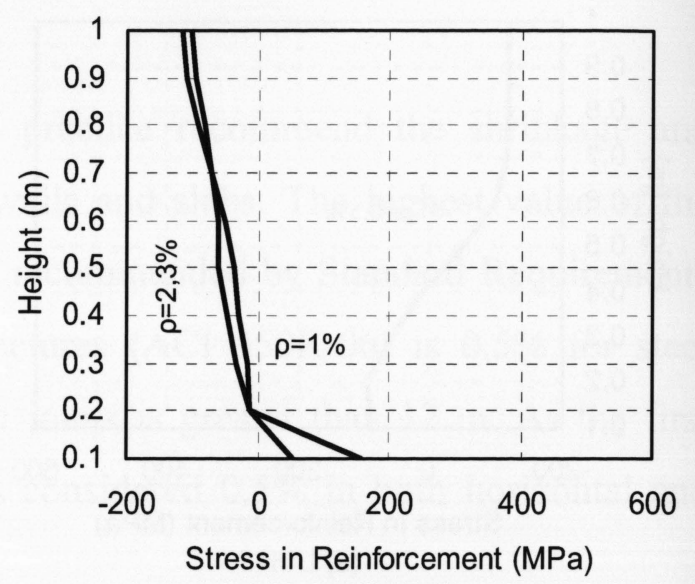

(b) $\mathrm{L} / \mathrm{H}=2$

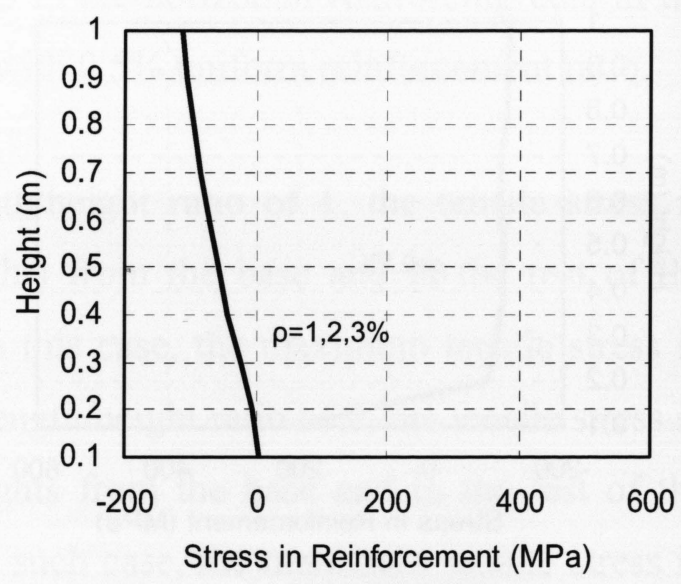

(d) $\mathrm{L} / \mathrm{H}=1,2$ (L2)

Figure 5.4- The maximum tensile stress in horizontal reinforcement $(\rho=1,2,3 \%)$

\subsection{Non-uniform Reinforcement}

Cracking in concrete structures is inevitable and in the areas where concrete cracks, reinforcement is provided to control crack width and crack spacing. In section 5.5, it was concluded that by increase of reinforcement ratio from $0.5 \%$ to $1 \%$, cracks develop up to 0.2 heights. Keeping the same amount of reinforcement ratio in the areas where concrete does not crack may not be economical. As the next step in this study, the reinforcement ratio was reduced from the base to the top and the response of the tanks to the nonuniform distribution of the reinforcement was investigated. 
Figure 5.5 presents the profile of non-uniform distribution of reinforcement in the tanks.

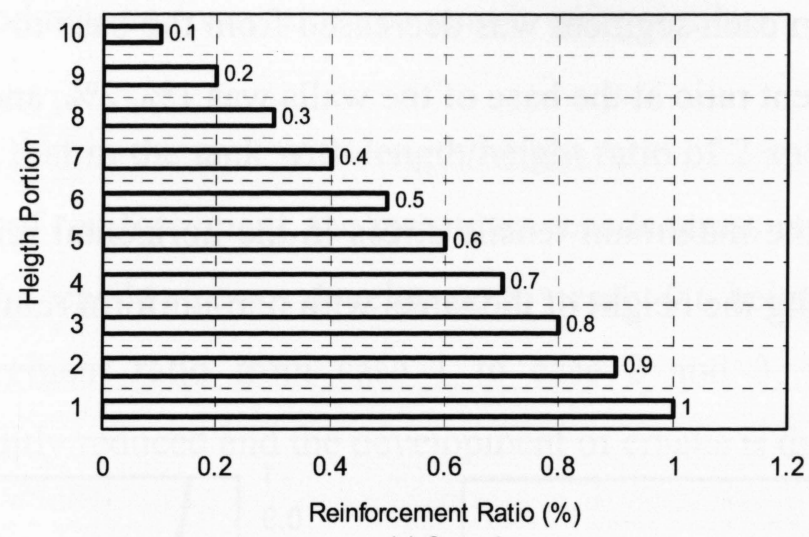

(a) Case 1
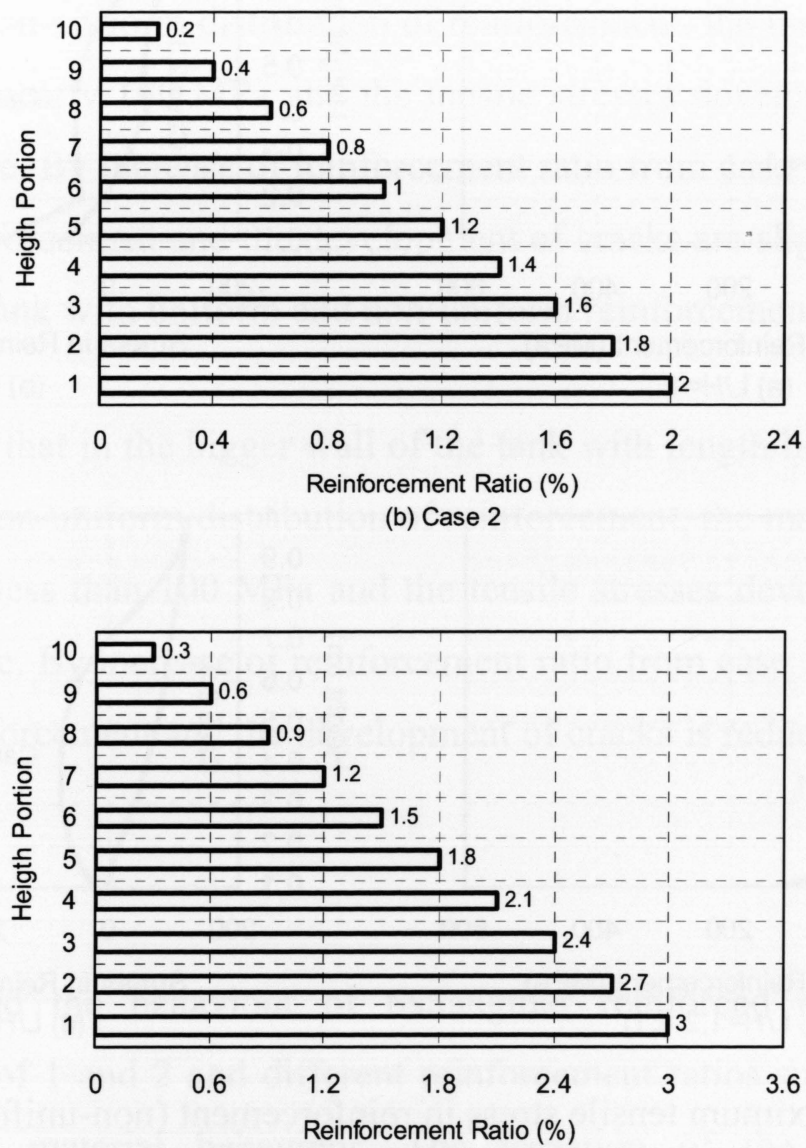

(c) Case 3

Figure 5.5- Non-uniform distribution of reinforcement 
In this analysis, three cases of non-uniform distribution of reinforcement were considered. In all cases, the height of the walls was divided into 10 segments and the reinforcement ratio in each segment was decreased from the base to the top. In case 1, 2, and 3 the reinforcement ratio at the base of the walls was $1 \%, 2 \%$, and $3 \%$, respectively.

Figure 5.6 presents the maximum tensile stress in the horizontal reinforcing bars in the vicinity of cracks along the height of the tanks with non-uniform reinforcement.

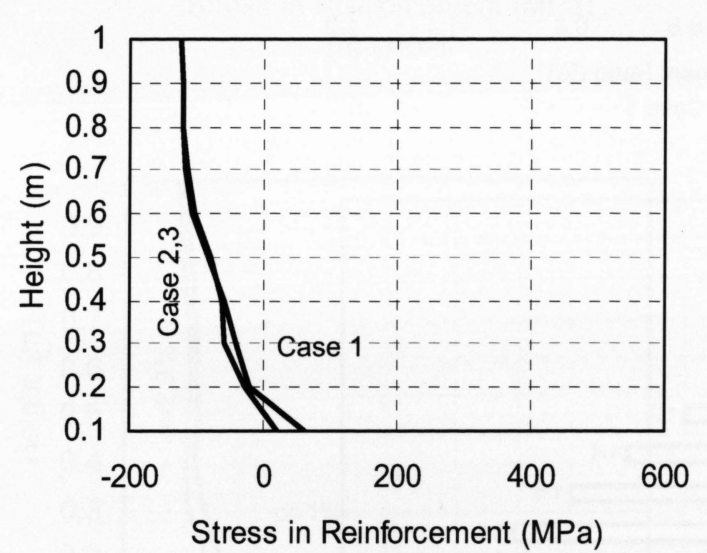

(a) $\mathrm{L} / \mathrm{H}=1$

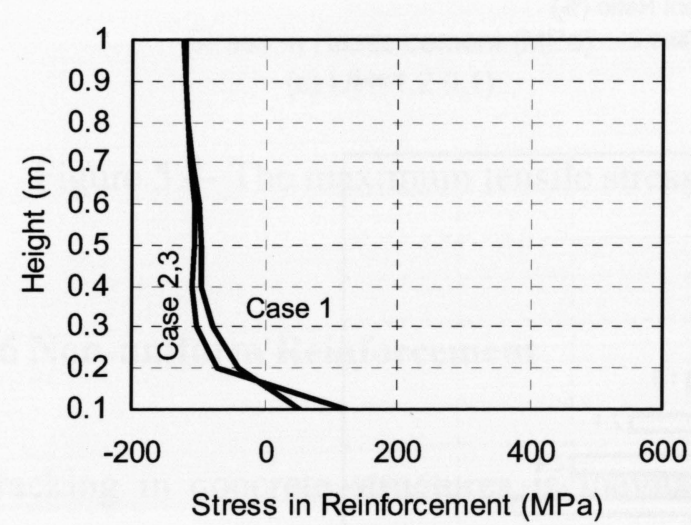

(c) $\mathrm{L} / \mathrm{H}=1,2$ (L1)

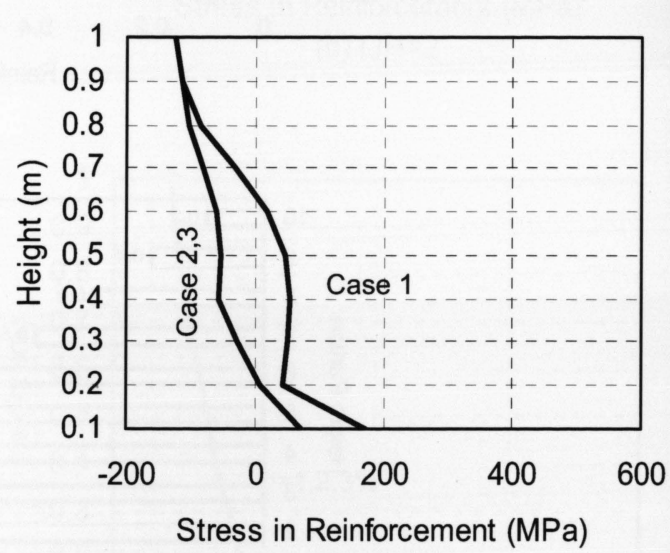

(b) $\mathrm{L} / \mathrm{H}=2$

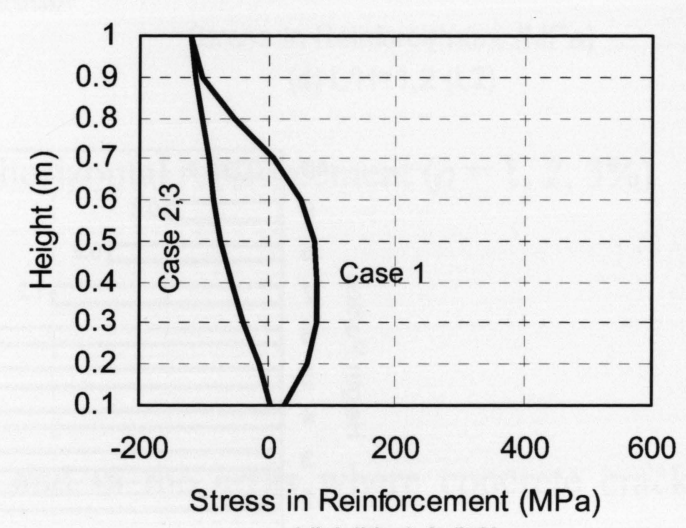

(d) $\mathrm{L} / \mathrm{H}=1,2$ (L2)

Figure 5.6- The maximum tensile stress in reinforcement (non-uniform reinforcement)

As seen in Figure 5.6(a), in the tank with length/height ratio of 1 and with case 1 of nonuniform distribution of reinforcement, the maximum tensile stress in reinforcement is less than $100 \mathrm{MPa}$ and the tensile stresses develop up to less than 0.2 heights from the base. 
By increase of reinforcement ratio from case 1 to case 2 and 3, the tensile stress in reinforcement and the development of cracks are slightly reduced. The response of the tank with uniform and non-uniform reinforcement is quite similar.

Figure 5.6(b) shows that in the tank with length/height ratio of 2 and with case 1 of nonuniform distribution of reinforcement, the maximum tensile stress in reinforcement is less than $200 \mathrm{MPa}$ and the tensile stresses develop up to nearly 0.6 heights from the base. By increase of reinforcement ratio from case 1 to case 2 and 3 , the tensile stress in reinforcement is slightly reduced and the development of cracks is dropt to 0.2 heights.

As seen in Figure 5.6(c), in the smaller wall of the tank with length/height ratio of 1 and 2 and with case 1 of non-uniform distribution of reinforcement, the maximum tensile stress in reinforcement is nearly $100 \mathrm{MPa}$ and the tensile stresses develop up to less than 0.2 heights from the base. By increase of reinforcement ratio from case 1 to case 2 and 3 , the tensile stress in reinforcement and the development of cracks are slightly reduced. Again, the response of the tank with uniform and non-uniform reinforcement is quite similar.

Figure 5.6(d) shows that in the bigger wall of the tank with length/height ratio of 1 and 2 and with case 1 of non-uniform distribution of reinforcement, the maximum tensile stress in reinforcement is less than $100 \mathrm{MPa}$ and the tensile stresses develop up to nearly 0.7 heights from the base. By increase of reinforcement ratio from case 1 to case 2 and 3 , the tensile stress in reinforcement and the development of cracks is reduced.

\subsection{Summary}

This chapter studied the behaviour of rectangular reinforced concrete tanks with length/height ratios of 1 and 2 and different reinforcement ratios subjected to shrinkage assuming nonlinear material behaviour. The variation of the tensile stresses in reinforcement in the vicinity of cracks was investigated.

The highest value of the shrinkage and temperature reinforcement ratio recommended by Standard Requirements for Environmental Engineering Concrete Structures, ACI 350R- 
06 , is $0.5 \%{ }^{[4]}$. It was found that in the tank with length/height ratio of 2 and having $0.5 \%$ reinforcement ratio, the tensile stress in reinforcement reaches to nearly $300 \mathrm{MPa}$ which may cause serviceability problems. However, in the other cases, the maximum tensile stress in reinforcement is less than $200 \mathrm{MPa}$. By increase of reinforcement ratio to $1 \%$, the maximum tensile stress in reinforcement and the development of cracks are considerably reduced.

The effect of non-uniform distribution of reinforcement was investigated. It was found that in all cases the maximum tensile stress in reinforcement is quite small which suggests that non-uniform distribution of reinforcement is desired. 


\section{CHAPTER 6}

\section{DESIGN CRITERIA}

\subsection{Introduction}

This chapter reviews design requirements of shrinkage and temperature reinforcement recommended in major concrete standards and codes of practice. This study considers provisions recommended for environmental engineering concrete structures where cracking of concrete is more critical. This review includes "Design of Concrete Structures", CSA A23.3-04 (Canada), "Standard Requirements for Environmental Engineering Concrete Structures", ACI 350-06 (US), "Code of Practice for Design of Concrete Structures for Retaining Aqueous Liquids", BS 8007: 1987 (UK), "Eurocode 2, Design of Concrete Structures, General Rules and Rules for Buildings", EN 1992-1-1 (EU), and "Code of Practice for Concrete Structures for the Storage of Liquids", NZS 3106: 1986 (New Zeeland).

\subsection{CSA A23.3-04}

The Canadian Standards on Design of Concrete Structures (CSA A23.3-04) recommends a minimum reinforcement ratio for shrinkage and temperature effect in walls and slabs as given by

$\rho=0.002$

Where, $\rho$ is the ratio of reinforcement area to gross concrete area.

Shrinkage and temperature reinforcement shall be provided in each direction and shall not be spaced farther apart than the smaller of five times the slab thickness or $500 \mathrm{~mm}$.

The Code, recommends that for exposure conditions where crack control is essential, reinforcement exceeding that required by Eq. 6.1 shall be provided. However, it does not mention how to calculate the required reinforcement. 


\subsection{ACI 350-06}

Standard Requirements for Environmental Engineering Concrete Structures (ACI 350-06) recommends a minimum reinforcement ratio for shrinkage and temperature effect for members subjected to environmental exposure conditions or required to be liquid-tight. The minimum shrinkage and temperature reinforcement ratio shall be provided according to Table 6.1.

Table 6.1- Minimum shrinkage and temperature reinforcement ratio

\begin{tabular}{|c|c|c|}
\hline \multirow{2}{*}{$\begin{array}{c}\text { Length between } \\
\text { movement joints, } \mathrm{ft}\end{array}$} & \multicolumn{2}{|c|}{$\begin{array}{c}\text { Minimum shrinkage and } \\
\text { temperature reinforcement ratio }\end{array}$} \\
\cline { 2 - 3 } & Steel Grade 40 & Steel Grade 60 \\
\hline Less than 20 & 0.003 & 0.003 \\
\hline 20 to less than 30 & 0.004 & 0.003 \\
\hline 30 to less than 40 & 0.005 & 0.004 \\
\hline 40 and greater & 0.006 & 0.005 \\
\hline
\end{tabular}

In members without movement joints, the maximum shrinkage and temperature reinforcement indicated in the Table shall be provided. This Table applies to spacing between expansion joints or full contraction joints. When partial contraction joints are used in a member, the minimum reinforcement ratio shall be determined by multiplying the actual length between partial contraction joints by 1.5 .

Concrete sections that are at least $24 \mathrm{in.} \mathrm{thick} \mathrm{may} \mathrm{have} \mathrm{the} \mathrm{minimum} \mathrm{shrinkage} \mathrm{and} \mathrm{temperature}$ reinforcement based on a 12 in. concrete thickness at each face. At least $1 / 3$ of the required area of shrinkage and temperature reinforcement shall be distributed at any one face. The reinforcement in the bottom of base slabs in contact with soil may be reduced to 50 percent of that required in Table 6.1. Shrinkage and temperature reinforcement shall not be spaced farther apart than 12 in. with the minimum bar size of No. 4. 
The minimum shrinkage and temperature reinforcement ratio recommended by the ACI Code is empirical and has been satisfactory where shrinkage and temperature movements are permitted to occur. The code recommends that for members where shrinkage and temperature movements are significantly restrained, it may be necessary to increase the reinforcement ratio. However, it does not mention how to calculate the required reinforcement.

$\mathrm{ACI}$ Committee 350 is currently revising the requirements for the shrinkage and temperature reinforcement in members subjected to environmental exposure conditions or required to be liquid-tight. In a proposed draft, the effect of degree of restraint has been included in the design of shrinkage and temperature reinforcement. In this revision, three levels of restraint are considered in a concrete member:

1. Reduced Restraint

2. Normal Restraint

3. Maximum Restraint

Reduced restraint includes membrane slab-on-grade construction with positive means of separation from a smooth and stable sub-grade or mud mat. Reduced restraint also applies to the horizontal reinforcement in walls initially separated from (and without dowels directly into) the footing or base slab.

In a reduced restraint zone, the minimum shrinkage and temperature reinforcement ratio is determined from

$\rho=0.005-\frac{0.002\left(13-8 d_{b}\right)}{s-3}$

Where, $\rho$ is the ratio of reinforcement area to gross concrete area, $d_{b}$ is the diameter of the bar or steel wire in inches, and $s$ is the spacing of reinforcing bars or wires in inches.

Normal restraint includes conventional slab-on-grade construction (on backfill or gravel). Normal restraint also applies to the horizontal reinforcement in conventional wall, and suspended 
slab, construction away from the maximum restraint zones for these elements defined below Normal restraint may always be assumed for movement joint spacing of less than $20 \mathrm{ft}$.

In a normal restraint zone, the minimum shrinkage and temperature reinforcement ratio is determined from

$$
\rho=0.006-\frac{0.002\left(13-8 d_{b}\right)}{s-3}
$$

Where, $\rho$ is the ratio of reinforcement area to gross concrete area, $d_{b}$ is the diameter of the bar or steel wire in inches, and $s$ is the spacing of reinforcing bars or wires in inches.

Maximum restraint includes the first six feet above a horizontal construction joint, and the first six feet adjacent to a vertical construction joint (on the subsequently placed side of the joint). When suspended slabs are doweled into walls, the shrinkage and temperature reinforcement parallel to the wall shall be based on the maximum restraint ratio for the first half-bay, or $10 \mathrm{ft}$. of the slab, whichever is larger. Other portions of the slabs may be considered as normal restraint zone.

In a maximum restraint zone, the minimum shrinkage and temperature reinforcement ratio is determined from

$$
\rho=0.010-\frac{0.002\left(13-8 d_{b}\right)}{s-3}
$$

Where, $\rho$ is the ratio of reinforcement area to gross concrete area, $d_{b}$ is the diameter of the bar or steel wire in inches, and $s$ is the spacing of reinforcing bars or wires in inches.

Shrinkage and temperature reinforcement shall not be spaced farther apart than $12 \mathrm{in}$. and the minimum size of reinforcing bars shall be No. 4 . At least $1 / 3$ of the total required reinforcement area shall be distributed at any one face. 
Considering No. 4 reinforcing bars at 12 in. spacing, the minimum shrinkage and temperature reinforcement ratio in reduced, normal, and maximum restraint zone would be $0.003,0.004$, and 0.008 , respectively.

On the whole, the proposed revision offers higher minimum temperature and shrinkage reinforcement which is consistent with this study. Also, the proposed revision enables the nonuniform distribution of shrinkage and temperature reinforcement based on the change of restraint which is again consistent with this study.

The proposed revision specifies absolute value to identify different level of restraint within a concrete member. Instead, it is suggested that the length/height ratio of an element be specified. As indicated in ACI Committee Report 207.2R, the variation of restraint factor is dependent on the length/height ratio not the length of the member alone. This study also showed that the length/height ratio has considerable effect on the crack pattern and tensile stresses in reinforcement in a concrete member.

In addition, it is suggested that the fundamental definition of Reduced, Normal, and Maximum Restraint zones be clarified by figures to simplify the application of the requirements for design purposes. Since this study does not include the effect of bar size and bar spacing in shrinkage cracking, author cannot comment on theses parameters.

\subsection{BS 8007: 1987}

Code of Practice for Design of Concrete Structures for Retaining Aqueous Liquids (BS 8007: 1987) adopts three options for the design of shrinkage and temperature reinforcement. The Code applies provisions for movement joints and their spacing to allow for or restrains shrinkage and thermal contractions in walls and slabs and accordingly recommends the amount of reinforcement to control crack widths and crack spacing.

The three main options for the design of shrinkage and temperature reinforcement are as follows:

1. Design for full restraint 
In this case, no movement joints are provided within the wall or slab and crack widths and crack spacing are controlled by providing substantial amount of reinforcement in the form of small diameter bars at close spacing. The Code recommends a minimum reinforcement ratio as

$\rho=0.0064 \quad$ for steel grade 250

$\rho=0.0035$ for steel grade 460

Where, $\rho$ is the ratio of reinforcement area to gross concrete area.

\section{Design for partial restraint}

In this case, crack widths and crack spacing are controlled by providing movement joints and reinforcement. The movement joint spacing is such that some of the daily and seasonal movements in the mature wall or slab are accommodated at the joints. Therefore, the amount of movement to be accommodated at cracks is reduced. In the case of complete movement joint and partial movement joint, the joint spacing shall be less than $15 \mathrm{~m}$ and $7.5 \mathrm{~m}$, respectively. Again, the Code recommends a minimum reinforcement ratio as in Equation 6.5.

\section{Design for freedom of movement}

In this case, closely spaced movement joints are provided within the wall or slab in conjunction with a moderate proportion of reinforcement. The reinforcement should be sufficient to transmit movement at any cracked section to the adjacent movement joints and significant cracking between movement joints should not occur. The Code recommends a minimum reinforcement ratio as

$\rho=0.0043 \quad$ for steel grade 250

$\rho=0.0023$ for steel grade 460

Where, $\rho$ is the ratio of reinforcement area to gross concrete area. 


\subsection{BS EN 1992-1-1: 2004}

Eurocode 2, Design of Concrete Structures, General Rules and Rules for Buildings (BS EN 1992-1-1: 2004) recommends a minimum reinforcement ratio for shrinkage and temperature effect in walls and slabs as in Equation 6.7.

$$
\rho=k_{c} k \frac{f_{c t, e f f}}{\sigma_{s}}
$$

Where,

$\rho$ is the ratio of reinforcement area to gross concrete area

$k_{c}$ is a coefficient taking account of the form of the loading

$k$ is a coefficient taking account of the possible presence of non-linear stress distributions

$f_{c t, e f f}$ is the mean value of the tensile strength of the concrete effective at the time when the first crack form

$\sigma_{s}$ is the steel stress.

The code offers a table to determine the value of $f_{c t, e f f}$. The stress in steel can generally be taken as the specified yield strength of the steel. However, there are cases where it may be more convenient to use lower values.

The value of $k_{c}$ is 1.0 and 0.4 for pure tension and pure flexure in rectangular reinforced concrete sections, respectively. The value of $k_{c}$ can be reduced if there is a compressive force applied to the section and similarly can be increased where there is an applied tension.

The factor $k$ includes the effect of internal self equilibrating stresses. In cases where concrete is restrained the deformation of the surface concrete is restrained by the interior concrete and higher tensions will be developed near the surface. In the design of shrinkage and temperature reinforcement, $k$ should be taken as 1.0 and 0.65 for members less than $300 \mathrm{~mm}$ deep and greater than $800 \mathrm{~mm}$ deep, respectively. The intermediate values may be interpolated. 


\subsection{NZS 3106: 1986}

Code of Practice for Concrete Structures for the Storage of Liquids (NZS 3106: 1986) recommends a minimum shrinkage and temperature reinforcement ratio using deformed bars in those parts of the structure not restrained from movement as

$\rho=0.0025$

Where, $\rho$ is the ratio of reinforcement area to gross concrete area.

The shrinkage and temperature reinforcement shall be provided in each of two directions at right angles. In concrete sections with thickness of $200 \mathrm{~mm}$ or greater, the reinforcement shall be distributed between two layers with at least $1 / 3$ of the required area at any one face.

The Code recommends that for those parts of the structure partially restrained against shrinkage, the minimum shrinkage and temperature reinforcement ratio shall be determined based on the rational analysis of the degree of restraint to shrinkage. In such cases, the stress in reinforcement shall not exceed $150 \mathrm{MPa}$.

\subsection{Summary}

This chapter studied design requirements of shrinkage and temperature reinforcement for environmental engineering structures recommended in major concrete standards and codes of practise. In general, concrete standards and codes of practice recommend $0.2 \%$ to $0.6 \%$ shrinkage and temperature reinforcement ratio for walls and slabs for severe exposure conditions.

The new versions of the concrete codes include the effect of the degree of restraint in the design of shrinkage and temperature reinforcement. This approach increases the amount of reinforcement in the area where a concrete member is significantly restrained. In addition, it enables the non-uniform distribution of reinforcement which is desired from the economic point of view. 


\section{CHAPTER 7}

\section{CONCLUSION AND FUTURE WORK}

\subsection{Concluding Remarks}

1. The horizontal degree of restraint on the centerline of uncracked walls varies considerably by the length/height ratio of walls. Along any restrained edge, the horizontal degree of restraint is to the maximum value 1.0 .

2. In fixed base uncracked concrete walls, the horizontal degree of restraint at the top free edge is 0.0 in the walls with length/height ratio of 1 and 2, 0.8 in the wall with length/height ratio of 5 , and 1.0 in the walls with length/height ratio of 10 and 20.

3. In fixed base and top uncracked concrete walls, the horizontal degree of restraint at the mid height is 0.0 and 0.6 in the walls with length/height ratio of 1 and 2, respectively. In the walls with length/height ratio of 5,10, and 20 the horizontal degree of restraint remains constant 1.0 from the base to the top.

4. In fixed base and ends uncracked concrete walls, the horizontal degree of restraint at the top free edge is 0.4 and 0.7 in the walls with length/height ratio of 1 and 2, respectively. In the walls with length/height ratio of 5,10 , and 20 the horizontal degree of restraint remains constant 1.0 from the base to the top.

5. A new equation to calculate the degree of restraint caused by reinforcement in uncracked concrete was derived. It was found that by providing $0.5 \%$ reinforcement ratio, the degree of restraint caused by reinforcement is 0.03 .

6. Linear analysis shows that in restrained shrinkage of concrete walls reinforcement is always in compression. However, nonlinear analysis enables to present the development of tensile stresses in reinforcement in the vicinity of cracks by removing cracked concrete elements from calculation and transferring tensile stresses to reinforcement. 
7. Comparing the smeared cracking model with the brittle cracking model available in ABAQUS, it was found that the brittle cracking model simulates more accurately the behaviour of reinforced concrete walls subjected to restrained shrinkage.

8. In fixed base concrete walls, by providing $0.5 \%$ reinforcement ratio and applying $600 \times 10^{-6}$ $\mathrm{mm} / \mathrm{mm}$ shrinkage strain, cracks develop to 0.5 and 0.8 heights in the walls with length/height ratio of 1 and 2, respectively. However, in the walls with length/height ratio of 5,10 , and 20 full height cracks are observed and cracks are wider at the top free edge. The tensile stress in reinforcement in the vicinity of cracks reaches to $50 \mathrm{MPa}$ and $300 \mathrm{MPa}$ in the walls with length/height ratio of 1 and 2, respectively. However, in the walls with length/height ratio of 5, 10, and 20 almost all the reinforcement yields.

9. In fixed base concrete walls by increase of reinforcement ratio to $1 \%$ with uniform distribution, cracking is not observed in the walls with length/height ratio of 1 and 2 . In addition, in the walls with length/height ratio of 5, 10, and 20 the development of full height cracks is prevented and tensile stresses in reinforcement in the vicinity of cracks are quite small.

10. Non-uniform distribution of reinforcement with a gradual decrease from the base to the top is not desired in the fixed base concrete walls with length/height ratio of 5, 10, and 20. In such cases, even by providing $3 \%$ reinforcement ratio near the restrained edge, full height cracks develop and reinforcement near the top free edge yields. However, cracking is not observed in the walls with length/height ratio of 1 and 2.

11. In concrete tanks, by providing $0.5 \%$ reinforcement ratio and applying $600 \times 10^{-6} \mathrm{~mm} / \mathrm{mm}$ shrinkage strain, cracks develop to 0.4 and 0.75 heights in the tanks with length/height ratio of 1 and 2, respectively. Also, the tensile stress in reinforcement in the vicinity of cracks reaches to $100 \mathrm{MPa}$ and $300 \mathrm{MPa}$ in the tanks with length/height ratio of 1 and 2, respectively. The tensile stresses in reinforcement in the vicinity of cracks in tanks are slightly higher than that in fixed base walls with the same length/height ratio. 
12. In concrete tanks with length/height ratio of 1 and 2 , by increase of reinforcement ratio to $1 \%$, tensile stresses in reinforcement are dramatically reduced to less than $150 \mathrm{MPa}$ and cracks develop to less than 0.2 heights.

13. The response of concrete tanks with length/height ratio of 1 and 2 and with uniform and nonuniform reinforcement is quite similar. The tensile stresses in reinforcement in the vicinity of cracks are quite small. Therefore, Non-uniform distribution of reinforcement with a gradual decrease from the base to the top in such tanks is desired.

14. From structural point of view, design of walls with the lowest possible length/height ratio is preferred. In this case the non-uniform distribution of reinforcement can considerably reduce the amount of reinforcement used in the construction of the walls.

15. On the proposed revisions to the requirements of shrinkage and temperature reinforcement in ACI 350-06 the following comments and recommendations are made:

- In general, higher shrinkage and temperature reinforcement has been offered which is consistent with this study.

- Non-uniform distribution of shrinkage and temperature reinforcement has been suggested which is again consistent with the results of this study.

- Instead of specifying values for wall lengths, it would be more appropriate to use the length/height ratios $(\mathrm{L} / \mathrm{H})$. As indicated in ACI Committee Report 207.2R, the restraint factors depend on $\mathrm{L} / \mathrm{H}$ and not on the length of the wall alone. This study also showed that the $\mathrm{L} / \mathrm{H}$ approach is more appropriate.

\subsection{Future Works}

1. In this study, one amount of shrinkage strain was applied whereas the final shrinkage strain in a concrete structure varies with the ambient temperature. Different shrinkage strains should be examined to account for concreting in different climates. 
2. It was assumed that shrinkage strain is fixed through the concrete section. However, the shrinkage movement of a concrete surface is different than that of inside the concrete section. This induces additional stresses that should be considered.

3. Shrinkage of concrete varies with time. The tensile strength of concrete and the bond stress between concrete and steel develop with time, too. In addition, the rate of tensile strength gain of concrete is not as significant as its compressive strength. In order to avoid complexity in this study, the time dependant behaviour of concrete was ignored. However, in simulating the real response of the structure such time dependant characteristic of concrete should be included. 


\section{REFERENCES}

1. ACI Committee 207, ACI 207.2R-07, Report on Thermal and Volume Change Effects on Cracking of Mass Concrete, American Concrete Institute, 2007

2. ACI Committee 224, ACI 224R-01, Control of Cracking Concrete Structures, American Concrete Institute, 2001

3. ACI Committee 224, ACI 224.2R-92, Cracking of Concrete Members in Direct Tension, American Concrete Institute, 1992

4. ACI Committee 350, ACI 350-06, Standard Requirements for Environmental Engineering Concrete Structures, American Concrete Institute, 2006

5. Anchor, R. D., Hill, A. W., and Hughes, B. P., Handbook on BS 5337: 1976, Viewpoint Publication, 1979

6. Beeby, W. and Forth, J. P., Control of Cracking in Walls Restrained along Their Base against Early Thermal Movement, Thomas Telford Publishing, 2005

7. British-Adopted European Standard, BS EN 1992-1-1: 2004, Eurocode 2: Design of Concrete Structures, General Rules and Rules for Buildings, British Standards Institution, 2004

8. British Standards Institution, BS 8007:1987, Code of Practice for Design of Concrete Structures for Retaining Aqueous Liquids, British Standards Institution, 1987

9. Canadian Standards Association, CSA A23.3-04, Design of Concrete Structures, Canadian Standards Association, 2004

10. Carlson, R. W., "Drying Shrinkage of Large Concrete Members", ACI Journal, Proceedings, V. 33, No. 3, American Concrete Institute, 1937 
11. Deacon, R. C., Watertight Concrete Construction, Cement and Concrete Association, $2^{\text {nd }}$ Edition, 1978

12. Favre, R., et al, "Fissuration et Deformations", Manual du Comite Ewo-International du Beton (CEB), Ecole Polytechnique Federale de Lausanne, 1983

13. Gilbert, R.I., "Shrinkage Cracking in Fully Restrained Concrete Members", $A C I$ Structural Journal, V. 89, No. 2, American Concrete Institute, 1992

14. Harrison, T. A., "Early-age Thermal Crack Control in Concrete", CIRIA Report No. 91, Construction Industry Research and Information Association, 1981

15. Kheder, G. F., "A New Look at the Control of Volume Change Cracking of Base Restrained Concrete walls", ACI Structural Journal, V. 94, No. 3, American Concrete Institute, 1997

16. Murray, M. H., "Shrinkage Crack Control in AS3600", Transactions of the Institution of Engineers, Australia: Civil Engineering, V. CE33, No. 4, 1991

17. Schleech, W., "The Positive Strains in One-way Restrained Walls", Beton und Stahlbetonbau, V. 57, No. 3, 1962

18. Standards Association of New Zealand, NZS 3106: 1986, Code of Practice for Concrete Structures for the Storage of Liquids, Standards Association of New Zealand, 1986

19. Stoffers, H., "Cracking Due to Shrinkage and Temperature Variation in Walls", Heron, V. 23, No. 3, 1978

20. U.S. Bureau of Reclamation, "Control of Cracking in Mass Concrete Structures", Engineering Monograph, No. 34, U.S. Department of Interior, 1965 


\section{APPENDIX}

\section{A.1 Linear analysis of the fixed base wall with $\mathrm{L} / \mathrm{H}=1$}

*Heading

** Job name: Job-1 Model name: Model-1

*Preprint, echo=NO, model $=\mathrm{NO}$, history $=\mathrm{NO}$, contact $=\mathrm{NO}$

$\star \star$

* PARTS

$\star \star$

$\star$ Part, name $=$ Part -1

*Node

$\begin{array}{rr}1, & 500 ., \\ 2, & 400 ., \\ 3, & 300 ., \\ 4, & 200 ., \\ 5, & 100 ., \\ 6, & 0 ., \\ 7, & -100 ., \\ 8, & -200 ., \\ 9, & -300 ., \\ 10, & -400 ., \\ 11, & -500 ., \\ 12, & 500 ., \\ 13, & 400 ., \\ 14, & 300 ., \\ 15, & 200 ., \\ 16, & 100 ., \\ 17, & 0 ., \\ 18, & -100 .,\end{array}$

18,

$-100 .$,

19 ,

$-200$.

$-300$.

-400 .

$-500 .$,

500 .,

400 .,

300 .,

200 .,

100 .

$0 .$,

$-100 .$,

$-200 .$,

$-300 .$,

$-400 .$,

$-500 .$,

500 .,

400 .,

300 .,

200 .,

100 .

$0 .$,

39 ,

40 ,

41 ,

$-100$.

$-200 .$,

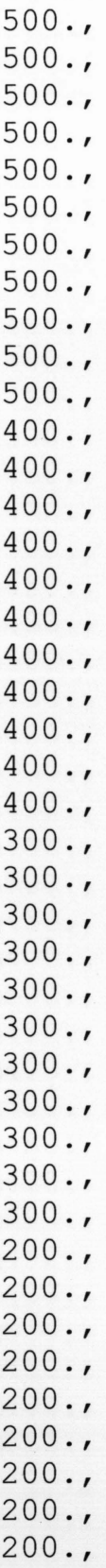

0 .

0 .

0.

0 .

0 .

0 .

0 .

0 .

0 .

0 .

0 .

0 .

0 .

0 .

0 .

0 .

0 .

0 .

0 .

0 .

0 .

0 .

0 .

0 .

0 .

0 .

0 .

0 .

0 .

0 .

0 .

0 .

0 .

0 .

0 .

0 .

0 .

0 .

0 .

42 ,

-300 .,

0 . 


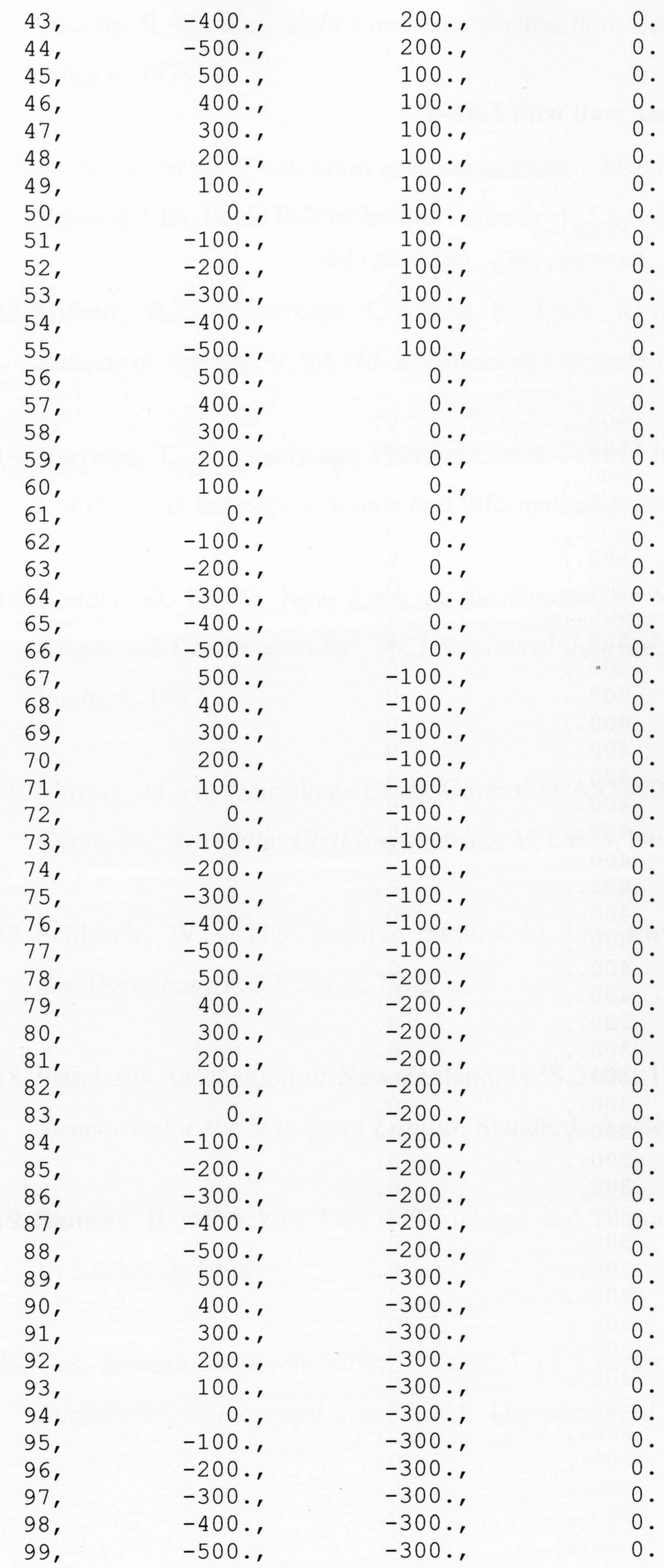




\begin{tabular}{|c|c|c|c|}
\hline 100, & 500. & -400. & 0 . \\
\hline 101, & $400 .$, & $-400 .$, & 0 . \\
\hline 102, & 300. & $-400 .$, & 0 . \\
\hline 103, & 200. & -400. & 0 . \\
\hline 104, & $100 .$, & -400. & 0 . \\
\hline 105, & 0. & -400. & 0 . \\
\hline 106, & -100. & $-400 .$, & 0 . \\
\hline 107, & -200. & -400. & 0 . \\
\hline 108, & -300. & -400. & 0 . \\
\hline 109, & $-400 .$, & $-400 .$, & 0 . \\
\hline 110, & -500. & $-400 .$, & 0 . \\
\hline 111, & 500 & -500. & 0 . \\
\hline 112, & 400. & -500. & 0 . \\
\hline 113, & 300. & -500. & 0 . \\
\hline 114, & 200. & -500. & 0 . \\
\hline 115, & 100. & -500. & 0 . \\
\hline 116, & 0. & -500. & 0 . \\
\hline 117, & -100. & -500. & 0 . \\
\hline 118, & -200. & -500. & 0 . \\
\hline 119, & -300. & -500. & 0 . \\
\hline 120, & -400. & -500. & 0 . \\
\hline 121, & -500. & -500. & 0 . \\
\hline 122, & 450. & 500. & 0 . \\
\hline 123, & 400. & 450. & 0 . \\
\hline 124, & 450. & $400 .$, & 0 . \\
\hline 125, & $500 .$, & $450 .$, & 0 . \\
\hline 126, & $350 .$, & $500 .$, & 0 . \\
\hline 127, & $300 .$, & $450 .$, & 0 . \\
\hline 128, & $350 .$, & $400 .$, & 0 . \\
\hline 129, & $250 .$, & $500 .$, & 0 . \\
\hline 130, & $200 .$, & $450 .$, & 0 . \\
\hline 131, & $250 .$, & $400 .$, & 0 . \\
\hline 132, & $150 .$, & $500 .$, & 0 . \\
\hline 133, & $100 .$, & $450 .$, & 0 . \\
\hline 134, & $150 .$, & $400 .$, & 0 . \\
\hline 135, & 50. & $500 .$, & 0 . \\
\hline 136, & 0. & 450. & 0 . \\
\hline 137, & 50. & 400. & 0 . \\
\hline 138, & -50 & $500 .$, & 0 . \\
\hline 139, & -100. & $450 .$, & 0 . \\
\hline 140, & -50 & $400 .$, & 0 . \\
\hline 141, & -150. & $500 .$, & 0 . \\
\hline 142, & -200 & $450 .$, & 0 . \\
\hline 143， & -150. & $400 .$, & 0 . \\
\hline 144, & -250. & $500 .$, & 0 . \\
\hline 145, & -300. & $450 .$, & 0 . \\
\hline 146, & -250. & $400 .$, & 0 . \\
\hline 147, & $-350 .$, & $500 .$, & 0 . \\
\hline 148, & $-400 .$, & $450 .$, & 0 . \\
\hline 149, & -350. & $400 .$, & 0 . \\
\hline 150, & -450. & $500 .$, & 0 . \\
\hline 151, & $-500 .$, & $450 .$, & 0 . \\
\hline 152, & $-450 .$, & $400 .$, & 0 . \\
\hline 153, & 400 & $350 .$, & 0 . \\
\hline 154, & $450 .$, & $300 .$, & 0 . \\
\hline 155, & $500 .$, & 350. & 0 . \\
\hline 156, & $300 .$, & $350 .$, & 0 . \\
\hline
\end{tabular}




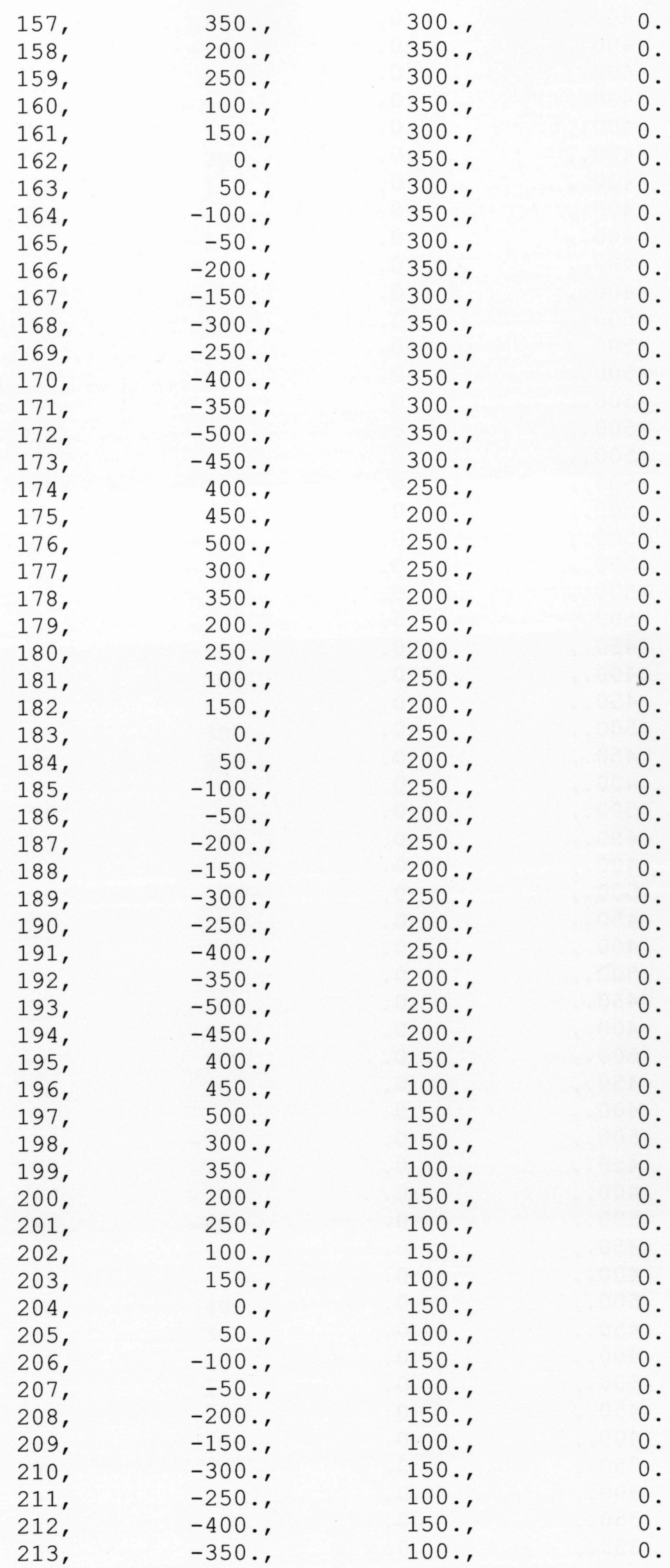

93 


\begin{tabular}{|c|c|c|c|}
\hline $214 ，$ & -500. & $150 .$, & 0 . \\
\hline 215 & -450. & $100 .$, & 0 . \\
\hline 216, & 400. & 50. & 0 . \\
\hline 217, & 450. & $0 .$, & 0 . \\
\hline 218, & $500 .$, & $50 .$, & 0 . \\
\hline 219, & $300 .$, & $50 .$, & 0 . \\
\hline 220, & $350 .$, & $0 .$, & 0 . \\
\hline 221, & $200 .$, & $50 .$, & 0 . \\
\hline 222, & $250 .$, & $0 .$, & 0 . \\
\hline 223, & $100 .$, & $50 .$, & 0 . \\
\hline 224, & $150 .$, & $0 .$, & 0 . \\
\hline 225, & 0. & $50 .$, & 0 . \\
\hline 226, & 50. & $0 .$, & 0 . \\
\hline 227, & $-100 .$, & $50 .$, & 0 . \\
\hline 228, & -50. & $0 .$, & 0 . \\
\hline 229, & -200. & $50 .$, & 0 . \\
\hline 230, & $-150 .$, & $0 .$, & 0 . \\
\hline 231, & -300. & $50 .$, & 0 . \\
\hline 232, & $-250 .$, & $0 .$, & 0 . \\
\hline 233, & $-400 .$, & $50 .$, & 0 . \\
\hline 234, & $-350 .$, & $0 .$, & 0 . \\
\hline 235, & $-500 .$, & $50 .$, & 0 . \\
\hline 236, & $-450 .$, & 0. & 0 . \\
\hline 237, & 400 & -50. & 0 . \\
\hline 238, & 450. & -100. & 0 . \\
\hline 239, & 500. & -50. & 0 . \\
\hline 240, & 300. & -50. & 0 . \\
\hline 241, & 350. & -100. & 0 . \\
\hline 242, & 200. & -50. & 0 . \\
\hline 243, & $250 .$, & $-100 .$, & 0 . \\
\hline 244, & $100 .$, & -50. & 0 . \\
\hline 245, & $150 .$, & -100. & 0 . \\
\hline 246, & 0. & -50. & 0 . \\
\hline 247, & 50. & -100. & 0 . \\
\hline 248, & $-100 .$, & -50. & 0 . \\
\hline 249, & -50. & -100. & 0 . \\
\hline 250, & -200. & -50. & 0 . \\
\hline 251, & $-150 .$, & -100. & 0 . \\
\hline 252, & -300. & -50. & 0 . \\
\hline 253, & -250. & -100. & 0 . \\
\hline 254, & -400. & -50. & 0 . \\
\hline 255, & $-350 .$, & -100. & 0 . \\
\hline 256, & $-500 .$, & -50. & 0 . \\
\hline 257, & $-450 .$, & -100. & 0 . \\
\hline 258, & 400 & -150. & 0 . \\
\hline 259, & 450. & -200. & 0 . \\
\hline 260 & 500 & -150. & 0 . \\
\hline 261, & $300 .$, & -150. & 0 . \\
\hline 262 & $350 .$, & -200. & 0 . \\
\hline 263, & $200 .$, & -150. & 0 . \\
\hline 264, & $250 .$, & -200. & 0 . \\
\hline 265, & $100 .$, & -150. & 0 . \\
\hline 266, & $150 .$, & -200. & 0 . \\
\hline 267, & 0. & -150. & 0 . \\
\hline 268, & 50. & -200. & 0 . \\
\hline 269, & $-100 .$, & -150. & 0 . \\
\hline 270 & -50. & -200. & 0 . \\
\hline
\end{tabular}




\begin{tabular}{|c|c|c|}
\hline 271, & -200. & -150. \\
\hline 272, & -150. & -200 \\
\hline 273, & -300. & $-150 .$, \\
\hline 274, & -250. & $-200 .$, \\
\hline 275, & -400. & $-150 .$, \\
\hline 276, & -350. & $-200 .$, \\
\hline 277, & -500. & $-150 .$, \\
\hline 278, & -450. & -200. \\
\hline 279, & 400 & -250. \\
\hline 280, & $450 .$, & -300. \\
\hline 281, & $500 .$, & $-250 .$, \\
\hline 282, & $300 .$, & $-250 .$, \\
\hline 283, & $350 .$, & $-300 .$, \\
\hline 284, & $200 .$, & -250. \\
\hline 285, & $250 .$, & $-300 .$, \\
\hline 286, & $100 .$, & -250. \\
\hline 287, & $150 .$, & $-300 .$, \\
\hline 288, & 0. & $-250 .$, \\
\hline 289, & 50. & $-300 .$, \\
\hline 290, & $-100 .$, & $-250 .$, \\
\hline 291, & -50. & $-300 \cdot$, \\
\hline 292, & -200. & -250. \\
\hline 293, & $-150 .$, & -300. \\
\hline 294, & -300. & $-250 .$, \\
\hline 295, & $-250 .$, & $-300 .$, \\
\hline 296, & -400. & -250. \\
\hline 297, & -350. & $-300 .$, \\
\hline 298, & $-500 .$, & $-250 .$, \\
\hline 299, & -450. & -300. \\
\hline 300, & 400. & $-350 .$, \\
\hline 301, & 450. & $-400 .$, \\
\hline 302 , & $500 .$, & $-350 .$, \\
\hline 303, & 300. & -350. \\
\hline 304, & $350 .$, & $-400 .$, \\
\hline 305, & 200. & $-350 .$, \\
\hline 306, & $250 .$, & $-400 .$, \\
\hline 307, & $100 .$, & $-350 .$, \\
\hline 308, & $150 .$, & $-400 .$, \\
\hline 309, & 0. & $-350 .$, \\
\hline 310, & 50. & $-400 .$, \\
\hline 311, & $-100 .$, & $-350 .$, \\
\hline 312, & $-50 .$, & $-400 .$, \\
\hline 313, & -200. & -350. \\
\hline 314, & -150. & -400. \\
\hline 315, & -300. & -350. \\
\hline 316, & -250 & $-400 .$, \\
\hline 317, & -400 & $-350 .$, \\
\hline 318, & -350. & $-400 .$, \\
\hline 319, & $-500 .$, & $-350 .$, \\
\hline 320, & $-450 .$, & $-400 .$, \\
\hline 321, & 400. & $-450 .$, \\
\hline 322, & 450. & $-500 .$, \\
\hline 323, & $500 .$, & $-450 .$, \\
\hline 324, & 300. & $-450 .$, \\
\hline 325, & $350 .$, & $-500 .$, \\
\hline 326, & 200. & -450. \\
\hline 327, & 250 & $-500 .$, \\
\hline
\end{tabular}




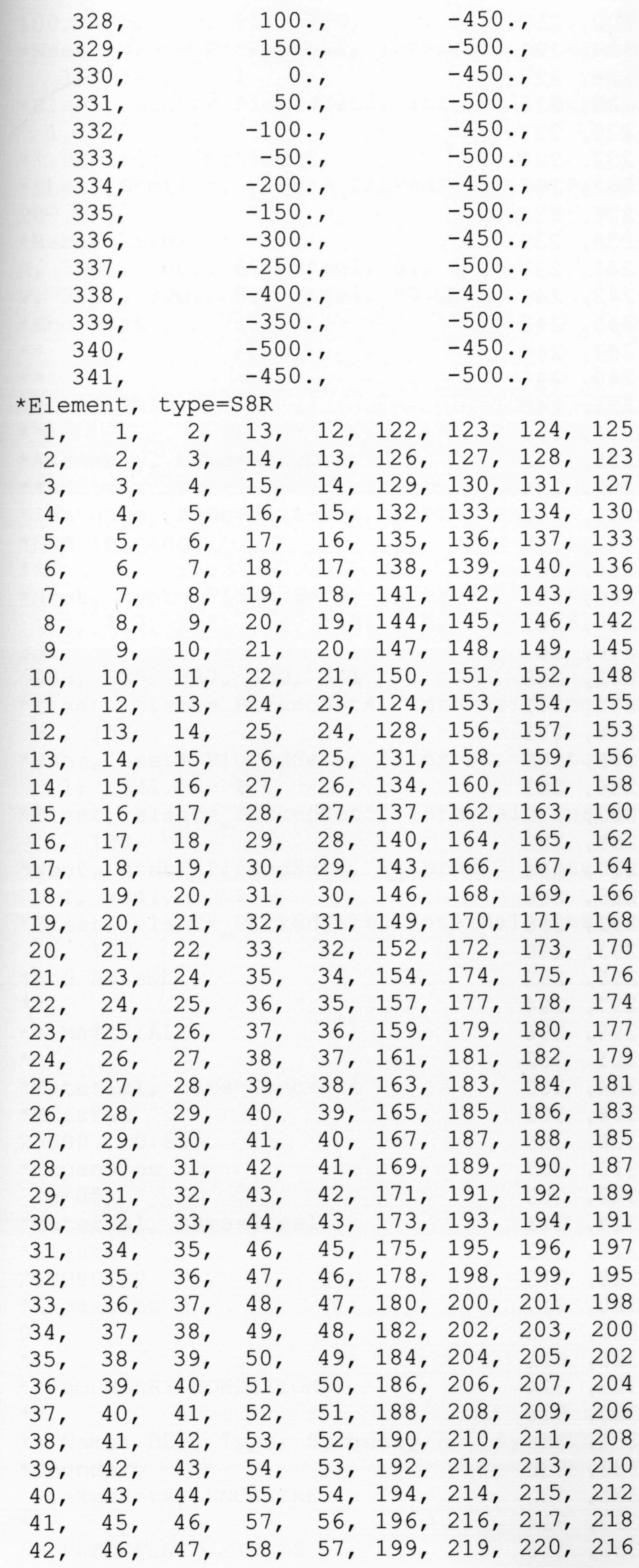


$43,47,48,59,58,201,221,222,219$

$44,48,49,60,59,203,223,224,221$

$45,49,50,61,60,205,225,226,223$

$46,50,51,62,61,207,227,228,225$

$47,51,52,63,62,209,229,230,227$

$48,52,53,64,63,211,231,232,229$

$49,53,54,65,64,213,233,234,231$

$50,54,55,66,65,215,235,236,233$

$51,56,57,68,67,217,237,238,239$

$52,57,58,69,68,220,240,241,237$

$53,58,59,70,69,222,242,243,240$

$54,59,60,71,70,224,244,245,242$

$55,60,61,72,71,226,246,247,244$

$56,61,62,73,72,228,248,249,246$

$57,62,63,74,73,230,250,251,248$

$58,63,64,75,74,232,252,253,250$

$59,64,65,76,75,234,254,255,252$

$60,65,66,77,76,236,256,257,254$

$61,67,68,79,78,238,258,259,260$

$62,68,69,80,79,241,261,262,258$

$63,69,70,81,80,243,263,264,261$

$64,70,71,82,81,245,265,266,263$

$65,71,72,83,82,247,267,268,265$

$66,72,73,84,83,249,269,270,267$

$67,73,74,85,84,251,271,272,269$

$68,74,75,86,85,253,273,274,271$

$69,75,76,87,86,255,275,276,273$

$70,76,77,88,87,257,277,278,275$

$71,78,79,90,89,259,279,280,281$

$72,79,80,91,90,262,282,283,279$

$73,80,81,92,91,264,284,285,282$

$74,81,82,93,92,266,286,287,284$

$75,82,83,94,93,268,288,289,286$

$76,83,84,95,94,270,290,291,288$

$77,84,85,96,95,272,292,293,290$

$78,85,86,97,96,274,294,295,292$

$79,86,87,98,97,276,296,297,294$

$80,87,88,99,98,278,298,299,296$

$81,89,90,101,100,280,300,301,302$

$82,90,91,102,101,283,303,304,300$

83, 91, 92, 103, 102, 285, 305, 306, 303

$84,92,93,104,103,287,307,308,305$

$85,93,94,105,104,289,309,310,307$

$86,94,95,106,105,291,311,312,309$

$87,95,96,107,106,293,313,314,311$

$88,96,97,108,107,295,315,316,313$

$89,97,98,109,108,297,317,318,315$

$90,98,99,110,109,299,319,320,317$

$91,100,101,112,111,301,321,322,323$

$92,101,102,113,112,304,324,325,321$

$93,102,103,114,113,306,326,327,324$

$94,103,104,115,114,308,328,329,326$

$95,104,105,116,115,310,330,331,328$

$96,105,106,117,116,312,332,333,330$

$97,106,107,118,117,314,334,335,332$

$98,107,108,119,118,316,336,337,334$

$99,108,109,120,119,318,338,339,336$ 
$100,109,110,121,120,320,340,341,338$

*Nset, nset $=$ PickedSet2, internal, generate $1,341,-1$

*Elset, elset=_PickedSet2, internal, generate

$1,100,1$

** Section: Section-1

*Shell Section, elset=_PickedSet2, material=Concrete

$200 ., 5$

*Rebar Layer

H, 300., 300., 0., Steel, 0., 1

V, 300., 300., 0., Steel, 90., 1

*End Part

$\star \star$

$\star \star$

$\star \star$ ASSEMBLY

$\star \star$

*Assembly, name $=$ Assembly

$\star \star$

*Instance, name=Part $-1-1$, part $=$ Part -1

*End Instance

$\star *$

*Nset, nset=_PickedSet4, internal, instance=Part-1-1

$111,112,1 \overline{1} 3,114,115,116,117,118,119,120,121,322,325,327,329$, 331

$333,335,337,339,341$

*Elset, elset=PickedSet4, internal, instance=Part-1-1, generate $91,100,1$

*Nset, nset=_PickedSet5, internal, instance=Part-1-1, generate $1,341,-1$

*Elset, elset=_PickedSet5, internal, instance=Part-1-1, generate $1,100,1$

*Nset, nset=_PickedSet6, internal, instance=Part-1-1, generate $1,341,-1$

*Elset, elset $=$ PickedSet6, internal, instance=Part-1-1, generate $1,100,1$

*End Assembly

$\star \star$

** MATERIALS

$\star \star$

*Material, name=Concrete

*Elastic

$25000 ., 0.15$

*Expansion $1 e-05$,

*Material, name=Steel

*Elastic

210000,0 .

*Expansion

$0 .$,

$\star \star$

** BOUNDARY CONDITIONS

$\star \star \star *$

** Name: BC-1 Type: Symmetry/Antisymmetry/Encastre

*Boundary

PickedSet4, ENCASTRE

$\bar{\star} \star$

$\star \star$ PREDEFINED FIELDS 
** Name: Predefined Field-1 Type: Temperature

*Initial Conditions, type=TEMPERATURE

PickedSet5, 60 .

$\star \star$

* STEP: Step-1

$\star \star$

* Step, name=Step-1

* Static

$1 ., 1 ., 1 e-05,1$.

$\star \star$

* PREDEFINED FIELDS

$\star \star$

** Name: Predefined Field-2 Type: Temperature

* Temperature

PickedSet 6,0 .

** OUTPUT REQUESTS

$\star \star$

* Restart, write, frequency $=0$

$\star \star$

** FIELD OUTPUT: F-Output-1

$\star \star$

*Output, field

*Element Output, directions=YES

$E, S$

*Element Output, rebar, directions=YES

$E, \quad S$

*Output, history, frequency $=0$

*End Step 


\section{A.2 Nonlinear analysis of the fixed base wall with $\mathrm{L} / \mathrm{H}=1$}

*Heading

** Job name: Job-1 Model name: Model-1

*Preprint, echo=NO, model=NO, history $=\mathrm{NO}$, contact $=\mathrm{NO}$

$\star \star$

** PARTS

$\star \star$

*Part, name=Part -1

$\star$ Node

\begin{tabular}{|c|c|c|c|}
\hline 1 , & 500. & -400 & 0 . \\
\hline 2, & -500. & -400. & 0 . \\
\hline 3, & -500. & -500. & 0 . \\
\hline 4, & 500 & -500. & 0 . \\
\hline 5 , & 500. & -300. & 0 . \\
\hline 6, & -500. & -300. & 0 . \\
\hline 7, & 500 & $-200 .$, & 0 . \\
\hline 8, & -500. & -200. & 0 . \\
\hline 9, & 500 & -100. & 0 . \\
\hline 10, & $-500 .$, & -100. & 0 . \\
\hline 11, & 500 & 0. & 0 . \\
\hline 12, & -500. & 0. & 0 . \\
\hline 13, & 500 & 100. & 0 . \\
\hline 14, & -500. & 100. & 0 . \\
\hline 15, & 500 & 200. & 0 . \\
\hline 16, & -500. & 200. & 0 . \\
\hline 17, & 500 & 300. & 0 . \\
\hline 18, & -500. & 300. & 0 . \\
\hline 19, & -500. & 400. & 0 . \\
\hline 20, & 500 & $400 .$, & 0 . \\
\hline 21, & 500 & $500 .$, & 0 . \\
\hline 22, & -500. & 500 & 0 . \\
\hline 23, & 450 & -400. & 0 . \\
\hline 24, & 400. & -400. & 0 . \\
\hline 25, & 350. & -400 & 0 . \\
\hline 26, & 300. & -400 & 0 . \\
\hline 27, & $250 .$, & -400. & 0 . \\
\hline 28, & $200 .$, & -400. & 0 . \\
\hline 29, & $150 .$, & -400. & 0 . \\
\hline 30, & $100 .$, & -400. & 0 . \\
\hline 31 , & 50. & $-400 .$, & 0 . \\
\hline 32, & 0. & $-400 .$, & 0 . \\
\hline 33, & $-50 .$, & $-400 .$, & 0 . \\
\hline 34, & $-100 .$, & $-400 .$, & 0 . \\
\hline 35, & $-150 .$, & $-400 .$, & 0 . \\
\hline 36, & $-200 .$, & $-400 .$, & 0. \\
\hline 37, & $-250 .$, & $-400 .$, & 0. \\
\hline 38, & -300. & $-400 .$, & 0. \\
\hline 39, & $-350 .$, & $-400 .$, & 0. \\
\hline 40， & $-400 .$, & $-400 .$, & 0. \\
\hline 41, & $-450 .$, & $-400 .$, & 0. \\
\hline 42, & -500. & -450. & 0. \\
\hline 43, & -450. & -500. & 0 . \\
\hline 44, & $-400 .$, & $-500 .$, & 0. \\
\hline 45, & -350. & $-500 .$, & 0. \\
\hline
\end{tabular}




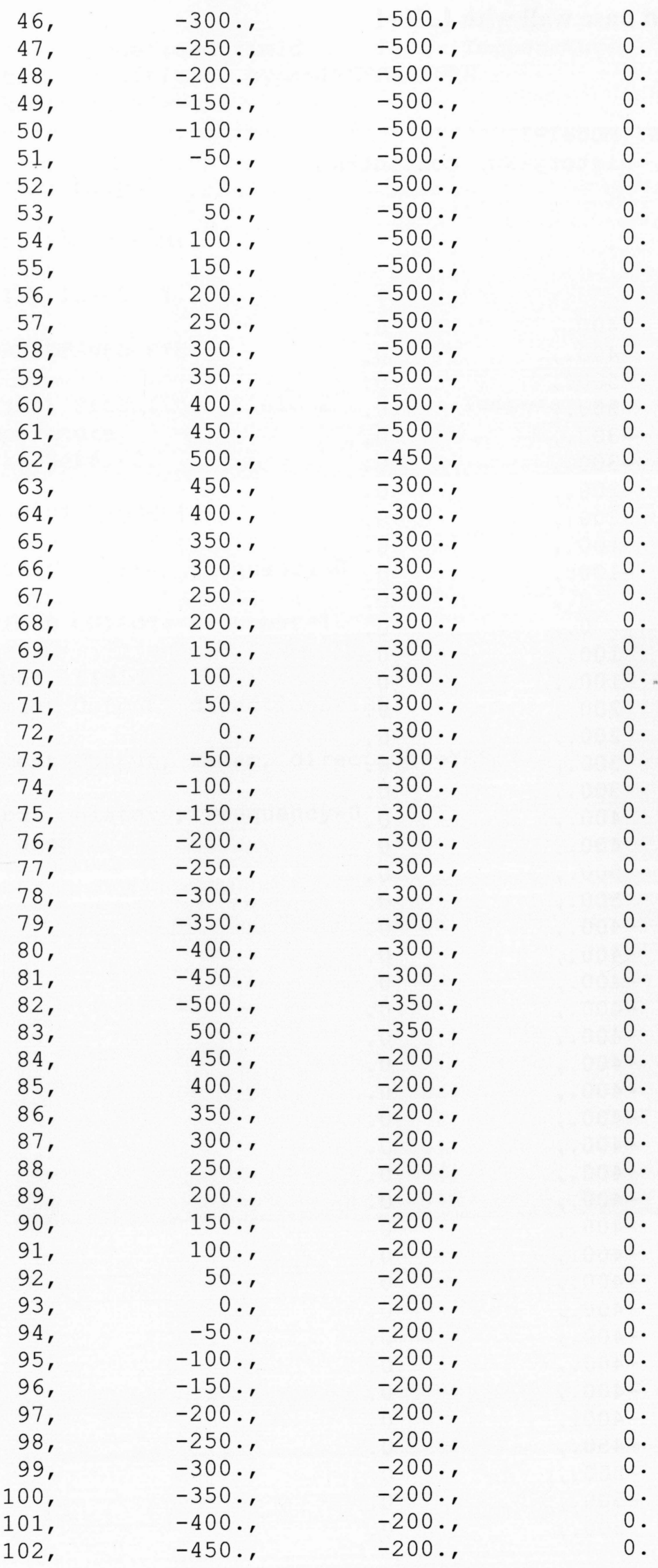




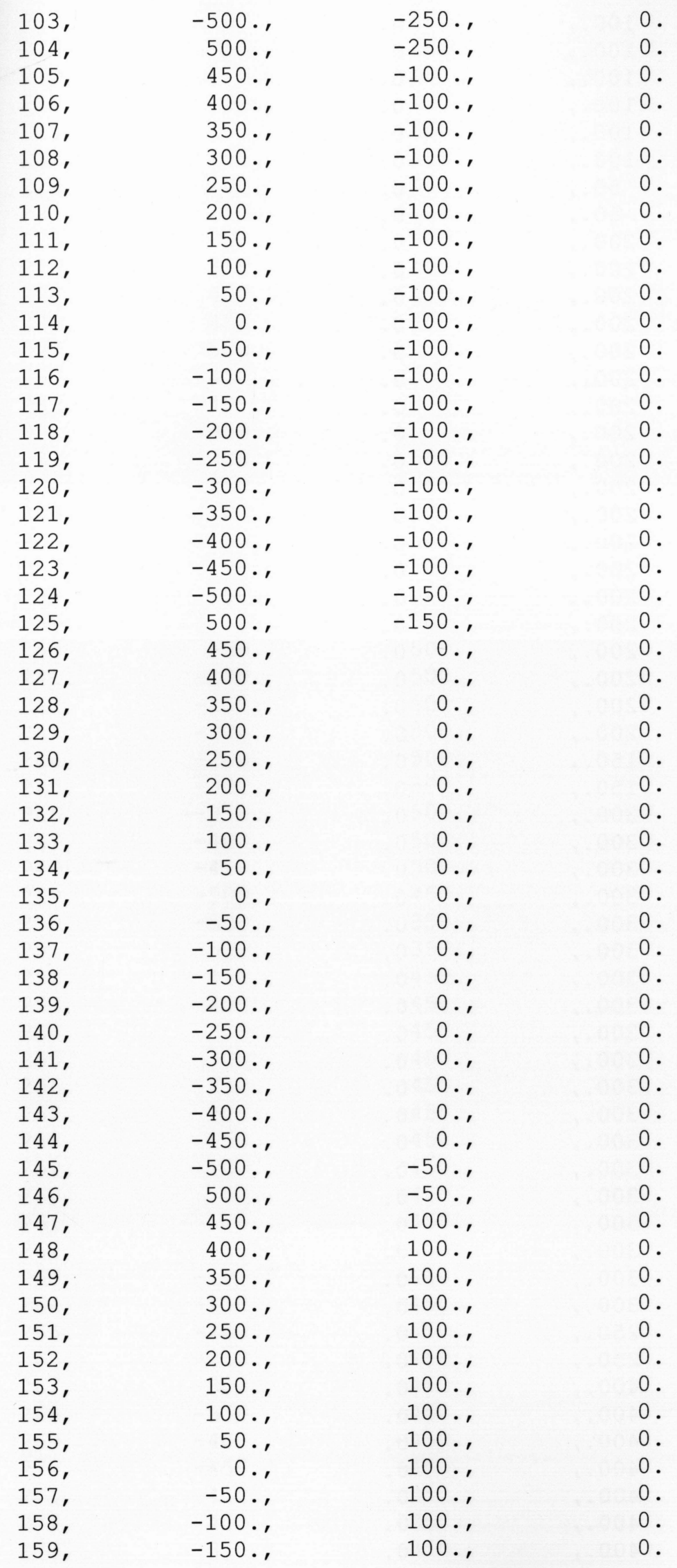




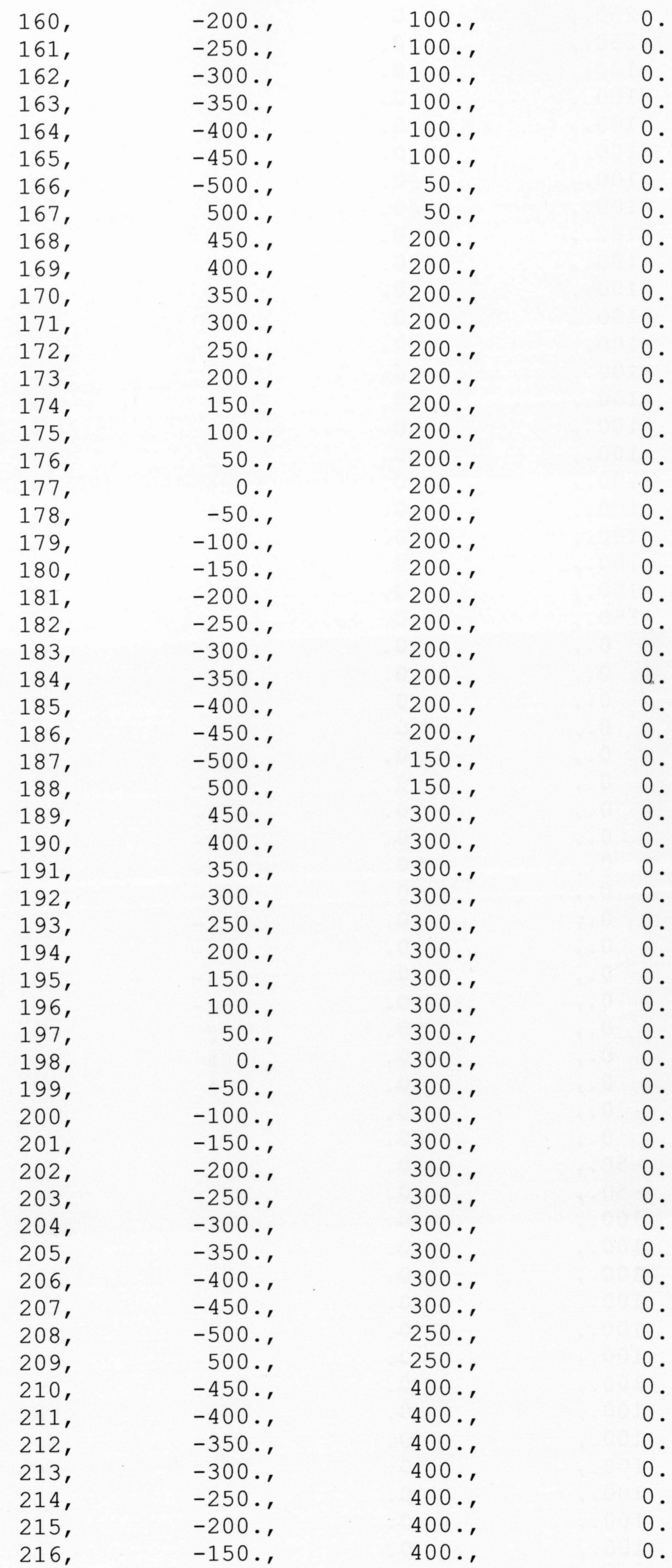




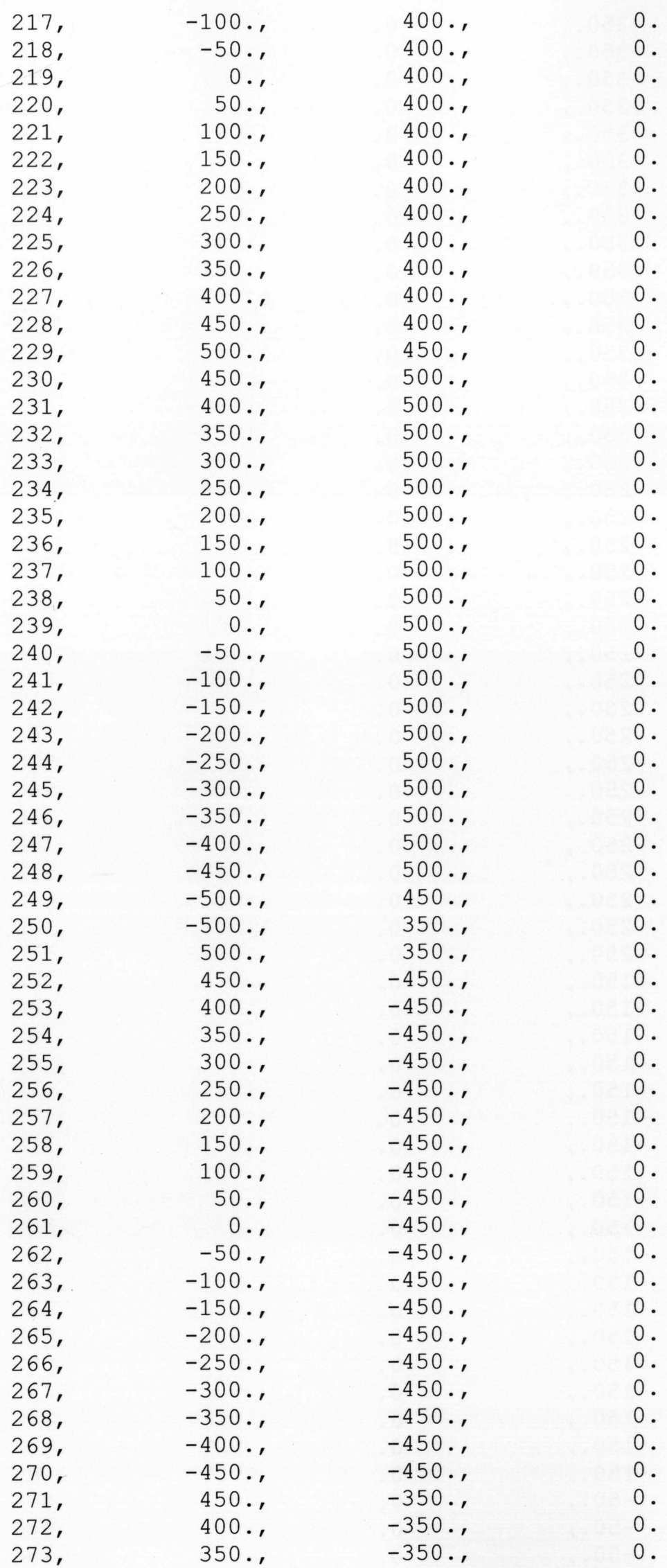




\begin{tabular}{|c|c|c|}
\hline 274, & $300 .$, & -350. \\
\hline 275, & 250. & $-350 .$, \\
\hline 276, & 200. & $-350 .$, \\
\hline 277, & $150 .$, & $-350 .$, \\
\hline 278, & $100 .$, & $-350 .$, \\
\hline 279, & 50. & $-350 .$, \\
\hline 280, & 0. & -350. \\
\hline 281, & -50. & $-350 .$, \\
\hline 282, & $-100 .$, & $-350 .$, \\
\hline 283, & $-150 .$, & $-350 .$, \\
\hline 284, & $-200 .$, & $-350 .$, \\
\hline 285, & $-250 .$, & $-350 .$, \\
\hline 286, & $-300 .$, & $-350 .$, \\
\hline 287, & $-350 .$, & $-350 .$, \\
\hline 288, & $-400 .$, & $-350 .$, \\
\hline 289, & $-450 .$, & $-350 .$, \\
\hline 290, & 450. & $-250 .$, \\
\hline 291, & 400. & $-250 .$, \\
\hline 292, & $350 .$, & $-250 .$, \\
\hline 293, & 300. & $-250 .$, \\
\hline 294, & 250. & $-250 .$, \\
\hline 295, & 200. & $-250 .$, \\
\hline 296, & $150 .$, & $-250 .$, \\
\hline 297, & 100. & $-250 .$, \\
\hline 298, & 50. & $-250 .$, \\
\hline 299, & 0. & $-250 .$, \\
\hline 300, & $-50 .$, & $-250 .$, \\
\hline 301, & $-100 .$, & $-250 .$, \\
\hline 302, & $-150 .$, & $-250 .$, \\
\hline 303, & $-200 .$, & $-250 .$, \\
\hline 304, & $-250 .$, & $-250 .$, \\
\hline 305, & $-300 .$, & $-250 .$, \\
\hline 306, & $-350 .$, & $-250 .$, \\
\hline 307, & $-400 .$, & $-250 .$, \\
\hline 308, & -450. & $-250 .$, \\
\hline 309, & 450. & $-150 .$, \\
\hline 310, & $400 .$, & $-150 .$, \\
\hline 311, & 350. & $-150 .$, \\
\hline 312, & $300 .$, & $-150 .$, \\
\hline 313, & 250. & $-150 .$, \\
\hline 314, & 200. & $-150 .$, \\
\hline 315, & $150 .$, & $-150 .$, \\
\hline 316, & $100 .$, & $-150 .$, \\
\hline 317, & 50. & $-150 .$, \\
\hline 318, & 0. & $-150 .$, \\
\hline 319, & $-50 .$, & $-150 .$, \\
\hline 320 , & $-100 .$, & $-150 .$, \\
\hline 321, & $-150 .$, & $-150 .$, \\
\hline 322, & -200. & $-150 .$, \\
\hline 323, & -250. & $-150 .$, \\
\hline 324, & $-300 .$, & $-150 .$, \\
\hline 325, & $-350 .$, & $-150 .$, \\
\hline 326, & -400. & $-150 .$, \\
\hline 327 & -450. & $-150 .$, \\
\hline 328, & 450. & $-50 .$, \\
\hline 329, & $400 .$, & $-50 .$, \\
\hline 330, & $350 .$, & -50. \\
\hline
\end{tabular}




\begin{tabular}{|c|c|c|c|}
\hline 331, & 300. & $-50 .$, & 0 . \\
\hline 332, & 250. & $-50 .$, & 0 . \\
\hline 333, & 200. & $-50 .$, & 0 . \\
\hline 334, & 150. & $-50 .$, & 0 . \\
\hline 335, & 100. & $-50 .$, & 0 . \\
\hline 336, & 50. & $-50 .$, & 0 . \\
\hline 337, & 0. & $-50 .$, & 0 . \\
\hline 338, & $-50 .$, & $-50 .$, & 0 . \\
\hline 339, & -100. & $-50 .$, & 0 . \\
\hline 340, & -150. & $-50 .$, & 0 . \\
\hline 341, & -200. & $-50 .$, & 0 . \\
\hline 342, & -250. & $-50 .$, & 0 . \\
\hline 343, & -300. & $-50 .$, & 0 . \\
\hline 344, & -350. & $-50 .$, & 0 . \\
\hline 345, & -400. & $-50 .$, & 0 . \\
\hline 346, & -450. & $-50 .$, & 0 . \\
\hline 347, & 450 & 50. & 0 . \\
\hline 348, & 400. & 50. & 0 . \\
\hline 349, & 350. & 50. & 0 . \\
\hline 350, & $300 .$, & $50 .$, & 0 . \\
\hline 351, & $250 .$, & $50 .$, & 0 . \\
\hline 352, & 200. & 50. & 0 . \\
\hline 353, & $150 .$, & 50. & 0 . \\
\hline 354, & $100 .$, & 50. & 0 . \\
\hline 355, & 50. & 50. & 0 . \\
\hline 356, & 0. & 50. & 0 . \\
\hline 357, & -50. & 50. & 0 . \\
\hline 358, & -100. & $50 .$, & 0 . \\
\hline 359, & -150. & $50 .$, & 0 . \\
\hline 360, & -200. & $50 .$, & 0 . \\
\hline 361, & -250. & $50 .$, & 0 . \\
\hline 362 , & -300. & $50 .$, & 0 . \\
\hline 363, & -350. & $50 .$, & 0 . \\
\hline 364, & -400. & $50 .$, & 0 . \\
\hline 365 , & -450. & 50. & 0 . \\
\hline 366, & 450 & $150 .$, & 0 . \\
\hline 367, & $400 .$, & $150 .$, & 0 . \\
\hline 368, & $350 .$, & $150 .$, & 0 . \\
\hline 369, & 300. & $150 .$, & 0 . \\
\hline 370, & $250 .$, & $150 .$, & 0 . \\
\hline 371, & $200 .$, & $150 .$, & 0 . \\
\hline 372, & $150 .$, & $150 .$, & 0 . \\
\hline 373, & 100. & $150 .$, & 0 . \\
\hline 374, & $50 .$, & $150 .$, & 0 . \\
\hline 375, & 0. & $150 .$, & 0 . \\
\hline 376, & -50 & $150 .$, & 0 . \\
\hline 377, & -100. & $150 .$, & 0 . \\
\hline 378, & -150. & $150 .$, & 0 . \\
\hline 379, & -200 & $150 .$, & 0 . \\
\hline 380, & $-250 .$, & $150 .$, & 0 . \\
\hline 381, & -300. & $150 .$, & 0 . \\
\hline 382, & -350. & $150 .$, & 0 . \\
\hline 383, & $-400 .$, & $150 .$, & 0 . \\
\hline 384, & $-450 .$, & $150 .$, & 0 . \\
\hline 385, & 450. & $250 .$, & 0 . \\
\hline 386, & 400. & $250 .$, & 0 . \\
\hline 387, & $350 .$, & $250 .$, & 0 . \\
\hline
\end{tabular}




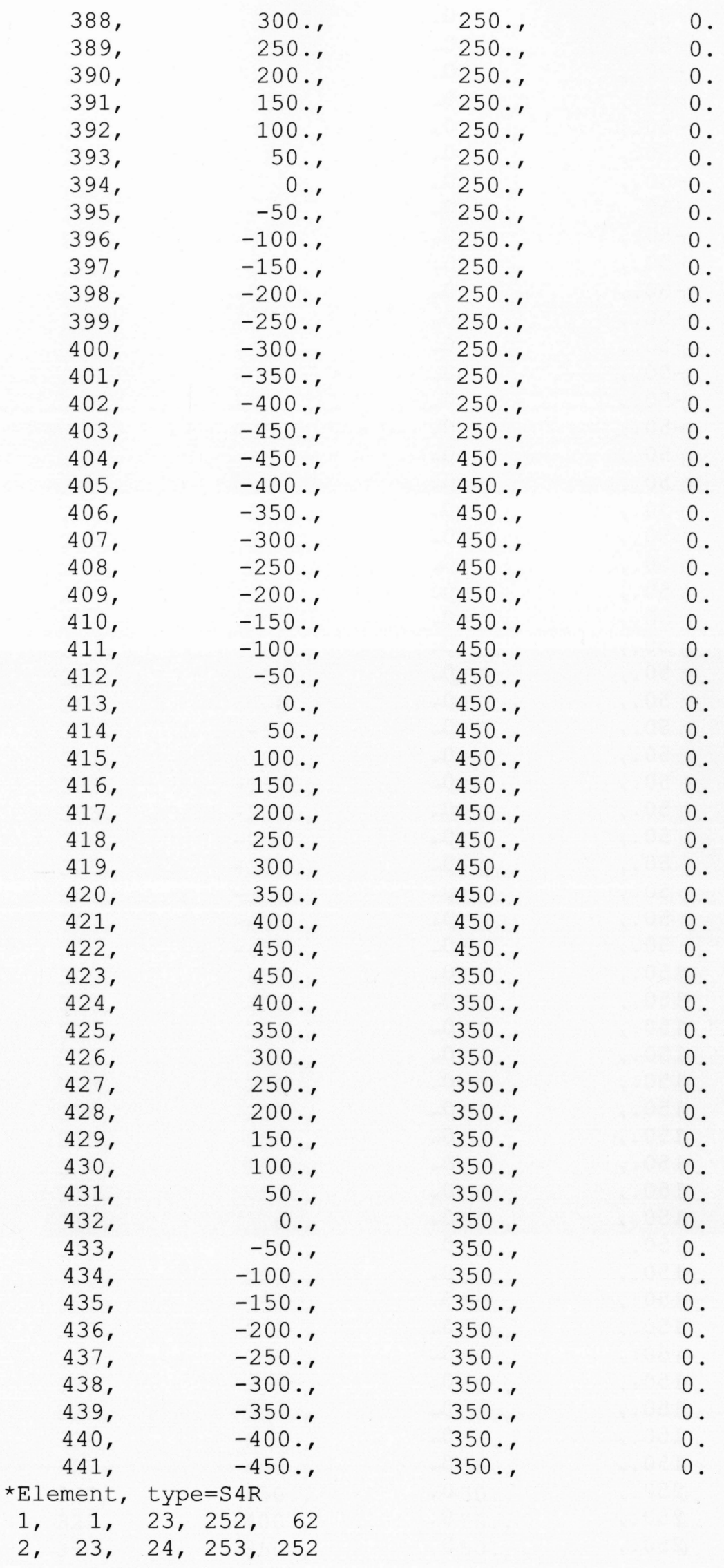




\begin{tabular}{|c|c|c|c|c|}
\hline & 24, & 25, & 254, & \\
\hline & 25, & 26, & 255, & \\
\hline & 26, & 27, & 256, & \\
\hline & 27, & 28, & 257, & \\
\hline & 28, & 29, & 258, & \\
\hline & 29, & 30, & 59, & \\
\hline & 30, & 31, & 60 , & \\
\hline & 31, & 32, & 51, & \\
\hline & 32 , & 33, & & \\
\hline & 33, & 34, & & \\
\hline & 34, & 35, & 4 , & \\
\hline & 35, & 36, & 5 , & \\
\hline & 36, & 37, & & \\
\hline & 37, & 38, & & \\
\hline & 38, & 9, & & \\
\hline & 39, & 40, & 59, & \\
\hline & 40, & 41, & 70 , & \\
\hline & 41, & 2, & 2 , & \\
\hline & & 252, & 1, & \\
\hline & 252, & & & \\
\hline & 3, & & & \\
\hline & 54, & & & \\
\hline & 25 & & 7, & \\
\hline & 256, & 57, & 6 , & \\
\hline & 57, & & & \\
\hline & 58, & & & \\
\hline & 259, & & & \\
\hline & 260 , & & & \\
\hline & 261 , & & & \\
\hline & 262, & & & \\
\hline & 263, & 64, & 9, & \\
\hline & 264, & 265, & 8, & \\
\hline & 265, & 266, & 7, & \\
\hline & 266, & 267, & 6 , & \\
\hline & 267, & 268, & 5 , & \\
\hline & 268, & 269, & 4 , & \\
\hline & 269, & 270, & 43, & \\
\hline & 270, & 42 & & \\
\hline & 5, & 3, & 271, & \\
\hline & 63, & 64, & 272 , & \\
\hline & 64, & 65, & 273, & \\
\hline & 65, & 66, & 274, & \\
\hline & 66, & 67, & 275, & \\
\hline & 67 & 68, & 276, & \\
\hline & 68 & 69, & 277, & \\
\hline & 69 & 70, & 278, & \\
\hline & 70 & 71, & 279, & \\
\hline & 71 & 72 , & 280, & \\
\hline & 72, & 73, & 281, & \\
\hline & 73 & 72 & 282, & \\
\hline & 7 & 75 & & \\
\hline & 75 & 7 & & \\
\hline & 7 & & & \\
\hline & & & & \\
\hline & & & & \\
\hline & & & & \\
\hline & & & & \\
\hline
\end{tabular}


$60,81,6,82,289$

$61,83,271,23,1$

$62,271,272,24,23$

$63,272,273,25,24$

$64,273,274,26,25$

$65,274,275,27,26$

$66,275,276,28,27$

$67,276,277,29,28$

$68,277,278,30,29$

$69,278,279,31,30$

$70,279,280,32,31$

$71,280,281,33,32$

$72,281,282,34,33$

$73,282,283,35,34$

$74,283,284,36,35$

$75,284,285,37,36$

$76,285,286, \quad 38, \quad 37$

$77,286,287,39, \quad 38$

$78,287,288,40,39$

$79,288,289,41,40$

$80,289,82, \quad 2,41$

$81,7,84,290,104$

$82,84,85,291,290$

$83,85,86,292,291$

$84,86,87,293,292$

$85,87,88,294,293$

$86,88,89,295,294$

$87,89,90,296,295$

$88,90,91,297,296$

$89,91,92,298,297$

$90,92,93,299,298$

$91,93,94,300,299$

$92,94,95,301,300$

$93,95,96,302,301$

$94,96,97,303,302$

$95,97,98,304,303$

$96,98,99,305,304$

$97,99,100,306,305$

$98,100,101,307,306$

$99,101,102,308,307$

$100,102,8,103,308$

$101,104,290,63,5$

$102,290,291,64,63$

$103,291,292,65,64$

$104,292,293,66,65$

$105,293,294,67,66$

$106,294,295,68,67$

$107,295,296,69,68$

$108,296,297,70,69$

109, 297, 298, 71, 70

$110,298,299,72,71$

$111,299,300,73,72$

$112,300,301,74,73$

$113,301,302,75,74$

$114,302,303,76,75$

$115,303,304,77,76$

$116,304,305,78,77$ 
$117,305,306,79,78$

$118,306,307,80,79$

$119,307,308,81,80$

$120,308,103,6,81$

$121,9,105,309,125$

$122,105,106,310,309$

$123,106,107,311,310$

$124,107,108,312,311$

$125,108,109,313,312$

$126,109,110,314,313$

$127,110,111,315,314$

$128,111,112,316,315$

$129,112,113,317,316$

$130,113,114,318,317$

$131,114,115,319,318$

$132,115,116,320,319$

$133,116,117,321,320$

$134,117,118,322,321$

$135,118,119,323,322$

$136,119,120,324,323$

$137,120,121,325,324$

$138,121,122,326,325$

$139,122,123,327,326$

$140,123,10,124,327$

$141,125,309,84,7$

$142,309,310,85,84$

$143,310,311,86,85$

$144,311,312,87,86$

$145,312,313,88,87$

$146,313,314,89,88$

$147,314,315,90,89$

$148,315,316,91,90$

$149,316,317,92,91$

$150,317,318,93,92$

$151,318,319,94,93$

$152,319,320,95,94$

$153,320,321,96,95$

$154,321,322,97,96$

$155,322,323,98,97$

$156,323,324,99,98$

$157,324,325,100,99$

$158,325,326,101,100$

$159,326,327,102,101$

$160,327,124,8,102$

$161,11,126,328,146$

$162,126,127,329,328$

$163,127,128,330,329$

$164,128,129,331,330$

$165,129,130,332,331$

$166,130,131,333,332$

$167,131,132,334,333$

$168,132,133,335,334$

$169,133,134,336,335$

$170,134,135,337,336$

$171,135,136,338,337$

$172,136,137,339,338$

$173,137,138,340,339$ 


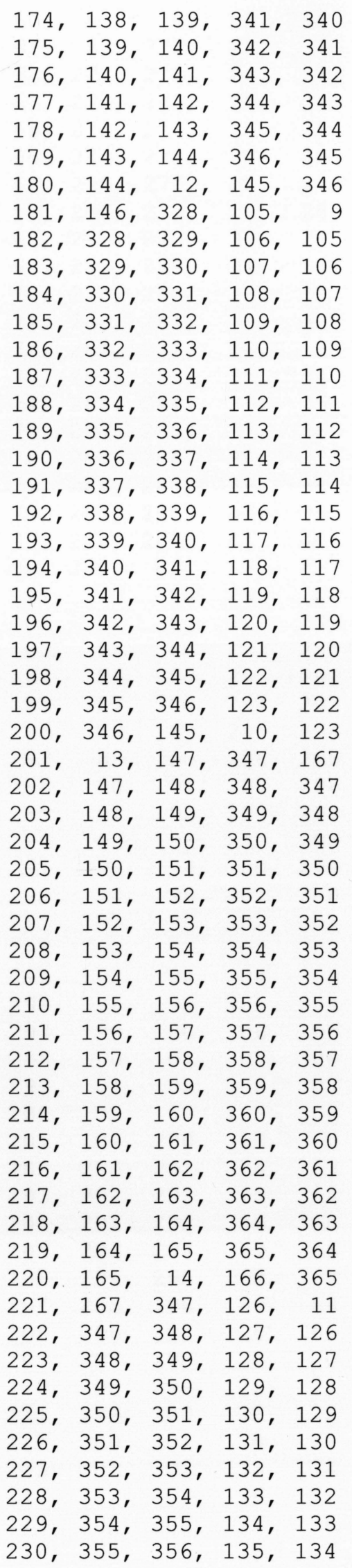


$231,356,357,136,135$

$232,357,358,137,136$

$233,358,359,138,137$

$234,359,360,139,138$

$235,360,361,140,139$

$236,361,362,141,140$

$237,362,363,142,141$

$238,363,364,143,142$

$239,364,365,144,143$

$240,365,166,12,144$

$241,15,168,366,188$

$242,168,169,367,366$

$243,169,170,368,367$

$244,170,171,369,368$

$245,171,172,370,369$

$246,172,173,371,370$

$247,173,174,372,371$

$248,174,175,373,372$

$249,175,176,374,373$

$250,176,177,375,374$

$251,177,178,376,375$

$252,178,179,377,376$

$253,179,180,378,377$

$254,180,181,379,378$

$255,181,182,380,379$

$256,182,183,381,380$

$257,183,184,382,381$

$258,184,185,383,382$

$259,185,186,384,383$

$260,186,16,187,384$

$261,188,366,147,13$

$262,366,367,148,147$

$263,367,368,149,148$

$264,368,369,150,149$

$265,369,370,151,150$

$266,370,371,152,151$

$267,371,372,153,152$

$268,372,373,154,153$

$269,373,374,155,154$

$270,374,375,156,155$

$271,375,376,157,156$

$272,376,377,158,157$

$273,377,378,159,158$

$274,378,379,160,159$

$275,379,380,161,160$

$276,380,381,162,161$

$277,381,382,163,162$

$278,382,383,164,163$

$279,383,384,165,164$

$280,384,187,14,165$

281, 17, 189, 385, 209

$282,189,190,386,385$

$283,190,191,387,386$

$284,191,192,388,387$

$285,192,193,389,388$

$286,193,194,390,389$

$287,194,195,391,390$ 


$$
\begin{aligned}
& \text { 288, 195, 196, 392, } 391 \\
& \text { 289, 196, 197, 393, } 392 \\
& 290,197,198,394,393 \\
& \text { 291, 198, 199, 395, } 394 \\
& \text { 292, 199, 200, 396, } 395 \\
& 293,200,201,397,396 \\
& 294,201,202,398,397 \\
& 295,202,203,399,398 \\
& 296,203,204,400,399 \\
& 297,204,205,401,400 \\
& 298,205,206,402,401 \\
& 299,206,207,403,402 \\
& 300,207,18,208,403 \\
& 301,209,385,168,15 \\
& 302,385,386,169,168 \\
& 303,386,387,170,169 \\
& 304,387,388,171,170 \\
& 305,388,389,172,171 \\
& 306,389,390,173,172 \\
& 307,390,391,174,173 \\
& 308,391,392,175,174 \\
& 309,392,393,176,175 \\
& 310,393,394,177,176 \\
& 311,394,395,178,177 \\
& 312,395,396,179,178 \\
& 313,396,397,180,179 \\
& 314,397,398,181,180 \\
& 315,398,399,182,181 \\
& 316,399,400,183,182 \\
& 317,400,401,184,183 \\
& 318,401,402,185,184 \\
& 319,402,403,186,185 \\
& 320,403,208,16,186 \\
& 321,19,210,404,249 \\
& 322,210,211,405,404 \\
& 323,211,212,406,405 \\
& 324,212,213,407,406 \\
& 325,213,214,408,407 \\
& 326,214,215,409,408 \\
& 327,215,216,410,409 \\
& 328,216,217,411,410 \\
& 329,217,218,412,411 \\
& 330,218,219,413,412 \\
& 331,219,220,414,413 \\
& 332,220,221,415,414 \\
& 333,221,222,416,415 \\
& 334,222,223,417,416 \\
& 335,223,224,418,417 \\
& 336,224,225,419,418 \\
& 337,225,226,420,419 \\
& 338,226,227,421,420 \\
& 339,227,228,422,421 \\
& 340,228,20,229,422 \\
& 341,249,404,248,22 \\
& 342,404,405,247,248 \\
& 343,405,406,246,247 \\
& 344,406,407,245,246
\end{aligned}
$$


$345,407,408,244,245$

$346,408,409,243,244$

$347,409,410,242,243$

$348,410,411,241,242$

$349,411,412,240,241$

$350,412,413,239,240$

$351,413,414,238,239$

$352,414,415,237,238$

$353,415,416,236,237$

$354,416,417,235,236$

$355,417,418,234,235$

$356,418,419,233,234$

$357,419,420,232,233$

$358,420,421,231,232$

$359,421,422,230,231$

$360,422,229,21,230$

$361,20,228,423,251$

$362,228,227,424,423$

$363,227,226,425,424$

$364,226,225,426,425$

$365,225,224,427,426$

$366,224,223,428,427$

$367,223,222,429,428$

$368,222,221,430,429$

$369,221,220,431,430$

$370,220,219,432,431$

$371,219,218,433,432$

$372,218,217,434,433$

$373,217,216,435,434$

$374,216,215,436,435$

$375,215,214,437,436$

$376,214,213,438,437$

$377,213,212,439,438$

$378,212,211,440,439$

$379,211,210,441,440$

$380,210,19,250,441$

$381,251,423,189,17$

$382,423,424,190,189$

$383,424,425,191,190$

$384,425,426,192,191$

$385,426,427,193,192$

$386,427,428,194,193$

$387,428,429,195,194$

$388,429,430,196,195$

$389,430,431,197,196$

$390,431,432,198,197$

$391,432,433,199,198$

$392,433,434,200,199$

$393,434,435,201,200$

$394,435,436,202,201$

$395,436,437,203,202$

$396,437,438,204,203$

$397,438,439,205,204$

$398,439,440,206,205$

$399,440,441,207,206$

$400,441,250,18,207$

*Nset, nset=_PickedSet47, internal 
$34,2,3,4,23,24,25,26,27,28,29,30,31,32,33$, $35,36,37,38,39,40,41,42,43,44,45,46,47,48,49$, $5051,52,53,54,55,56,57,58,59,60,61,62,252,253,254$ 255

$256,257,258,259,260,261,262,263,264,265,266,267,268,269,270$ *Elset, elset=PickedSet47, internal, generate

$1,40,1$

*Nset, nset $=$ PickedSet48, internal

$1,2,5,6,23,24,25,26,27,28,29,30,31,32,33$, $35,36,37,38,39,40,41,63,64,65,66,67,68,69,70$, $7173,73,74,75,76,77,78,79,80,81,82,83,271,272,273$, 274 $275,276,277,278,279,280,281,282,283,284,285,286,287,288,289$ *Elset, elset $=$ PickedSet48, internal, generate

$41,80,1$

*Nset, nset=_PickedSet49, internal

$546,7,8,63,64,65,66,67,68,69,70,71,72,73$, $75,76,77,78,79,80,81,84,85,86,87,88,89,90,91$, 92

93, 94, 95, 96, 97, 98, 99, 100, 101, 102, 103, 104, 290, 291, 292, 293

$294,295,296,297,298,299,300,301,302,303,304,305,306,307,308$

*Elset, elset=_PickedSet49, internal, generate

$81,120,-1$

*Nset, nset $=$ PickedSet50, internal 95

96, 97, 98, 99, 100, 101, 102, 105, 106, 107, 108, 109, 110, 111, 112, 113

$114,115,116,117,118,119,120,121,122,123,124,125,309,310,311$, 312

$313,314,315,316,317,318,319,320,321,322,323,324,325,326,327$ *Elset, elset=_PickedSet50, internal, generate

$121,160,-1$

*Nset, nset $=$ PickedSet51, internal 116

9, 10, $\overline{1} 1,12,105,106,107,108,109,110,111,112,113,114,115$, $117,118,119,120,121,122,123,126,127,128,129,130,131,132,133$, 134

$135,136,137,138,139,140,141,142,143,144,145,146,328,329,330$, 331

$332,333,334,335,336,337,338,339,340,341,342,343,344,345,346$

*Elset, elset=_PickedSet51, internal, generate

$161,200,-1$

*Nset, nset $=$ PickedSet52, internal

$11,12, \overline{1} 3,14,126,127,128,129,130,131,132,133,134,135,136$, 137

138, 139, 140, 141, 142, 143, 144, 147, 148, 149, 150, 151, 152, 153, 154, 155

156, 157, 158, 159, 160, 161, 162, 163, 164, 165, 166, 167, 347, 348, 349, 350

$351,352,353,354,355,356,357,358,359,360,361,362,363,364,365$ 
*Elset, elset=_PickedSet52, internal, generate

$201,240,-1$

*Nset, nset $=$ PickedSet58, internal

13, 14, 15, 16, 147, 148, 149, 150, 151, 152, 153, 154, 155, 156, 157, 158

$159,160,161,162,163,164,165,168,169,170,171,172,173,174,175$, 176

177, 178, 179, 180, 181, 182, 183, 184, 185, 186, 187, 188, 366, 367, 368, 369

$370,371,372,373,374,375,376,377,378,379,380,381,382,383,384$

*Elset, elset=_PickedSet58, internal, generate

$241,280,-1$

*Nset, nset $=$ PickedSet59, internal

15, 16, $17,18,168,169,170,171,172,173,174,175,176,177,178$, 179

180, 181, 182, 183, 184, 185, 186, 189, 190, 191, 192, 193, 194, 195, 196, 197

198, 199, 200, 201, 202, 203, 204, 205, 206, 207, 208, 209, 385, 386, 387, 388

$389,390,391,392,393,394,395,396,397,398,399,400,401,402,403$

*Elset, elset=_PickedSet59, internal, generate

$281,320,-1$

*Nset, nset=PickedSet60, internal

17, 18, $19,10,189,190,191,192,193,194,195,196,197,198,199$, 200

$201,202,203,204,205,206,207,210,211,212,213,214,215,216,217$, 218

$219,220,221,222,223,224,225,226,227,228,250,251,423,424,425$, 426

$427,428,429,430,431,432,433,434,435,436,437,438,439,440,441$

*Elset, elset=_PickedSet60, internal, generate

$361,400,-1$

*Nset, nset $=$ PickedSet61, internal

19, 20, $\overline{2} 1,22,210,211,212,213,214,215,216,217,218,219,220$, 221

$222,223,224,225,226,227,228,229,230,231,232,233,234,235,236$,

237

$238,239,240,241,242,243,244,245,246,247,248,249,404,405,406$, 407

$408,409,410,411,412,413,414,415,416,417,418,419,420,421,422$

*Elset, elset=_PickedSet61, internal, generate

$321,360, \quad 1$

** Section: Section-1

*Shell Section, elset=_PickedSet47, material=Concrete

$200 ., 5$

* Rebar Layer

H, 300., 300., 0., Steel, 0., 1

V, 300., 300., 0., Steel, 90., 1

** Section: Section-2

*Shell Section, elset=_PickedSet48, material=Concrete

$200 ., 5$

* Rebar Layer

H, 300., 300., 0., Steel, 0., 1

V, 300., 300., 0., Steel, 90., 1

* *ection: Section-3

*Shell Section, elset=_PickedSet49, material=Concrete $200 ., 5$ 
*Rebar Layer

H, 300., 300., 0., Steel, 0., 1

$\mathrm{V}, 300 ., 300 ., 0 .$, Steel, 90., 1

** Section: Section-4

*Shell Section, elset=_PickedSet50, material=Concrete $200 ., 5$

* Rebar Layer

H, 300., 300., 0., Steel, 0., 1

$\mathrm{V}, 300 ., 300 ., 0 .$, Steel, 90., 1

** Section: Section-5

*Shell Section, elset=_PickedSet51, material=Concrete 200 ., 5

* Rebar Layer

H, 300., 300., 0., Steel, 0., 1

$\mathrm{V}, 300 ., 300 ., 0 .$, Steel, 90., 1

** Section: Section-6

*Shell Section, elset=_PickedSet52, material=Concrete $200 ., 5$

* Rebar Layer

H, 300., 300., 0., Steel, 0., 1

V, 300., 300., 0., Steel, 90., 1

** Section: Section-7

*Shell Section, elset=_PickedSet58, material=Concrete $200 ., 5$

* Rebar Layer

H, 300., 300., 0., Steel, 0., 1

$\mathrm{V}, 300 ., 300 ., 0 .$, Steel, 90., 1

* Section: Section-8

*Shell Section, elset=_PickedSet59, material=Concrete 200 ., 5

* Rebar Layer

H, 300., 300., 0., Steel, 0., 1

V, 300., 300., 0., Steel, 90., 1

** Section: Section-10

*Shell Section, elset=_PickedSet61, material=Concrete 200 ., 5

* Rebar Layer

H, 300., 300., 0., Steel, 0., 1

V, 300., 300., 0., Steel, 90., 1

** Section: Section-9

*Shell Section, elset=_PickedSet60, material=Concrete $200 ., 5$

*Rebar Layer

H, 300., 300., 0., Steel, 0., 1

$\mathrm{V}, 300 ., 300 .$, 0., Steel, 90., 1

*End Part

$\star \star$

$\star \star$

$\star *$ ASSEMBLY

$\star \star$

$\star A s s e m b l y$, name $=$ Assembly

$\star \star$

*Instance, name=Part-1-1, part=Part -1

*End Instance

$\star \star$

*Instance, name=Part-1-2, part=Part-1

*End Instance 
*Nset, nset=PickedSet 8 , internal, instance=Part-1-1

$3,4,43,44,45,46,47,48,49,50,51,52,53,54,55,56$

$57,58,59,60,61$

*Elset, elset=_PickedSet8, internal, instance=Part-1-1, generate $21,40,1$

*Nset, nset=_PickedSet13, internal, instance=Part-1-1, generate $1,441,-1$

*Nset, nset=_PickedSet13, internal, instance=Part-1-2, generate $1,441,-1$

*Elset, elset=_PickedSet13, internal, instance=Part-1-1, generate $1,400,-1$

*Elset, elset=_PickedSet13, internal, instance=Part-1-2, generate $1,400,-1$

*Nset, nset=_PickedSet14, internal, instance=Part-1-1, generate $1,441,-1$

*Nset, nset=_PickedSet14, internal, instance=Part-1-2, generate $1,441,-1$

*Elset, elset=_PickedSet14, internal, instance=Part-1-1, generate $1,400,-1$

*Elset, elset=_PickedSet14, internal, instance=Part-1-2, generate $1,400,-1$

* End Assembly

$\star \star$

** MATERIALS

$\star \star$

* Material, name=Concrete

*Brittle Cracking

2.7, 0 .

$0 ., 0.002$

*Brittle Shear

$1 ., \quad 0$.

$0 ., 0.002$

*Density

2.4e-06,

*Elastic

$25000 ., 0.15$

*Expansion

1e-05,

*Material, name=Steel

*Density

7.8e-06,

*Elastic

$210000 ., 0$.

*Expansion

$0 .$,

*Plastic

400,0 .

$\star \star$

** BOUNDARY CONDITIONS

$\star \star$

** Name: BC-1 Type: Symmetry/Antisymmetry/Encastre

*Boundary

-PickedSet8, ENCASTRE

$\bar{\star} \star$

** PREDEFINED FIELDS

$\star \star$ 
** Name: Predefined Field-1 Type: Temperature

*Initial Conditions, type=TEMPERATURE

PickedSet13, 60 .

ॠ夫

$\star \star$

* STEP: Step -1

$\star \star$

* Step, name=Step-1

*Dynamic, Explicit

, 1 .

*Bulk Viscosity

$0.06,1.2$

$\star \star$

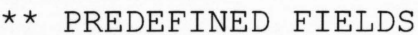

$\star \star$

** Name: Predefined Field-2 Type: Temperature

* Temperature

PickedSet14, 0 .

$\star \star$

* OUTPUT REQUESTS

$\star \star$

*Restart, write, number interval=1, time marks=NO

$\star \star$

$\star \star$ FIELD OUTPUT: F-Output-1

$\star \star$

*Output, field

*Element Output, directions=YES

$\mathrm{E}, \mathrm{NE}, \mathrm{S}$

*Element Output, rebar, directions=YES

$E, N E, \quad S$

$\star \star$

** HISTORY OUTPUT: H-Output-1

$\star \star$

*Output, history, variable=PRESELECT

*End Step 